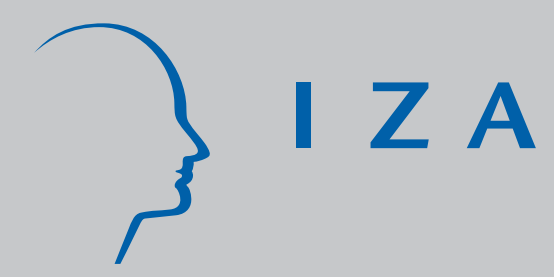

IZA DP No. 1727

Evaluating Dominance Ranking of PSID Incomes by Various Household Attributes

Esfandiar Maasoumi

Almas Heshmati

August 2005 


\title{
Evaluating Dominance Ranking of PSID Incomes by Various Household Attributes
}

\author{
Esfandiar Maasoumi \\ Southern Methodist University \\ Almas Heshmati \\ TEPP, Seoul National University \\ and IZA Bonn

\section{Discussion Paper No. 1727 \\ August 2005}

\author{
IZA \\ P.O. Box 7240 \\ 53072 Bonn \\ Germany \\ Phone: +49-228-3894-0 \\ Fax: +49-228-3894-180 \\ Email: iza@iza.org
}

\begin{abstract}
Any opinions expressed here are those of the author(s) and not those of the institute. Research disseminated by IZA may include views on policy, but the institute itself takes no institutional policy positions.

The Institute for the Study of Labor (IZA) in Bonn is a local and virtual international research center and a place of communication between science, politics and business. IZA is an independent nonprofit company supported by Deutsche Post World Net. The center is associated with the University of Bonn and offers a stimulating research environment through its research networks, research support, and visitors and doctoral programs. IZA engages in (i) original and internationally competitive research in all fields of labor economics, (ii) development of policy concepts, and (iii) dissemination of research results and concepts to the interested public.
\end{abstract}

IZA Discussion Papers often represent preliminary work and are circulated to encourage discussion. Citation of such a paper should account for its provisional character. A revised version may be available directly from the author. 
IZA Discussion Paper No. 1727

August 2005

\section{ABSTRACT \\ Evaluating Dominance Ranking of PSID Incomes by Various Household Attributes}

We examine the dynamic evolution of incomes, both disposable and gross, for several groups in the PSID panel data at several points from 1968 to 1997 . We employ the extended Kolmogorov-Smirnov tests of First and Second Order Stochastic Dominance (SD) as implemented by Maasoumi and Heshmati (2000). They do not impose the Least Favorable Case (LFC) of the composite null hypotheses of SD orders. This is in contrast to simulation and bootstrap-based techniques that do so, resulting in tests that are not asymptotically similar or unbiased. Our approach is also different from the subsampling technique of Linton et al (2005) who obtain critical values for these tests under very general sampling schemes. We offer partial control for many individual/family specific attributes, such as age, gender, education, number of children, work and marital status, by comparing group cells. This avoids having to specify and estimate models of dependence of incomes on these attributes, but lacks the multiple controls that is the promise of such techniques. We find a surprising number of strong rankings, both between groups and over time, in gross income and, to a lesser extent, in 'disposable' incomes.

JEL Classification: $\quad \mathrm{C} 14, \mathrm{D} 33, \mathrm{D} 63, \mathrm{H} 24$

Keywords: Stochastic Dominance, bootstrap, income distribution, testing, PSID, gender, education, age, marital status

Corresponding author:

Esfandiar Maasoumi

Department of Economics

Southern Methodist University

Dallas, TX 75275-0496

USA

Email: maasoumi@mail.smu.edu 


\section{Introduction}

In this paper we examine the existence of uniform weak orders between welfare outcomes measured by total real incomes. Partial strong orders are commonly used on the basis of specific utility functions and their corresponding indices. The latter is the predominant form of evaluation and is done when one employs indices of inequality or poverty in welfare, mean-variance analysis in finance, or performance indices such as average scores or wages in program evaluation. Such strong orderings do not command consensus. Based on the expected utility paradigm, Stochastic Dominance (SD), Lorenz and General Lorenz are examples of “orderings” that attempt to resolve this problem. These relations are defined over relatively large classes of utility functions and represent “majority” preferences. In evaluating distributed outcomes, as in all program and event evaluation exercises, average outcomes mask the differential impact on different participants and render index based assessments as blunt instruments for policy analysis. SD analysis reveals all of the distributional changes, especially amongst the target groups.

We follow an alternative bootstrap procedure for estimating the probability of rejection of the SD hypotheses with a suitably extended Kolmogorov-Smirnov (KS) test for first and second order stochastic dominance. Alternative simulation and bootstrap implementations of this test have been examined by several authors including McFadden (1989), Klecan, McFadden, and McFadden (1991), and Barrett and Donald (2003). The most general approach to date is given by Linton et al (2005) who allow for very general sampling schemes based on subsampling. Accommodating generic dependence between the variables which are to be ranked is especially necessary in substantive empirical settings where incomes are compared before and after taxes (or some other policy decision), or returns on different funds are compared in the same or interconnected markets. We employ matched pairs over time to preserve dependence, but looking at i.i.d. observed waves of the PSID, separated by several years, likely removes the dependence problem in the cases we consider here.

Our approach is similar to Linton et al (2005) in one aspect. We too do not impose the boundary of the null of dominance. We obtain unconstrained estimates of the probabilities of non-rejection in the actual samples. This allows a classical 'hypothesis 
testing' by confidence intervals that avoids the 'null hypothesis bias' of the frequentist method. All the other alternative implementations of the KS test, such as McFadden (1989), Barret and Donald (2003), and Chernozukov (2002), impose a subset of composite boundary of the null, the so called 'Least Favoarable Case' (LFC) of identical distributions, and estimate the asymptotic critical values of the classical KS test. Such tests would be biased and not `similar' on the boundary.

Let $X_{1}$ and $X_{2}$ be two variables (incomes, returns/prospects) at either two different points in time, or for different regions or countries, or with or without a program (treatment). Let $X_{k i}, \mathrm{i}=1, \ldots, \mathrm{N} ; \mathrm{k}=1,2$ denote the not necessarily i.i.d. observations. Let $U_{1}$ denote the class of all von Neumann-Morgenstern type utility functions, $u$, such that $u^{\prime} \geq 0$, (increasing). Also, let $U_{2}$ denote the class of all utility functions in $U_{1}$ for which $u^{\prime \prime} \leq 0$ (strict concavity), and $U_{3}$ denote a subset of $U_{2}$ for which $u^{\prime \prime \prime} \geq 0$. Let $X_{(1 p)}$ and $X_{(2 p)}$ denote the $p$-th quantiles, and $F_{1}(x)$ and $F_{2}(x)$ denote the cumulative distribution functions, respectively.

Definition: $X_{1}$ First Order Stochastic Dominates $X_{2}$, denoted $X_{1} F S D X_{2}$, if any of the following equivalent conditions holds:

(1) $\quad E\left[u\left(X_{1}\right)\right] \geq E\left[u\left(X_{2}\right)\right]$ for all $u \in U_{1}$, with strict inequality for some $u$; or $F_{1}(x) \leq F_{2}(x)$ for all $x$ with strict inequality for some $x$; or $X_{(1 p)} \geq X_{(2 p)}$ for all $0 \leq p \leq 1$, with strict inequality for some $p$.

Definition: $X_{1}$ Second Order Stochastic Dominates $X_{2}$, denoted $X_{1} \operatorname{SSD} X_{2}$, if any of the following equivalent conditions holds:

$$
\begin{aligned}
& E\left[u\left(X_{1}\right)\right] \geq E\left[u\left(X_{2}\right)\right] \text { for all } u \in U_{2} \text {, with strict inequality for some } u \text {; or } \\
& \int_{-\infty}^{x} F_{1}(t) d t \leq \int_{-\infty}^{x} F_{2}(t) d t \text { for all } x \text { with strict inequality for some } x \text {; or } \\
& \Phi_{1}(p)=\int_{0}^{p} X_{(1 t)} d t \geq \Phi_{2}(p)=\int_{0}^{p} X_{(2 t)} d t \text { for all } 0 \leq p \leq 1 \text {, with strict inequality for }
\end{aligned}
$$

some value(s) $p$. 
Weak orders of SD obtain by eliminating the requirement of strict inequality at some point. When these conditions are not met, as when Generalized Lorenz Curves of two distributions cross, unambiguous First and Second order SD is not possible. Any strong ordering by specific indices that correspond to the utility functions $U_{1}$ and $U_{2}$ classes, will generally not enjoy consensus. Whitmore introduced the concept of third order stochastic dominance (TSD) in finance, see (e.g.) Whitmore and Findley (1978). Shorrocks and Foster (1987) showed that the addition of a "transfer sensitivity" requirement leads to TSD ranking of income distributions. This requirement is stronger than the Pigou-Dalton principle of transfers since it makes regressive transfers less desirable at lower income levels. Higher order SD relations correspond to increasingly smaller subsets of $U_{2}$.

The statistical problems of conducting stochastic and Lorenz type dominance are quite formidable. See for example Anderson (1996), Davidson and Duclos (2000), Kaur et al. (1994), Dardanoni and Forcina (2000), Bishop et al. (1992), and Crawford (1999). Maasoumi (2001) contains a discussion of some of these alternative approaches. Davidson and Duclous (2000) is the most general example of formulating the SD nulls as multiple comparisons of partial moments and offers tests for higher order SD. The joint test of SD hypothesis based on quantiles follows the Chi-bar squared distribution techniques; see Fisher, Wilson and Xu (1995). Tse and Zhang (2000) provide some Monte Carlo evidence on the power of some of these alternative tests. There are just a handful of papers that have pursued the more general objective of consistency against all alternatives, as in Linton et al (2005).

Since the asymptotic null distribution of these tests depends on the unknown distributions, McFadden (1989) and Klecan, McFadden, and McFadden (1991) proposed a Monte Carlo permutation procedure for the computation of critical values that is only useful for i.i.d. observations and exchangeable variables. Barrett and Donald (2003) propose an alternative simulation method based on an idea of Hansen (1996) for deriving critical values in the case where the prospects are mutually independent, and the data are i.i.d. The methods relying on standard bootstrap or simulation typically try to mimic the asymptotic null distributions in the Least Favorable Case (LFC) of the equal distribution functions. However, even the boundary of the null hypothesis of SD 
is a set that is larger than the LFC region, thus such LFC-based tests are not asymptotically similar on the boundary of the null hypothesis. On the other hand, the LMW-test in Linton et al (2003) is based on a subsampling procedure which approximates the true sampling distribution under the composite null hypothesis and is asymptotically similar on the boundary. Consequently, the LMW-test might be asymptotically more powerful than the bootstrap (or simulation)-based tests for some local alternatives.

Our approach fixes the critical value (zero) at the boundary of our null, and estimates the associated 'significance level' by bootstrapping the sample or its blocks. This renders our tests 'asymptotically similar' and unbiased on the boundary. This is similar in spirit to inference based on p-values. This method could also be used to compare the two distributions up to any desired quantile, for instance, for poverty rankings.

\section{The Test Statistics}

Suppose that there are 2 prospects $X_{1}, X_{2}$ and let $A=\left\{X_{k}: k=1,2\right\}$. Let $\left\{X_{k i}: i=1,2, \ldots, N\right\}$ be realizations of $X_{k}$ for $\mathrm{k}=1,2$. These values could be "residuals" of income, say, "purged" of the influence of certain desired attributes, such as age, education and gender. When data are limited one may want to use a model to control for such attributes. Here we follow an alternative of grouping the data into subsets, say of families with different sizes, or by educational attainment, and then make comparisons across homogenous populations ${ }^{1}$.

For $\mathrm{k}=1,2$ define:

$$
F_{k}(x, \theta)=P\left(X_{k i}(\theta) \leq x\right)
$$

and

$$
\bar{F}_{k N}(x, \theta)=\frac{1}{N} \sum_{i=1}^{N} 1\left(X_{k i}(\theta) \leq x\right) .
$$

\footnotetext{
${ }^{1}$ We have studied these residuals elsewhere.
} 
We denote $F_{k}(x)=F_{k}\left(x, \theta_{k 0}\right)$ and $\bar{F}_{k N}(x)=\bar{F}_{k N}\left(x, \theta_{k 0}\right)$, and let $F\left(x_{1}, x_{2}\right)$ be the joint c.d.f. of $\left(X_{1}, X_{2}\right)^{\prime}$. Now define the following functionals of the joint distribution:

$$
\begin{aligned}
& d=\min _{k \neq l} \sup _{x \in \chi}\left[F_{k}(x)-F_{l}(x)\right] \\
& S=\min _{k \neq l} \sup _{x \in \chi} \int_{-\infty}^{x}\left[F_{k}(t)-F_{l}(t)\right] d t
\end{aligned}
$$

where $\chi$ denotes a given set contained in the union of the supports of $X_{k i}$ for $\mathrm{k}=1,2$. Without loss of generality we assume that the supports are bounded. The hypotheses of interest are:

$$
\begin{aligned}
& H_{0}^{d}: d \leq 0 \quad \text { vs. } \quad H_{1}^{d}: d>0 \\
& H_{0}^{s}: s \leq 0 \quad \text { vs. } \quad H_{1}^{s}: s>0
\end{aligned}
$$

The null hypothesis $H_{0}^{d}$ implies that the prospects in $A$ are not first-degree stochastically maximal, i.e., there exists at least one prospect in $A$ which first-degree dominates the others. Likewise for the second order case.

The test statistics we consider are based on the empirical analogues of (9)-(10). They are defined to be:

$$
\begin{aligned}
& D_{N}=\min _{k \neq l} \sup _{x \in X} \sqrt{N}\left[\bar{F}_{k N}\left(x, \dot{\theta}_{k}\right)-\bar{F}_{l N}\left(x, \dot{\theta}_{l}\right)\right] \\
& S_{N}=\min _{k \neq l} \sup _{x \in X} \sqrt{N} \int_{-\infty}^{x}\left[\bar{F}_{k N}\left(t, \dot{\theta}_{k}\right)-\bar{F}_{l N}\left(t, \dot{\theta}_{l}\right)\right] d t
\end{aligned}
$$

We next discuss the issue of how to compute the supremum in $D_{N}$ and $S_{N}$, and the integrals in $S_{N}$. There have been a number of suggestions in the literature that exploit the step-function nature of $\bar{F}_{k N}(t, \theta)$. The supremum in $D_{N}$ can be (exactly) replaced by a maximum taken over all the distinct points in the combined sample. Regarding the computation of $S_{N}$, Klecan et al. (1991) propose a recursive algorithm for exact computation of $S_{N}$, see also Barrett and Donald (2003) for an extension to third order dominance. 
To reduce the computation time, it may be preferable to compute approximations to the suprema in $D_{N}, S_{N}$ based on taking maxima over some smaller grid of points $X_{J}=\left\{x_{1}, \ldots ., x_{J}\right\}$ where $J<n$. Provided the set of evaluation points becomes dense in the joint support, the distribution theory is unaffected by using this approximation.

In our applications we report Probability $\left\{D_{N} \leq 0\right\}$ and Probability $\left\{S_{N} \leq 0\right\}$ and are able to identify which distribution dominates, if any. These are the maximum test sizes associated with our critical value of "zero" which is clearly the boundary of our null that includes the LFC. Thus we are reporting the critical level associated with this nonrejection region. These critical levels can be shown as in Linton et al (2005) to be "conservative" since, in the limit, they are at least as large as the corresponding levels for the asymptotic test on the boundary. Importantly, we do not impose the LFC on our bootstrap resampling.

\section{Testing for SD in PSID}

\subsection{Data}

We compare five waves of the Michigan Panel Study of Income Dynamics (PSID) ${ }^{2}$ in the years 1968, 1978, 1988, 1993 and 1997. Two definitions of income are used: gross and disposable incomes. For each year the 'gross income' represents 'husband and wife' or total family income including wages, interest, welfare payments, and unemployment receipts. 'Disposable income' is measured as gross income including transfer payments less family taxes. Incomes of spouses are added together and adjusted for family size to obtain per capita equivalent household incomes. Following a tradition in the literature we have chosen a weight of 1.0 for adult family members and 0.50 for children below the age of 18. Incomes and taxes are transformed to fixed 1993 prices using the urban consumer price index.

We do not have access to disposable income for 1993 and 1997 as these are not publicly available to download. The first 4 years are final releases, while the last, 1987, are early

\footnotetext{
2 The PSID data is available on http://www.isr.umich.edu/src/psid/ for free downloads. For a full description of the data please see the Guide to various interviewing years' procedures and codebooks.
} 
release data. The years were chosen to be representative as well as sufficiently far apart so that policy/events would have the time to produce measurable effects. Nevertheless, some of our "unconditional" comparisons reflect snap shots of points in time. In addition to unconditional comparison of household income distribution over time, incomes are compared conditional on a number of household characteristics. A household is identified by the household's head ${ }^{3}$. Head is defined as the husband in families with couples. When income distributions of groups are compared, the income variable is an average per capita income of individual/household head income over the period 1968-1993. Thus these comparisons are better than snap shots at points in time as they take out some transitory movements. This kind of aggregation is meant to avoid misleading results and follows the reasoning in mobility analysis with MaasoumiShorrocks-Zandvakili indices; see (e.g.) Maasoumi and Zandvakili (1990).

The household characteristics that we control for are: age, marital status, working status, racial status, gender, occupation, number of children, level of education, length of unemployment, and geographical mobility. Household characteristics are equivalent of the heads characteristics. Since these characteristics of head may differ over time, we have chosen to use the characteristics of head in 1993 as a reference, but mean gross and mean disposable incomes are defined as average of per capita income for the years 1968-1993 and 1968-1988, respectively. The 1997 gross income data were excluded as they are early release.

In defining age groups we have taken into account the productivity of age groups. The sample is divided into four groups: 18-35; 36-50; 51-65; and 66 and more. The heads by marital status are classified into three groups: married; single, widowed; and divorced, separated, or spouse absent. The working status includes three groups: working, temporarily laid off; unemployed; and retired, housewife, student and others. The racial stata are three: white; black; and "Indian, Spanish, Asian, others". Sex is the head of household gender: male and female. There are four occupational groups: professional and managers, self-employed unincorporated "businessmen”, other occupations, and not in the labor force. The number of children is divided into 4 groups: families with no children; one child; two children; and three and more children. Education is the head's

\footnotetext{
${ }^{3}$ Some advocate the recent approach where the head is defined as the person with the highest income.
} 
total years of schooling grouped into: 0-11 years; 12 plus grades; and college degree and higher. Unemployment is defined by the length of unemployment period in number of hours. The variable was transformed into months of unemployment (180 hours per months) divided into three groups: 0-1 month; 2-3 months; and more than 3 months. Finally, geographical mobility is classified into three groups: head living in the same state where he/she grew up; same region where grew up; and different state and region where grew up.

Our analysis is carried out in two parts. Part one is 'unconditional' tests for SD over the years for the entire distribution of incomes, with no controls for attributes, for both gross and disposable incomes. Part two is conditional by having controls for the above attributes. The analysis and comparison of results are carried out both with and without PSID population weights. The weight variable is the sampling weight provided by PSID meant to make these samples more 'representative' of the US population. They reflect the frequency of household types in the population and are used to produce unbiased estimation of the descriptive statistics. It is generally agreed that for inference about the "US population”, one must focus on the weighted results.

Summary of the number of observations by income definition and various sub-groups of household is given in Table 12. Since not all the families are in all years, we take only a balanced panel. This results in reduction in the number of observations. The summary statistics (number of observations, mean and standard deviation) of the two income definitions in weighted and un-weighted forms including the number of balanced observations are given in the first part of the Tables 1-11.

\subsection{Unconditional Analysis}

Consider Table 1. This first part summarizes our data by years of observation. The balanced number of households observed all 5 years is $3897 .^{4}$ The mean real gross income is continuously increasing over time from $\$ 12483$ in 1968 to $\$ 19632$ in 1997, as is the dispersion in income, increasing from \$10818 to \$20904. Increases in the dispersion of income are more pronounced in 1988 and 1997. The coefficient of variation increased from 86.6 to 106.5 indicating growing income “dispersion”. The

\footnotetext{
${ }^{4}$ Elimination of the unbalanced households was necessary to conduct matched-bootstrapping, where we obtain re-samples of the same households over time.
} 
level of real disposable income, ranging in the interval $\$ 11252-\$ 12409$, is $88-90 \%$ of gross income. It is increasing over time reflecting reduced share of income taxes and transfers. The dispersion in disposable income is somewhat smaller compared to those of gross income indicating income equalization effects of taxes and transfers.

Accounting for population weights increases both the gross and disposable mean incomes over time, in the interval \$14786-\$22231 and \$13208-\$18027, respectively. The temporal patterns are the same but level differences are large compared to the unweighted summaries. The difference is a reflection of higher weights being associated with higher income housholds.

Concerning temporal patterns of the household attributes we note that, the percentage share of households with zero income has increased from $0.1 \%$ in 1968 to $1.4 \%$ in 1993 . Households without children or with less than two children have increased in number, while those with three or more children decreased. The share of female headed households is large and varies in the interval $28 \%$ to $31 \%$. Significant variations in the age groups in the form of a shift from the lower age groups to the upper age groups is evident over time. The relative share of blacks has been reduced over time, while those of other race groups (Indian, Spanish, Asian, others) is increasing. The share of working population is decreasing, while the share of unemployed and those not in labor force is increasing. In the latter years, fewer persons are in marriage, while the unmarried, divorced and separated are increasing in number. The number of household heads with medium level of education is increasing significantly much more relative to those holding a college degree. Major changes in population occurs in the share of retired and those not in labor force. The share of heads with no unemployment record is decreasing, while those with more than 3 months of unemployment increasing. The within and between state mobility is constant while between state mobility is increasing at the expense of within region mobility. For frequency distribution by household characteristics see Table 12.

Results in Table 1 are based on data where household attributes are ignored. It provides test results for a selection of years (1968, 1978, 1988, 1993 and 1997). The years were chosen to be representative as well as sufficiently far apart such that there would be enough time for any enduring impact on income distribution to be measurable. It is to be 
noted that the consecutive time patterns of dominance using annual waves may differ from the current non-consecutive ones.

All results are based on 1000 bootstrap samples, 5\% income partitions and with/without accounting for population weights. In comparing two distributions, the first group is denoted the " $\mathrm{X}$ " distribution, and the second by "Y" distribution. Thus, "FSDxoy" denotes "first order stochastic dominance of $\mathrm{X}$ over $\mathrm{Y}$ ”, and "SSDxoy" is similarly defined for second order dominance of X over Y. The "FOmax" and "SOmax" denote the joint tests of X vs. Y and Y vs. X., referred to as “maximality” by McFadden (1989).

\subsubsection{Test results for the whole distribution over time}

In the second part of Table 1, our test statistics are summarized by their mean and standard errors, as well as the probability of the test statistic being negative or zero (the null).

For (un-weighted) gross income, several cases (5 out of 10) of first order and second order (9 out of 10) dominance are observed for recent years over earlier years. The exceptions are 1968 vs. 1978, 1978 vs. 1988, 1988 vs. 1993 and 1993 vs. 1997 where there is no FSD, while in the case of 1993 vs. 1997 no SSD either. The latter two years are found to be second order maximal (unrankable). The same patterns hold for disposable income distributions, where latter years SSD earlier years. One difference is that 1988 first order dominates 1978 at the 81\% level. Type I error would be too large perhaps, but power is enhanced. Taxes and transfers appear to cause a general right separation in the CDFs, but we do not have formal tests of the significance associated with this aspect of what is depicted in Figures 1A-1D. The level of significance is higher in the disposable income cases compared to gross incomes. Figures 1A-1D depict the corresponding sample CDFs and cumulated CDFs which indicate apparent SD rankings or lack thereof.

The test results based on the population weighted data are basically the same as those from the un-weighted cases. A few distinctions to be mentioned are: First, we observe FSD of gross income in 1978 over 1968. Second, the degree of significance for weighted data is systematically higher compared to those for un-weighted data. It appears that, in the presence of dominance, "significance" is an increasing function of the number of observation (weights) in the annual samples. (see also Figure 1B) 


\subsection{Conditional Analysis}

\subsubsection{Introduction}

As mentioned previously, the households are distinguished by the household heads characteristics in 1993, but mean gross and mean disposable incomes are defined as period average of per capita incomes. The characteristics that we condition on include head's: age, marital status, working status, race, gender, occupation, number of children, level of education, length of unemployment, and geographical mobility.

\subsubsection{Test results for age groups}

Table 2 summarizes the results for age groups (18-35, 36-50, 51-65, 65-), separately for weighted and un-weighted observations, and for gross and disposable incomes. The mean gross income is somewhat increasing with working age, but so is its dispersion. After taxes and transfers no notable change in this pattern is found. The mean disposable income constantly lies below gross income in all age groups. There are no cases of FSD between age groups. As expected the two middle age groups' gross incomes SSD those of the very young, but this ranking vanishes with disposable incomes suggesting significant income equalization impact of transfers and taxes. The weighting of observations is inconsequential. For disposable incomes, however, we note an SSD of the weighted 18-35 over the 66+ age group. Without controlling for other factors, such as martial status, education or employment, it appears that the younger households are better off than the "retired”. A further dis-aggregation of age groups might be necessary to reveal the existence and magnitude of further between group transfers. The disposable incomes of age groups are generally second order maximal, implying that they may be ranked only at higher levels than SSD. A neat result of Davidson and Duclos (2000) suggests that, if two distributions have an FSD ranking for some part of the (lower) support, they are rankable at some higher order. Figures 2A and 2B depict the corresponding sample CDFs and 2C-2D cumulative CDFs. They reveal a sometimes stark distinction between an apparent dominance and its lack of statistical significance. They also suggest, but we have not tested, the possibility that almost all the disposable incomes FSD or SSD the gross income distributions. With the exception of the peak income group, 36-55, this appears to cut across all age groups. It is worth recalling that SD rankings are transitive. 


\subsubsection{Test results by marital status}

In Table 3 we report the test results for grouping according to the head's marital status classified into three groups: married; single or widowed; and "divorced, separated, or spouse absent”. The mean gross and disposable incomes of the first two groups are somewhat higher than the third group who likely include many single mother families. In general the between group variations in mean and standard deviations are quite small. The pattern is very similar in comparing the samples with and without weighting. The married group second order dominates the unmarried at the $91 \%$ level. The unmarried/married and other groups are maximal. In the weighted case, again the married second order dominate the unmarried, while others also second order dominate the unmarried. There is no evidence of any statistically significant FSD or SSD in terms of disposable income unconditional on the number of children. Later we will be discussing disposable income conditional on the number of children. Sample CDFs are graphed in Figures 3A and 3B and cumulative CDFs in 3C and 3D.

\subsubsection{Test results by working status}

In Table 4 we report the test results by the working status of household heads. Households are divided into three groups: 1. Working or temporarily laid off; 2. unemployed; and 3. retired, housewife, student and others. The mean gross income of the first category is higher than that of remaining non-working groups. Given the tax structure in the US one might expect much larger income differences. The small difference might be due to the relatively short unemployment spells in the US and the averaging of incomes over this period. For these reasons, the working group has on average a slightly lower disposable income than the unemployed. When we do not account for weight differences, the gross income of the working group second order dominates the "others" not in labor force, while the working vs. unemployed and the unemployed vs. others are unrankable. This means that there are some welfare functions in our functional classes that are so equality preferring that make SD ranking of gross working incomes impossible. Clearly, there will be many indices in these situations that will provide complete ranking of these unrankable distributions.

The tests based on the un-weighted observations on disposable incomes show no first and second order dominance relationship. Similar patterns hold in the weighted case, 
with the exception that the "working" second order dominate "others" in terms of both incomes. In the definition of unemployment, one does not account for the length of unemployment. This might partially explain the absence of dominance relations by working status. Later we will investigate the role of unemployment distinguished by the length of the spell. Again for distribution of incomes by working status see Figures 4A to $4 \mathrm{D}$.

\subsubsection{Test results by racial status}

The heads are classified into three groups: white; black; others including Indian, Hispanic and Asians. In looking at the statistical summaries given in the first part of Table 5, as expected the gross income of the whites is above the income level of the other groups when observations are not weighted. For the un-weighted observations the mean disposable income of blacks is the highest. This surely demonstrates one of the better known problems with the un-weighted PSID observations. In the weigthed form the position of groups is changed, "others" showing higher gross income than white and blacks, respectively. The sample size is however small, and made smaller by our "balancing" over these many years, and might be affected by outlier and missing observations.

The test results provided in the second part of Table 5 show that un-weighted White gross income distribution second order dominates the Black incomes at the $92 \%$ level, but is unrankable in comparison with others. As mentioned above, accounting for taxes and transfers changes the dominance rankings. Blacks’ disposable incomes second order dominate the White's at the 94\% level.

When weighted data are used, the same relationship between gross incomes of Whites and Blacks holds, but others second order dominate the White distribution. Here, the White disposable income distribution second order dominates the corresponding Black distribution. See Figures 5A and 5B for sample CDFs and 5C and 5D for cumulative CDFs. Neglected within group heterogeneity might be another quite significant problem here.

\subsubsection{Test results by gender}

Table 6 indicates that mean gross incomes of males are greater than females' gross incomes, as is the within group income dispersions. In terms of disposable income the 
positions are reversed with almost equal income dispersion. The share of males is $70 \%$ of the total sample. The test results, based on un-weighted data, show that male incomes second order dominate the female incomes at 99\% level, while no such dominance relation is found when disposable incomes are considered. With weighted data the males gross income still second order dominates females, but the position is reversed in favor of females when disposable incomes are considered. Welfare policies through taxes and transfers appear to have been successful in bringing about welfare parity between male and females. For graphs of the distributions see Figure 6A to 6D.

\subsubsection{Test results by occupation}

There are three occupation groups in Table 7: professional and managers; other occupations; and not in labor force. Again the mean incomes differ in terms of gross incomes by occupation in favor of professionals, but the differences between groups vanish in terms of disposable incomes regardless of whether any observation weights are used or not. The test results indicate that professionals and managers second order dominate the remaining two groups when gross income is considered. The last two groups are not first and second order rankable, but clearly rankable at some higher level (see Figures 7A-7B). The same dominance relationship holds but stronger when weighted data are used. No first or second order dominance is found between disposable incomes. Again, higher order ranks cannot be ruled out. See Figures 7A-7D for sample CDFs and cumulative CDFs.

\subsubsection{Test results by number of children}

Summary of the results for households grouped by the number of children into households with no children, one child, two children; and three and more is found in Table 8. The mean gross income per capita and its dispersion are negative functions of the number of children. The relation is not obvious in disposable income terms. Despite the mean differences no group's gross or disposable incomes dominates another in the un-weighted form. In the weighted case there are two exceptions, where heads with no children second order dominate the groups with 1 and 2 children, but not those with 3 and more. Please see also the Figure 8A to 8D for sample CDFs and their cumulatives. It is to be noted that the results are in the line with the objectives of welfare policies to improve the living conditions of families with children, but at the same time quite 
surprising concerning absent of ant dominance relationship. Probably the results are influenced by grouping the households by characteristics valid for 1993, while incomes refer to the original periods. Presence of higher order ranks are possible.

\subsubsection{Test results by years of schooling}

Mean gross and disposable incomes are increasing function of years of schooling. Here education is defined as the head's total years of schooling grouped into: 0-11 years; 12+; and college degrees (Table 9). The test results indicate that medium education level second order dominates the low level, and is in turn second order dominated by the high level of education. This is valid for gross income in both un-weighted and weighted forms. The groups compared by un-weighted disposable income are maximal. For weighted observations on disposable incomes, the holders of a college degree turned out to dominate by second order the $0-11$ schooling group at the $91 \%$ level. The remaining two groups are not first and second order rankable. In order to discern the effects of human capital on earnings one should use a finer grouping of the households, as well as test for higher SD orders. This finding is consistent with regression-based results attributing certain returns to schooling since indices can be found to obtain complete rankings when FSD and SSD are not present. See also Figure 9A to 9D.

\subsubsection{Test results by length of unemployment}

Households are grouped by the length of unemployment period into: 0-1 month; 2-3 months; and more than 3 months. Mean and dispersion of gross incomes decreases by the length of unemployment spells. Test results provided on Table 10 indicate that the first group second order dominate the last group at $86 \%$ level. No dominance relation is found for the un-weighted disposable income data. The weight differences results in same relation in the case of gross income, while the second group second order dominates the first group in the case of disposable income. Other comparisons are first and second order maximal. For graphs of CDFs see the Figure $10 \mathrm{~A}$ and $10 \mathrm{~B}$ and cumulative CDFs the Figures 10C and 10D.

\subsubsection{Test results by geographical mobility}

The households by the last attribute, geographical mobility, are classified by location of the places they grow up into: living in the same state; same region; and different state and region (Table 11). Mobility affects positively the per capita gross incomes. The 
effect is however small. Head living in different state and region than they grow up second order dominates those growing up in the same state. Accounting for weight differences, produces similar result, but in addition we find also second order dominance of heads growing up in same region over those growing up in the same state. Non dominance relation is found in comparison of groups by per capita disposable incomes. See also Figures 11A to 11B for sample CDFs and cumulative CDFs.

In sum for the conditional analysis we find that first order dominance is very rare, but second order dominance holds in several cases when we consider per capita household gross income. In most comparisons there is no evidence of any dominance relationship in disposable income terms. Accounting for differences in weights improves the significance level and even frequency of second order dominance relationship. In several cases the patterns of results are quite similar regardless of attributes used to group households. It is surprising that effects of gender, education and number of children or seniority could be week on distribution of gross income. The post taxes income show very similar mean and dispersion levels. This could be due to the effect of index applied or transformation of income in per capita equivalent or exclusion of new entry and exit to the annual samples for the reasons of the block bootstrapping.

\section{Concluding Remarks}

In contrast to subsampling and our approach, one has to impose the null hypothesis in most resampling schemes. The usual practice in the literature has been to impose the least favorable case where:

$$
F_{i}(x)=\ldots=F_{k}(x) \text { for all } x \in X
$$

This is easy to apply when the prospects are mutually independent and independent over time and there are no estimated parameters - you just pool the data into a common distribution and draw from that in the bootstrap case. Klecan et al.(1991) showed that with suitable modification this idea can be applied to the case where the prospects are mutually dependent as long as the dependence is of a specific variety called generalized exchangeable. The recentering suggested in Chernozhukov (2002) also imposes the 
LFC implicitly, and works in general provided it is combined with an appropriate resampling procedure.

When the variables are mutually dependent but i.i.d. within each sample, one might use the bootstrap procedure. described in Linton, Maasoumi and Whang (2003). Their procedure allows the variables to be residuals of certain general models which provide controls for any desirable attributes, and centers all the bootstrapped CDFs around their sample counterparts. In an obvious notation, the centered statistic for FSD is:

$$
D_{N}^{*}=\min _{k \neq 1} \sup _{x \in X} \sqrt{N}\left[\bar{F}_{k N}^{*_{c}}(x)-\bar{F}_{i N}^{*_{c}}(x)\right]
$$

One can then compute the distribution of $D_{N}^{*}$ conditional on the original sample and take the critical value from this distribution. This approximates the sampling distribution $H_{N}$ of $D_{N}$ by:

$$
\hat{H}_{N}(w)=\frac{1}{M} \sum_{i=1}^{M} 1\left(D_{N, i}^{*} \leq w\right)
$$

where $\mathrm{M}$ is the number of bootstrap samples. Let $h_{N}(1-\alpha)$ denote the $(1-\alpha)$-th sample quantile of $\hat{H}_{N, b}($.$) , i.e.,$

$$
h_{N}(1-\alpha)=\inf \left\{w: \hat{H}_{N}(w) \geq 1-\alpha\right\}
$$

LMW (2003) call this the bootstrap critical value of significance level $\alpha$. Thus, one can reject the null hypothesis at the significance level $\alpha$ if $D_{N}>h_{N}(1-\alpha)$. It can be shown that this test is consistent; LMW (2003) investigate the finite sample behavior of this procedure. The re-centering in $D_{N}^{*}$ is crucial and is used to impose the LFC restriction. In the time series case, the resampling should be modified to account for the dependence. LMW (2003) describe the non-overlapping and overlapping block bootstrap procedures that can be used.

The test statistic $D_{N}$ has a non-degenerate limit distribution on the boundary " $D_{N}^{*}=0$ " of our null hypothesis $H_{0}^{d}$. Note that “ $D_{N}^{*}=0$ ” is in fact a composite hypothesis and 
includes the least favorable case . Therefore, when LFC fails to hold but $d=0$ is true ${ }^{5}$, then the test based on the bootstrap (or simulation) critical value would not have asymptotic size $\alpha$. This implies that the latter test is not asymptotically similar on the boundary, which in turn implies that the test is biased, i.e., there exist alternatives under which acceptance of the hypothesis is more likely than in some cases in which the hypothesis is true, see Lehmann (1986, Chapter 4) for the concept of similarity and unbiasedness. On the other hand, the LMW test based on the subsample critical value is unbiased and asymptotically similar on the boundary since the subsampling distribution mimics the true sampling distribution everywhere on the boundary. Note that, in general, an asymptotically similar test is more powerful than an asymptotically nonsimilar test for some local alternatives near the boundary, see, e.g., Hansen (2001). We plan to compare these alternative procedures in future work.

Based on our implementation of the KS type FSD and SSD tests, we were able to show a perhaps surprising number of cases of dominance between unconditional income distributions, improving steadily until the 1990s. These rankings are due to many other factors that may explain income differentials between population subgroups. Ceteris paribus examination is offered here by conducting SD tests for incomes of different groups identified by numerous characteristics, including race, age, gender, and education. Future work will examine regression based simultaneous controls which avoid the problem of small cell sizes that would arise in our approach.

\footnotetext{
${ }^{5}$ For example, if $\mathrm{K}=3$, this happens if $F_{1}(x)=F_{2}(x)$ for all $x \in X$ but $F_{3}(x)$ crosses with $F_{2}(x)$ and $F_{2}(x)$. More generally, this happens if $F_{k}(x) \leq F_{1}(x)$ with equality holding for $x$ in $B_{k l} \in X$ for some pair $(k, l)$ but there are crossings of the distributions (i.e., no FSD relationship) for the other pairs.
} 


\section{References}

Abadie, A., (2002), "Bootstrap Tests for Distributional Treatment Effects in Instrumental Variable Models”, Journal of the American Statistical Association, 97, 284-292.

Anderson, G. J. (1996), “Nonparametric tests of stochastic dominance in income distributions”, Econometrica 64, 1183-1193.

Barrett, G. and S. Donald (2003), "Consistent Tests for Stochastic Dominance”, Econometrica 71, 1, 71-104.

Bishop, J. A., J. P.Formby, and P. D. Thisle (1992), "Convergence of the South and non-South income distributions, 1969-1979”, American Economic Review 82, 262-272.

Chernozhukov, V. (2002), "Inference on Quantile Regression Process, an Alternative”, Working paper, MIT.

Crawford, I. (1999), "Nonparametric tests of Stochastic Dominance in Bivariate Distributions with an Application to UK data”, Institute for Fiscal Studies, WP 28/99.

Dardanoni, V. and A. Forcina (2000), "Inference for Lorenz curve orderings”, Econometrics Journal 2, 49-75.

Davidson, R. and J-Y. Duclos (2000), “Statistical inference for stochastic dominance and for the measurement of poverty and inequality”, Econometrica 68, 1435-1464.

Fisher, G., D. Wilson, and K. Xu (1998), “An Empirical Analysis of Term Premiums Using Significance Tests for Stochastic Dominance," Economics Letters, 60, 195203.

Hansen, B. E. (1996), “Inference when a nuisance parameter is not identified under the null Hypothesis”, Econometrica 64, 413-430.

Hansen, P.R. (2001), “An unbiased and powerful test for superior predictive ability,” Working paper, Brown University.

Kaur, A., B. L. S. Prakasa Rao, and H. Singh (1994), “Testing for second-order stochastic dominance of two distributions”, Econometric Theory 10, 849-866.

Klecan, L., R. McFadden, and D. McFadden (1991), “A robust test for stochastic dominance”, Working paper, Department of Economics, MIT.

Lehmann, E. L. (1986),“Testing statistical hypotheses”, $2^{\text {nd }}$ Edition, J. Wiley and Sons, New York.

Linton, O., E. Maasoumi, and Y-J. Whang (2005), “Consistent Testing for Stochastic Dominance under General Sampling Schemes”, Cowles Foundation, SMU, and the LSE EM/02/433, forthcoming, Review Of Economic Studies.

Maasoumi, E. (2001), “Parametric and nonparametric tests of limited domain and ordered hypotheses in economics”, chapter 25, in B. Baltagi (Ed.) A Companion to Econometric Theory, Basil Blackwell.

Maasoumi, E. and A. Heshmati (2000), "Stochastic dominance amongst Swedish income distributions”, Econometric Reviews 19,3, 287-320. 
Maasoumi, E. and D. Millimet (2005), "Robust Inference Concerning Recent Trends in U.S. Environmental Quality”', Journal of Applied Econometrics, 20, 55-77.

Maasoumi, E. and S. Zandvakili (1990), “Generalized Entropy Measures of Mobility for Different Sexes and Income Levels,” Journal of Econometrics 121-133.

McFadden, D. (1989), “Testing for stochastic dominance”, in Part II of T. Fomby and T.K. Seo (eds.) Studies in the Economics of Uncertainty (in honor of J. Hadar), Springer-Verlag.

Shorrocks A., and J. Foster (1987), “Transfer sensitive inequality measures”, Review of Economic Studies 54, 485-497.

Tse, Y.K. and X.B. Zhang (2000), “A Monte carlo Investigation of Some Tests for Stochastic Dominance”, unpublished manuscript, National University of Singapore.

Whitmore, G. A. and M. C. Findley (1978), "Stochastic Dominance: An approach to decision making under risk”, Heath, Lexington :Mars. 


\section{List of Figures:}

Figure 1.A-11A Un-weighted CDF of gross (g) and disposable (d) incomes by attributes.

Figure 1.B-11B Weighted CDF of gross (g) and disposable (d) incomes by attributes.

Figure 1C-11C Un-weighted cumulative CDF of gross (g) and disposable (d) incomes by attributes.

Figure 1.D-11D Weighted cumulative CDF of gross (g) and disposable (d) incomes by attributes.

\section{List of Tables:}

Table 1. Comparison of gross and disposable incomes by year of observation.

Table 2-11 Comparison of gross and disposable incomes by household attributes.

Table 12. Summary of the number of observations by household attributes.

\section{Attributes:}

\section{Unconditional:}

1. Year of observation $(1968,1978,1988,1993,1997)$

\section{Conditional:}

2. Age groups (18-35, 36-50, 51-65, 66-)

3. Marital status (married, unmarried, others)

4. Working status (working, unemployed, others)

5. Racial status (white, black, others)

6. Gender (male, female)

7. Occupation (professional, others, not in labor force)

8. Number of children $(0,1,2,3-)$

9. Schooling years $(0-11,12+$, college $)$

10. Length of unemployment (01-, 2-3, 3- months)

11. Geographical mobility (same state, same region, different state and region grew up) 
Figure 1.A Unweighted CDF of gross (g) and disposable (d) incomes by years of observation.

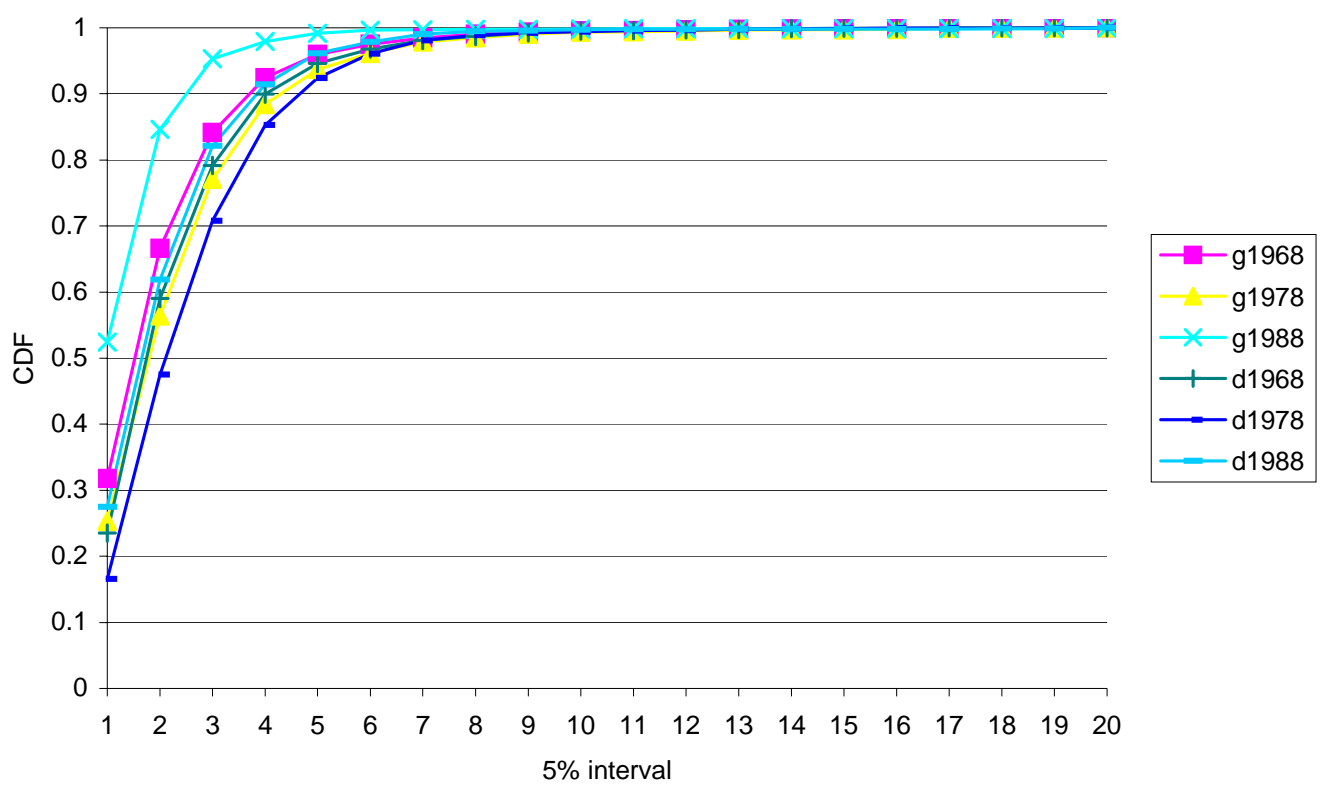

Figure 1.B Weighted CDF of gross (g) and disposable (d) incomes by years of observation.

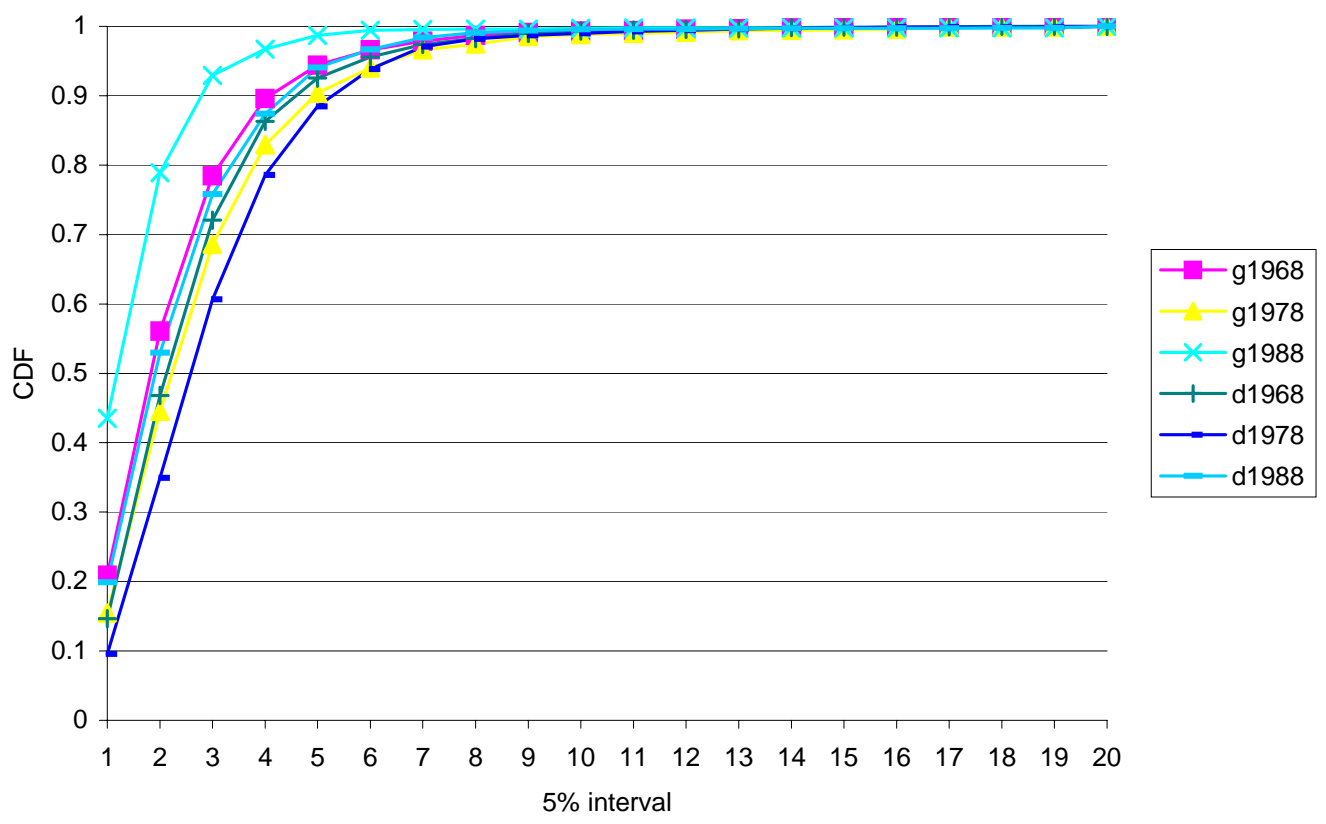


Figure 1.C Un-weighted cumulative gross (g) and disposable (d) incomes by years of observation.

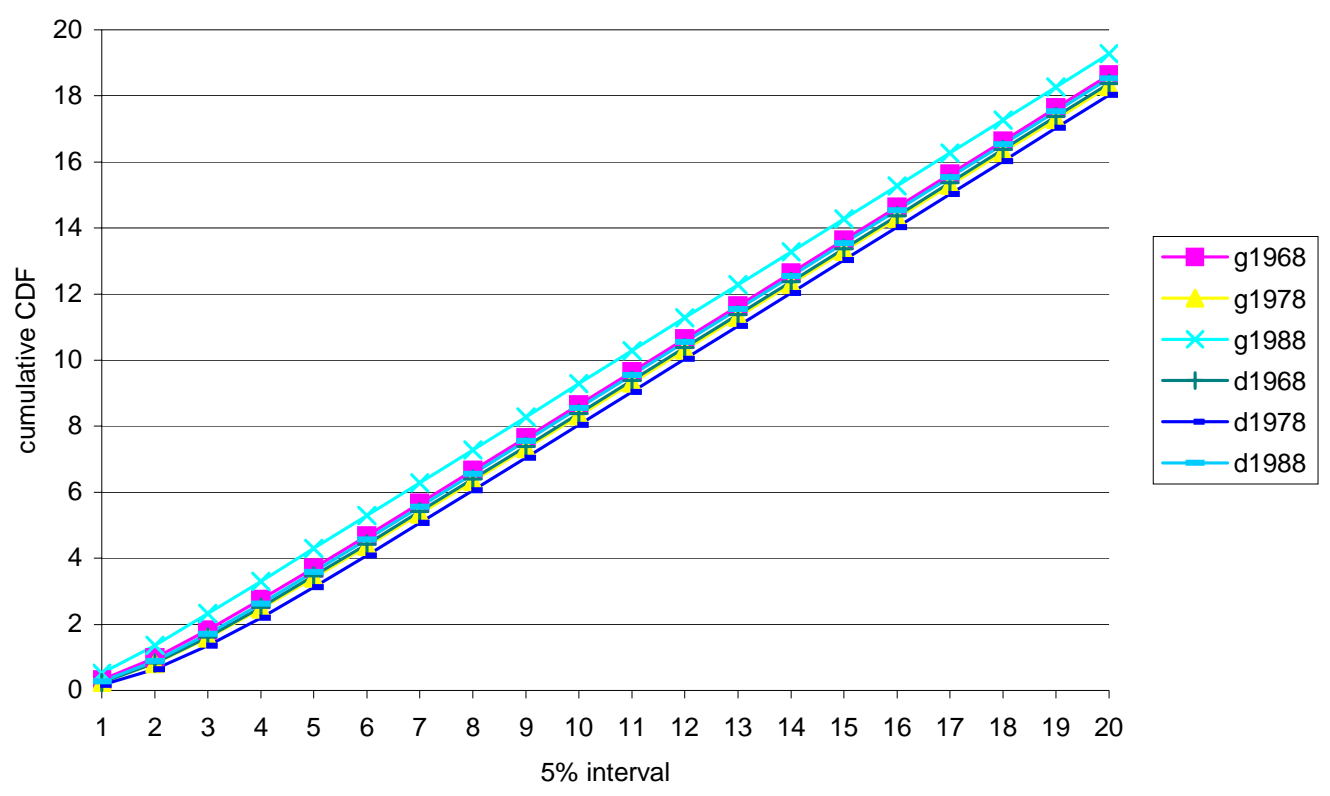

Figure 1.D Weighted cumulative CDF of gross ( $g$ ) and disposable (d) incomes by years of observation.

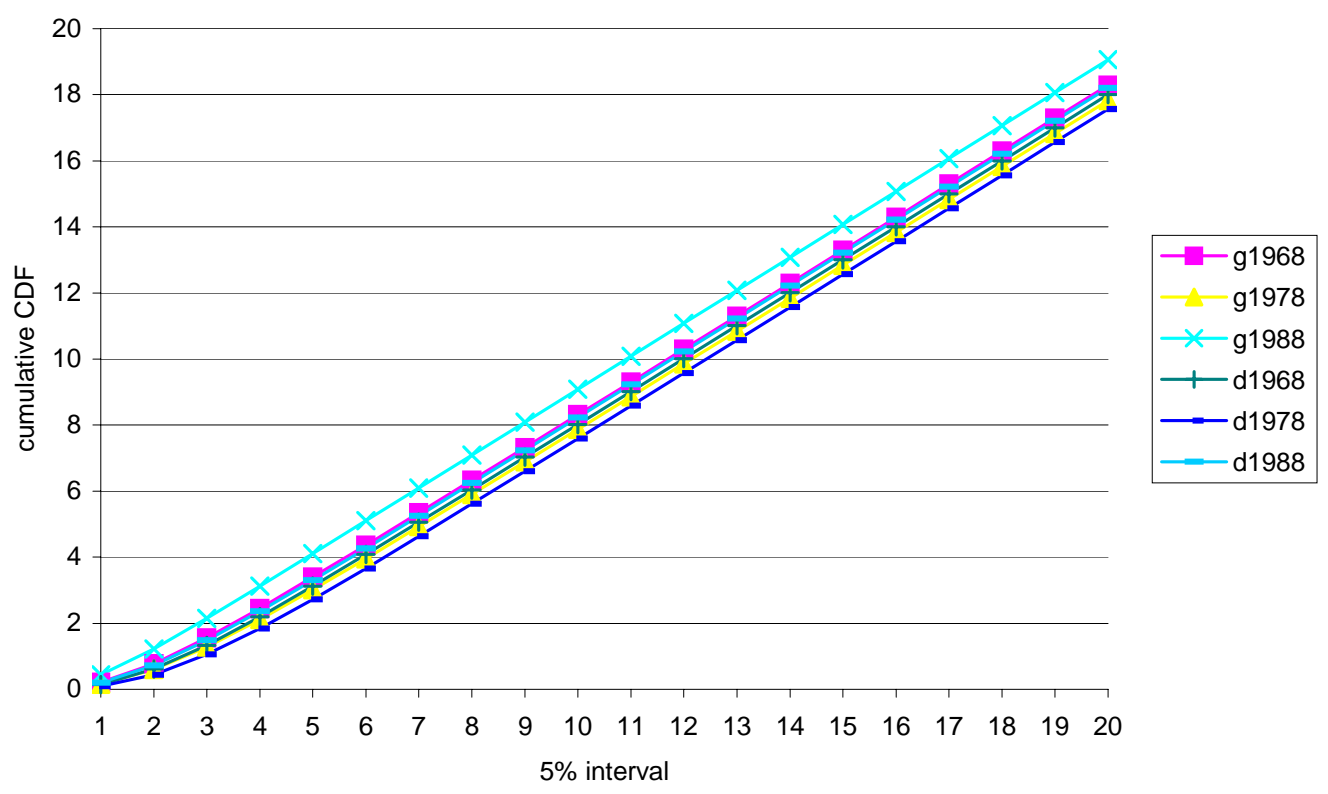


Figure 2.A Unweighted CDF of gross (g) and disposable (d) incomes by age groups.

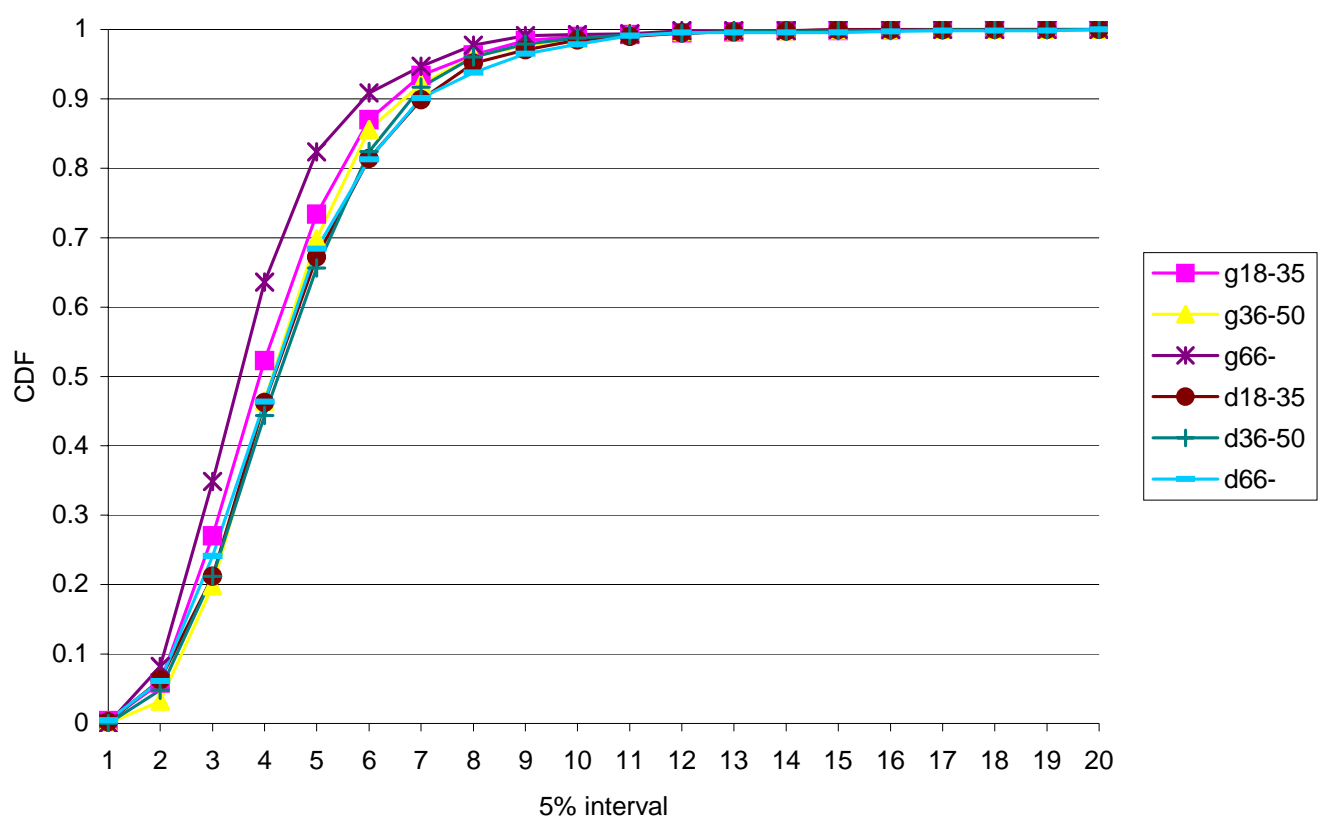

Figure 2.B Weighted CDF of gross (g) and disposable (d) incomes by age groups.

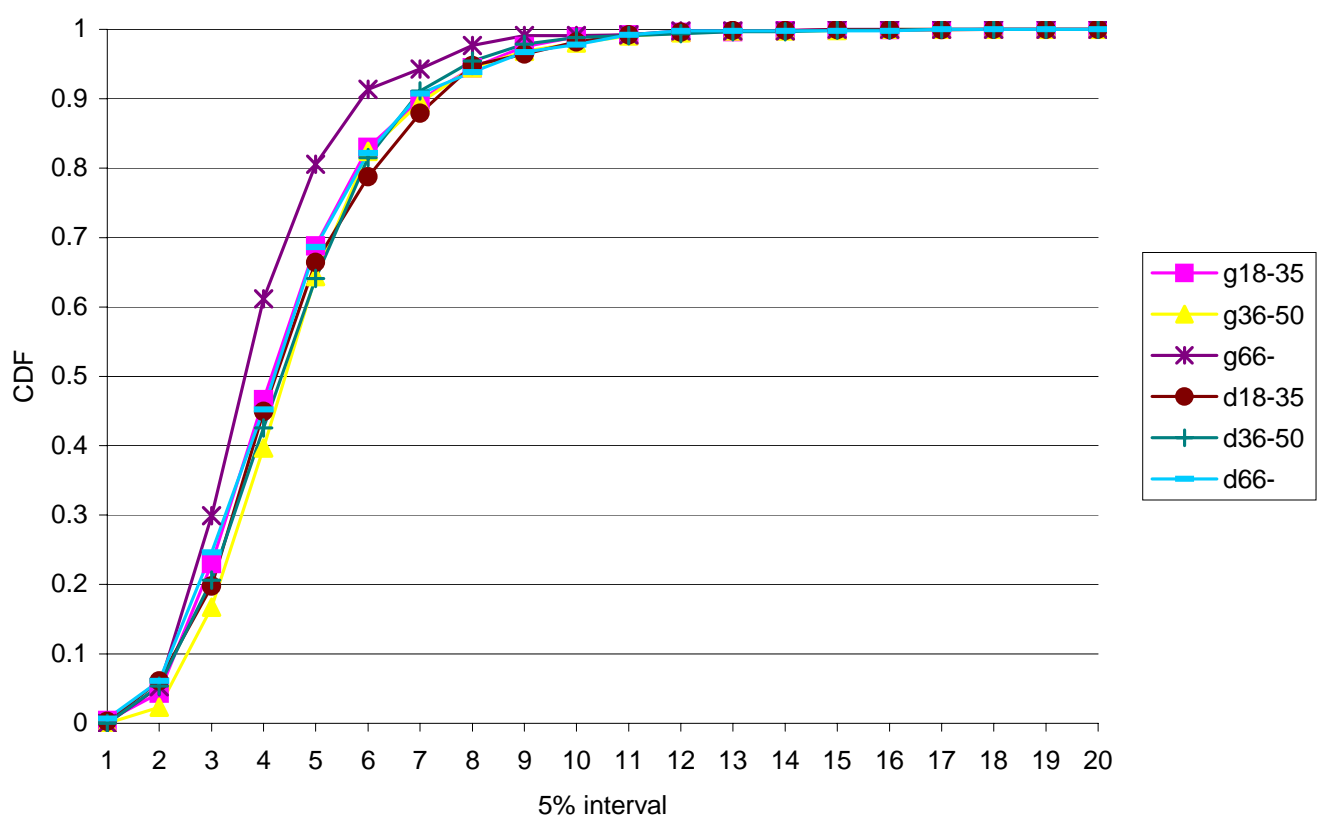


Figure 2.C Un-weighted cumulative CDF of gross ( $\mathrm{g}$ ) and disposable (d) incomes by ag groups.

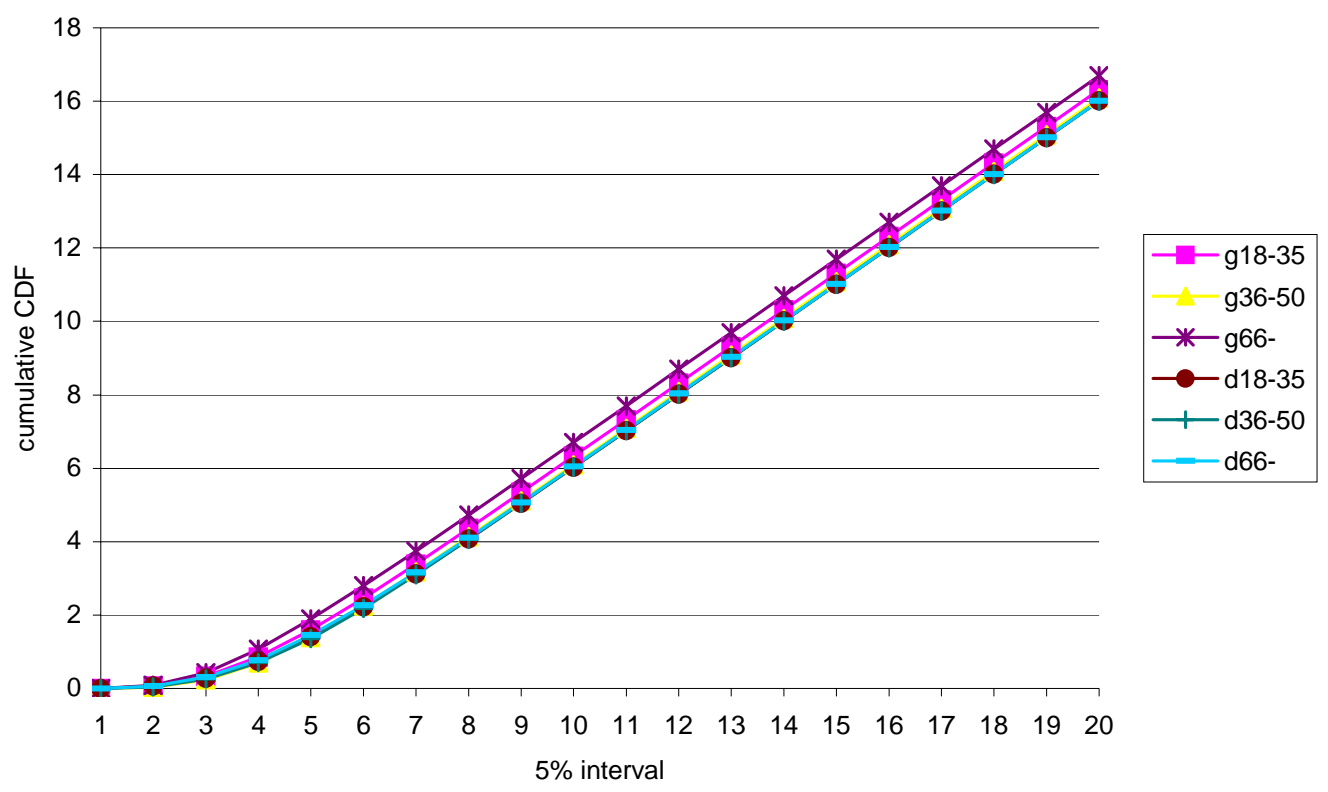

Figure 2.D Weighted cumulative CDF of gross (G) and disposable (d) incomes by age groups.

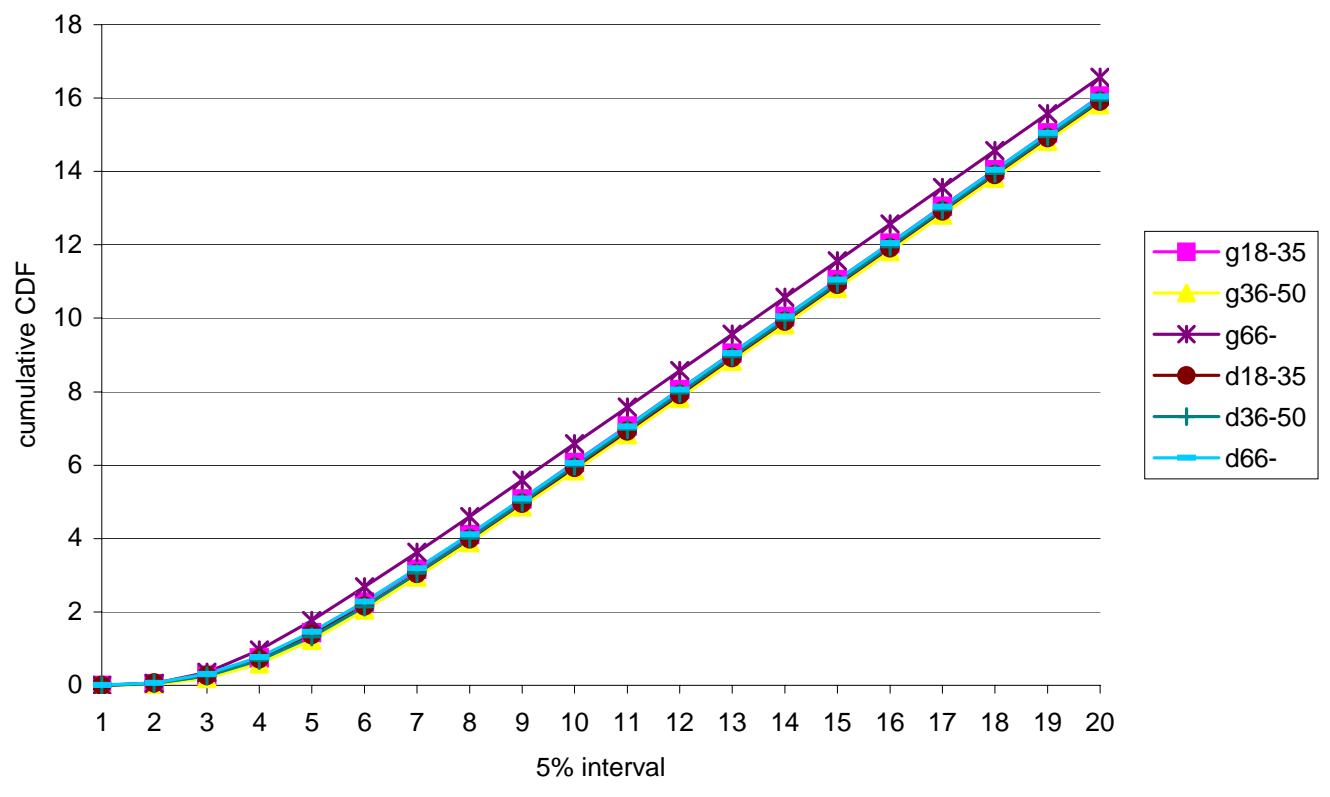


Figure 3.A Un-weighted CDF of gross (g) and disposable (d) incomes by marital status.

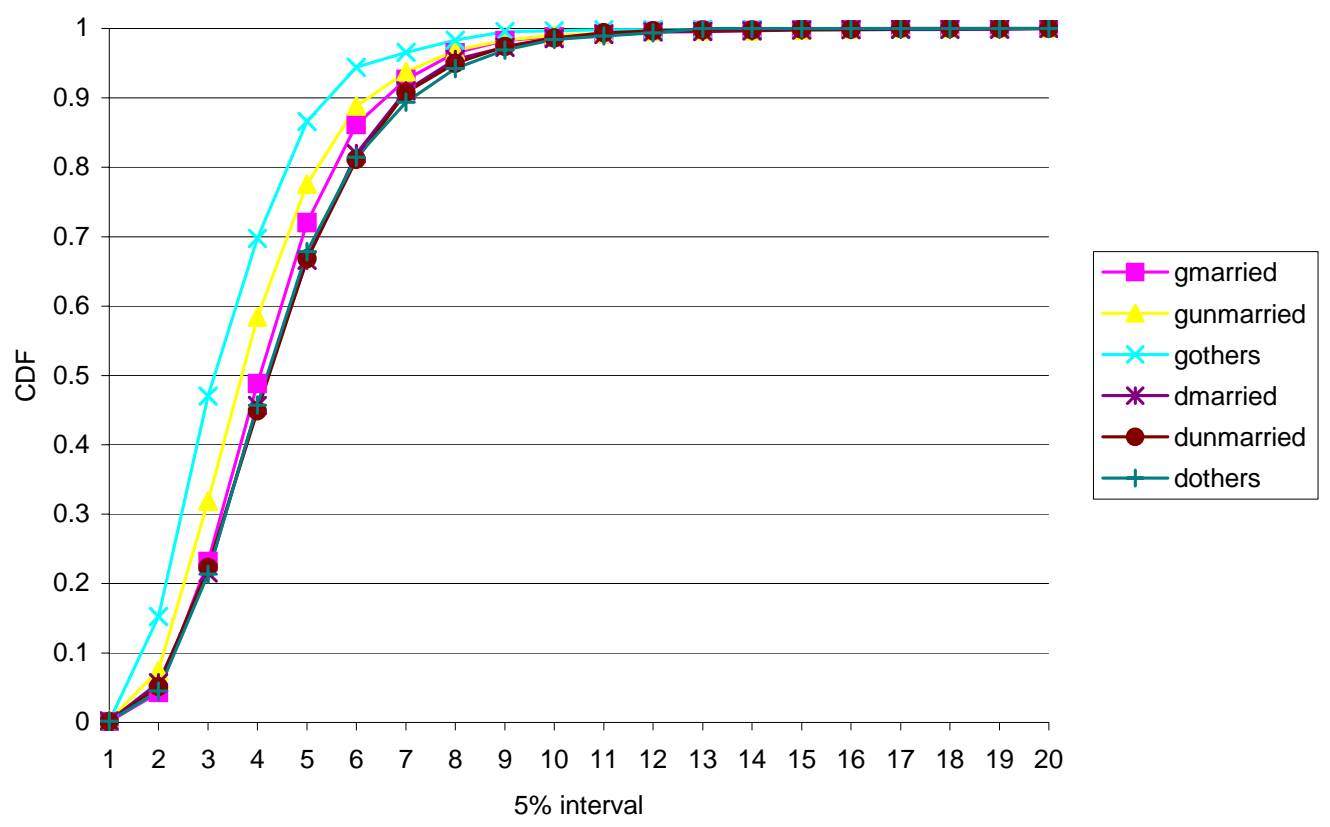

Figure 3.B Weighted CDF of gross (g) and disposable (d) incomes by marital status.

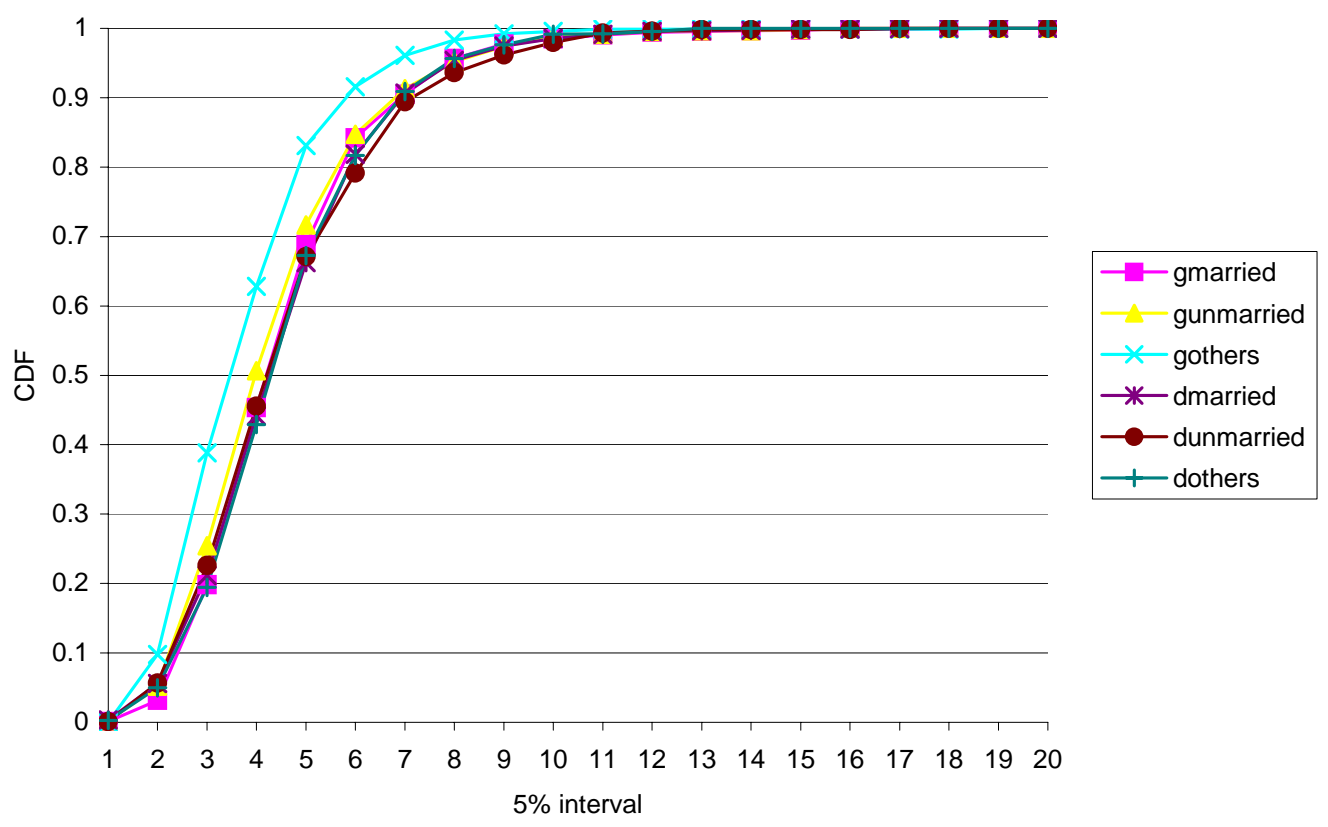


Figure 3.C Un-weighted cumulative CDF of gross (g) and disposable (d) incomes by marital status.

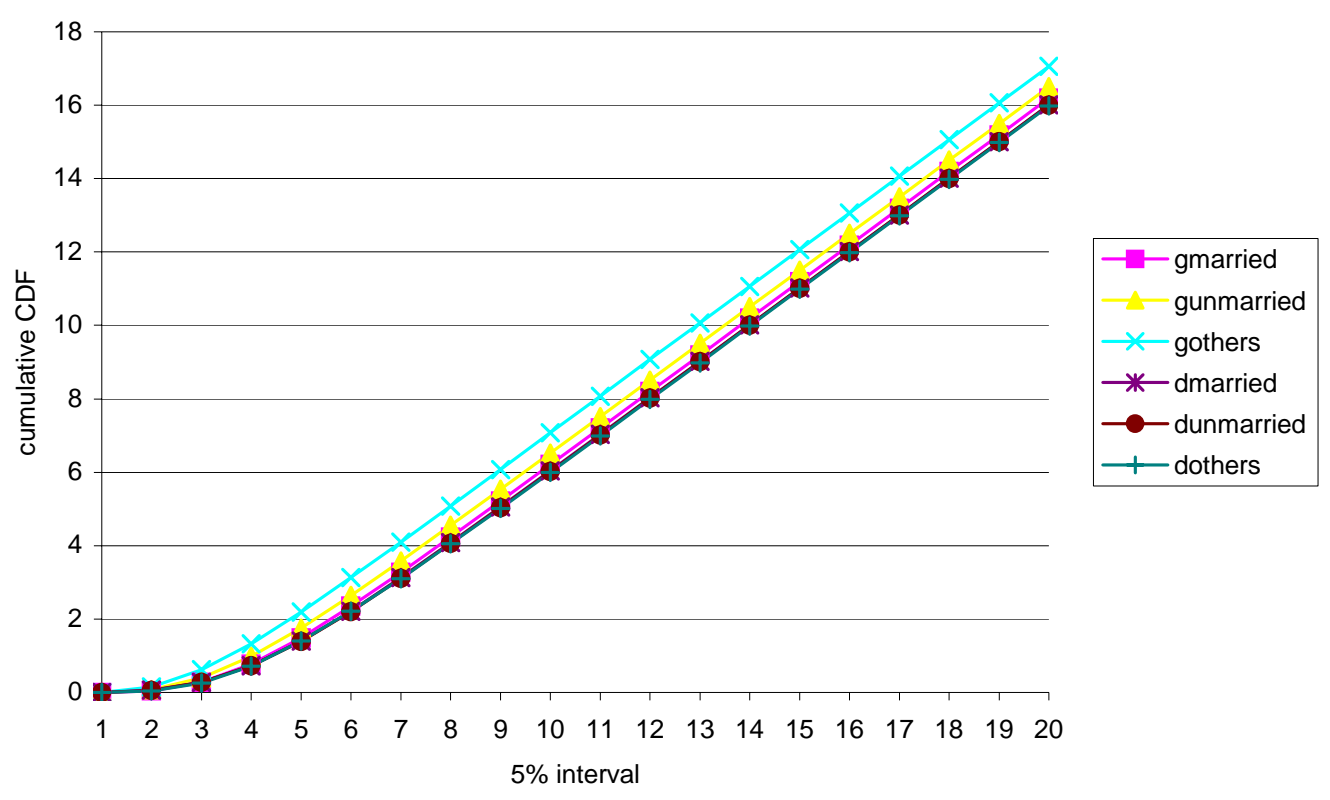

Figure 3.D Weighted cumulative CDF of gross (g) and disposable (d) incomes by marital status.

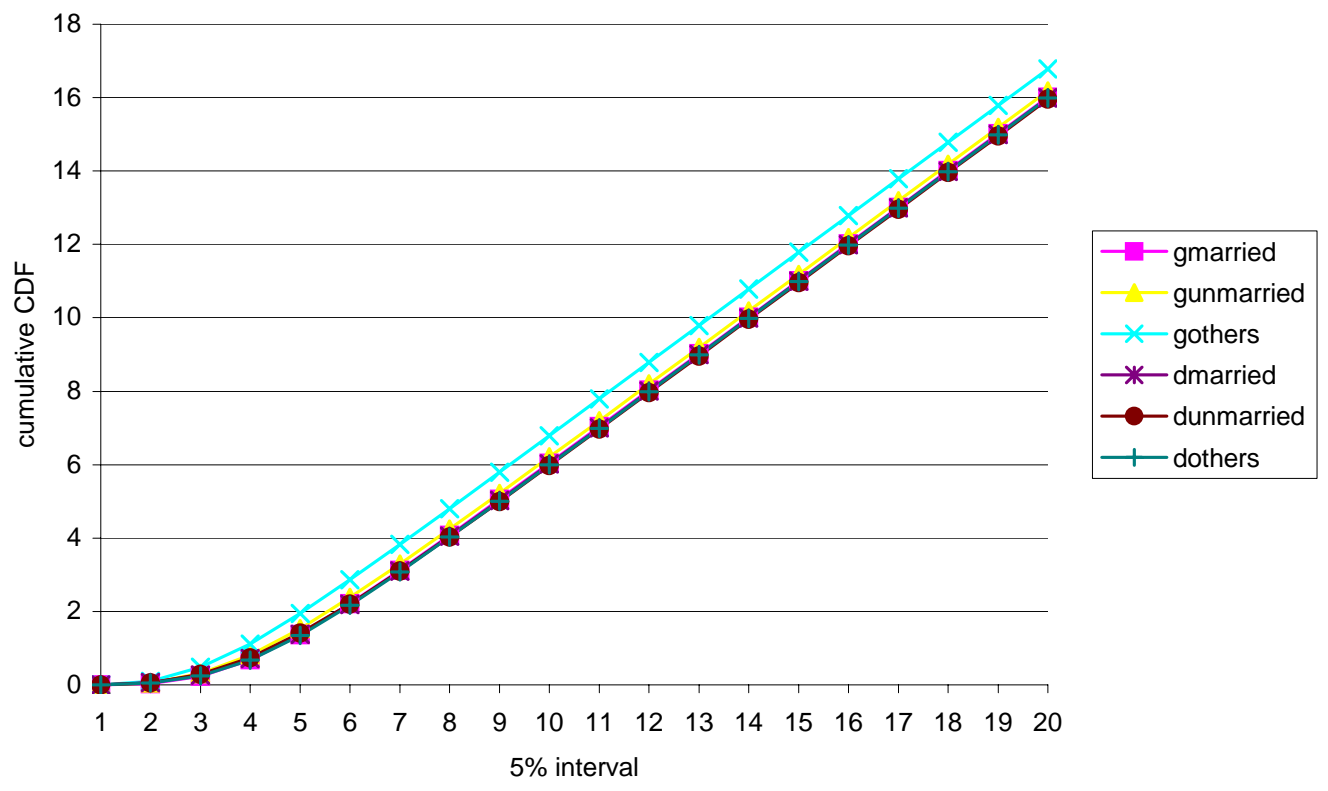


Figure 4.A Un-weighted CDF of gross (g) and disposable (d) incomes by working status.
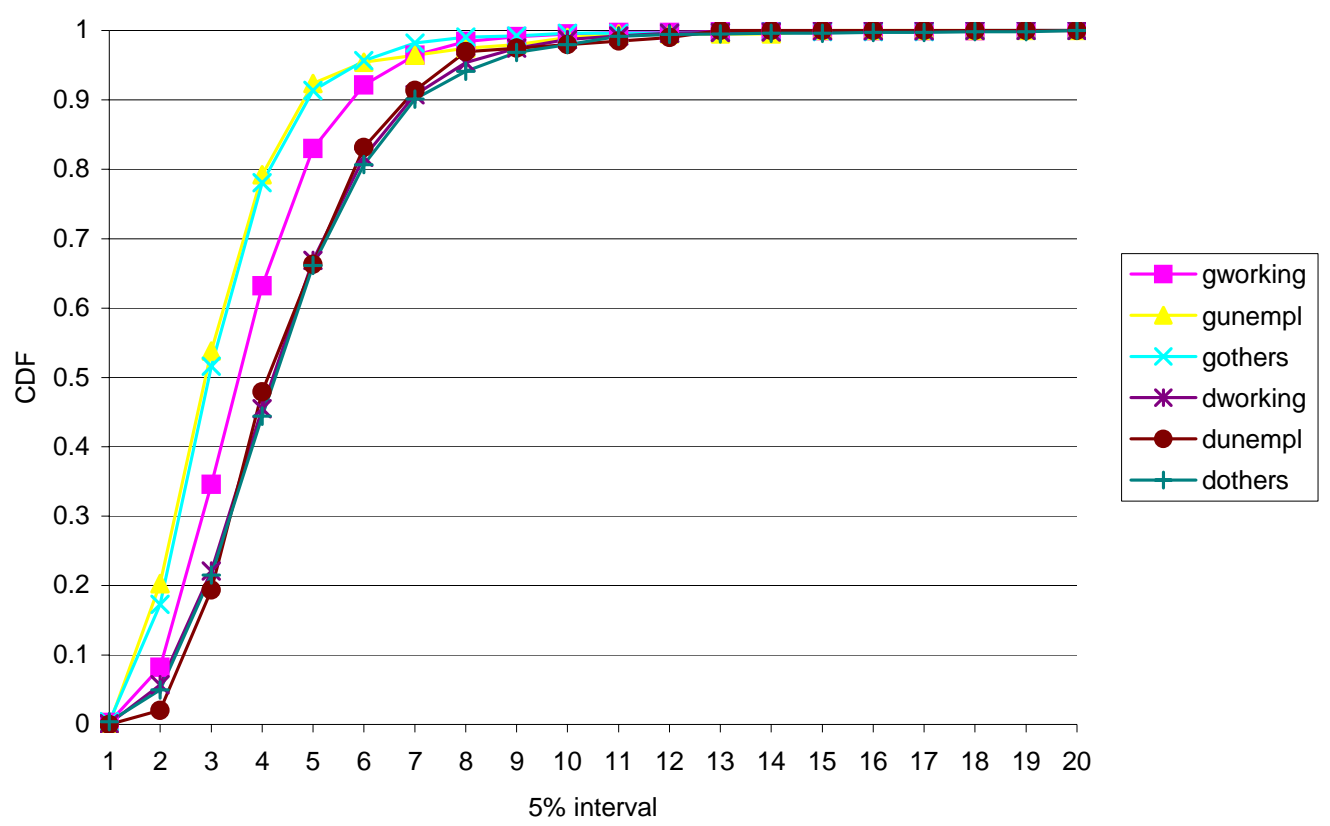

Figure 4.B Weighted CDF of gross $(\mathrm{g})$ and disposable $(\mathrm{d})$ incomes by working status.
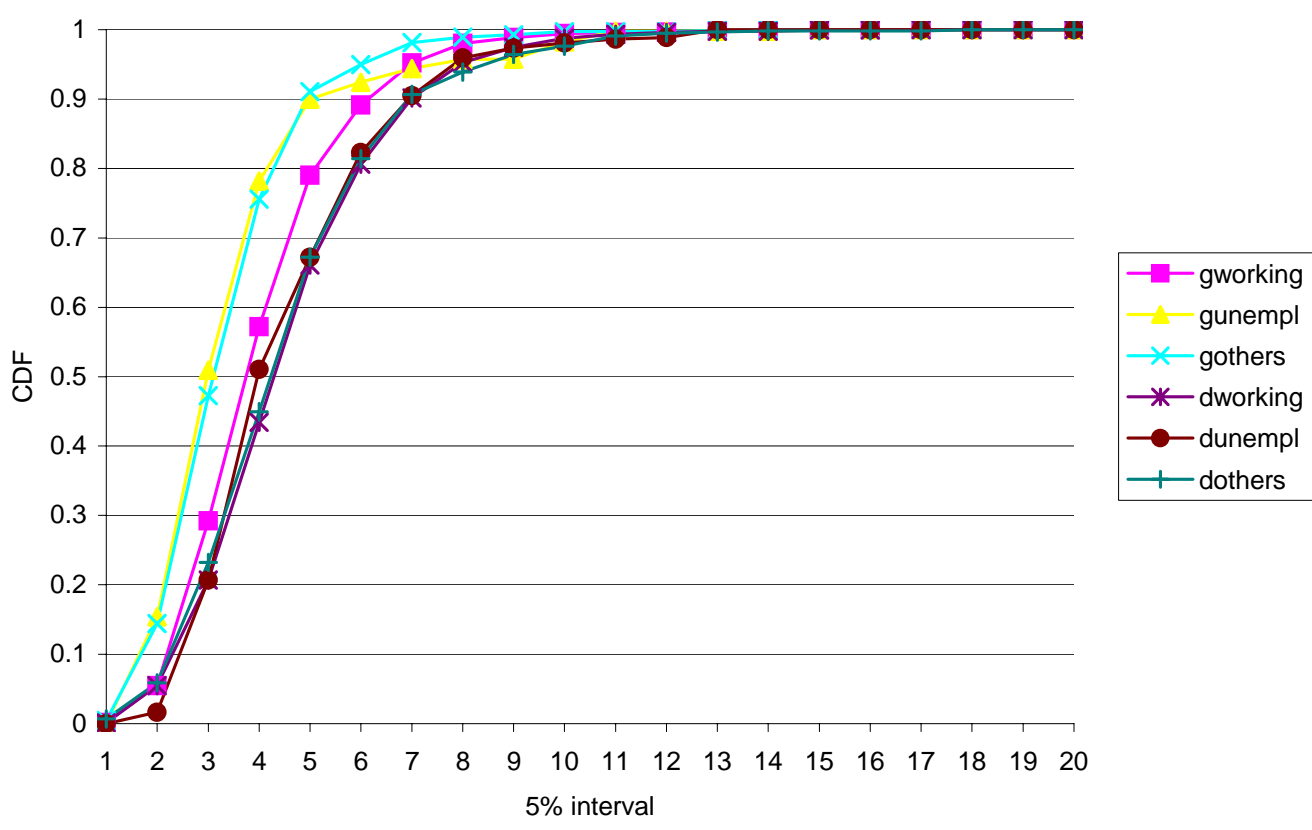
Figure 4.C Un-weighted cumulative CDF of gross (g) and disposable (d) incomes by working status.

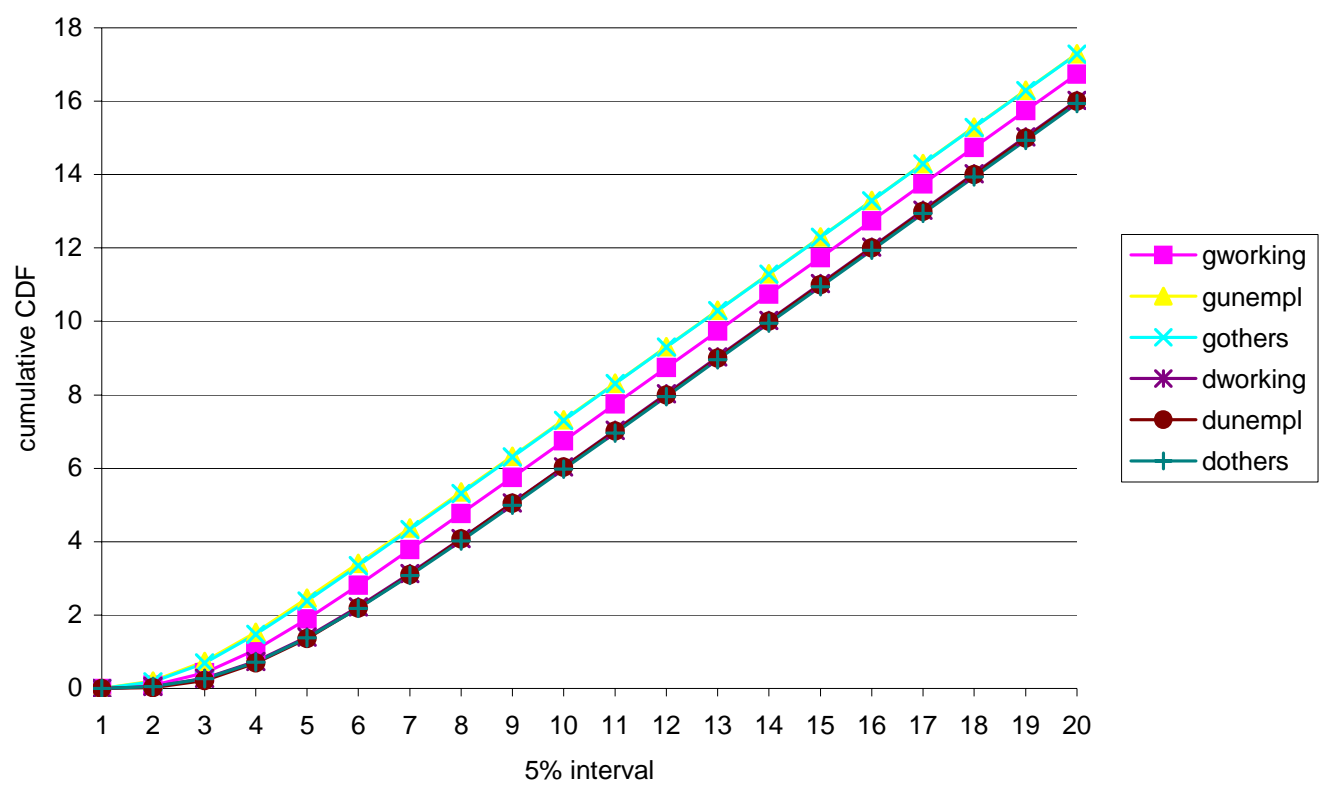

Figure 4.D Weighted cumulative CDF of groos (g) and disposable (d) incomes by working status.
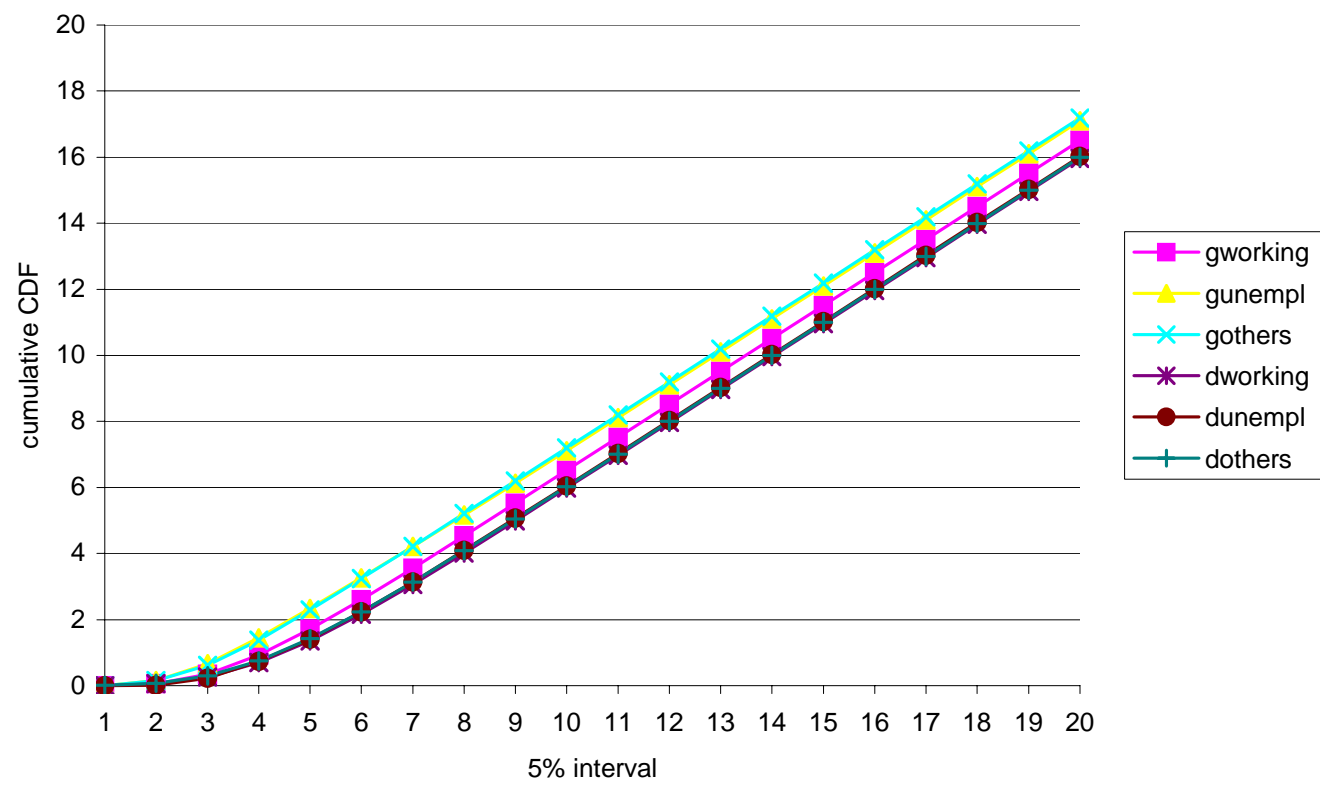
Figure 5.A Un-weighted CDF of gross ( $g$ ) and disposable (d) incomes by racial status.

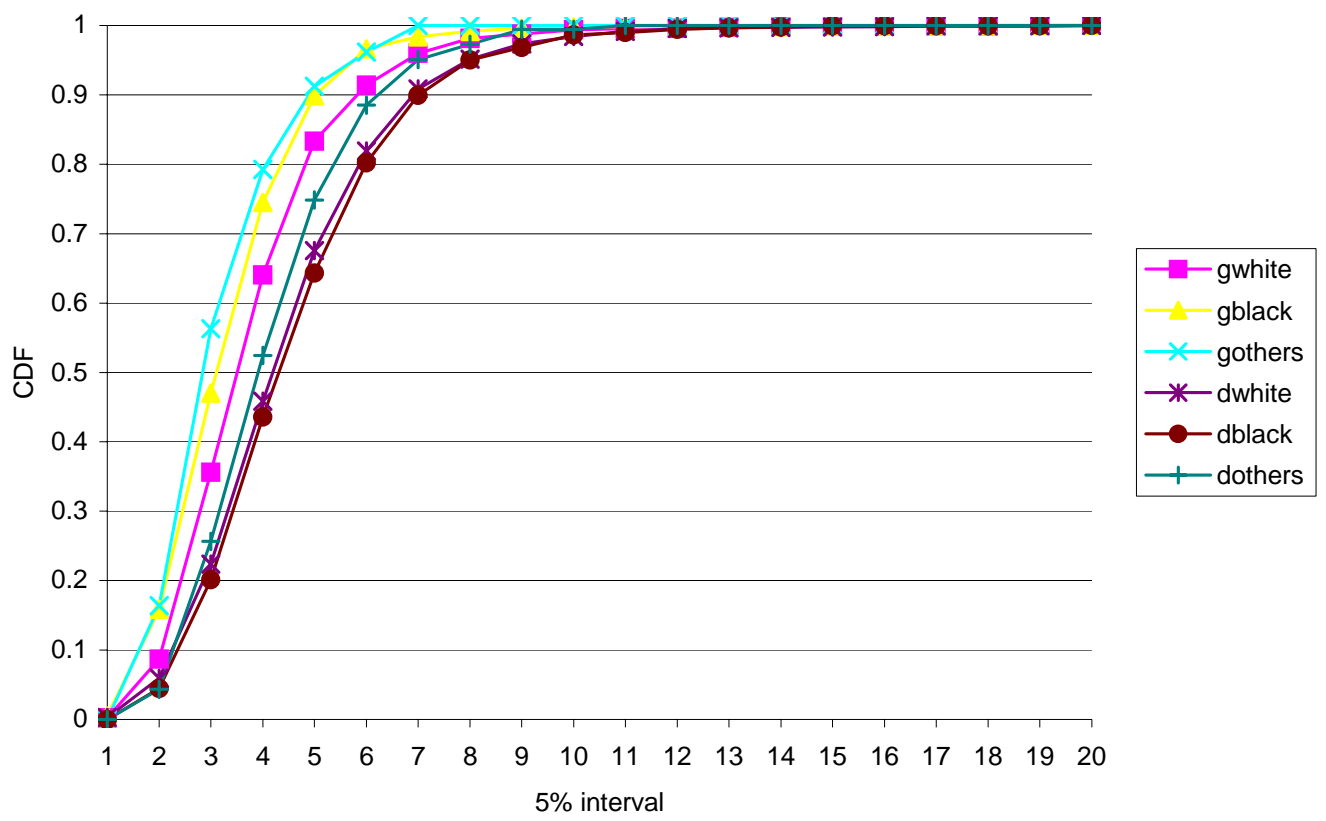

Figure 5.B Weighted CDF of gross (g) and disposable (d) incomes by racial status.

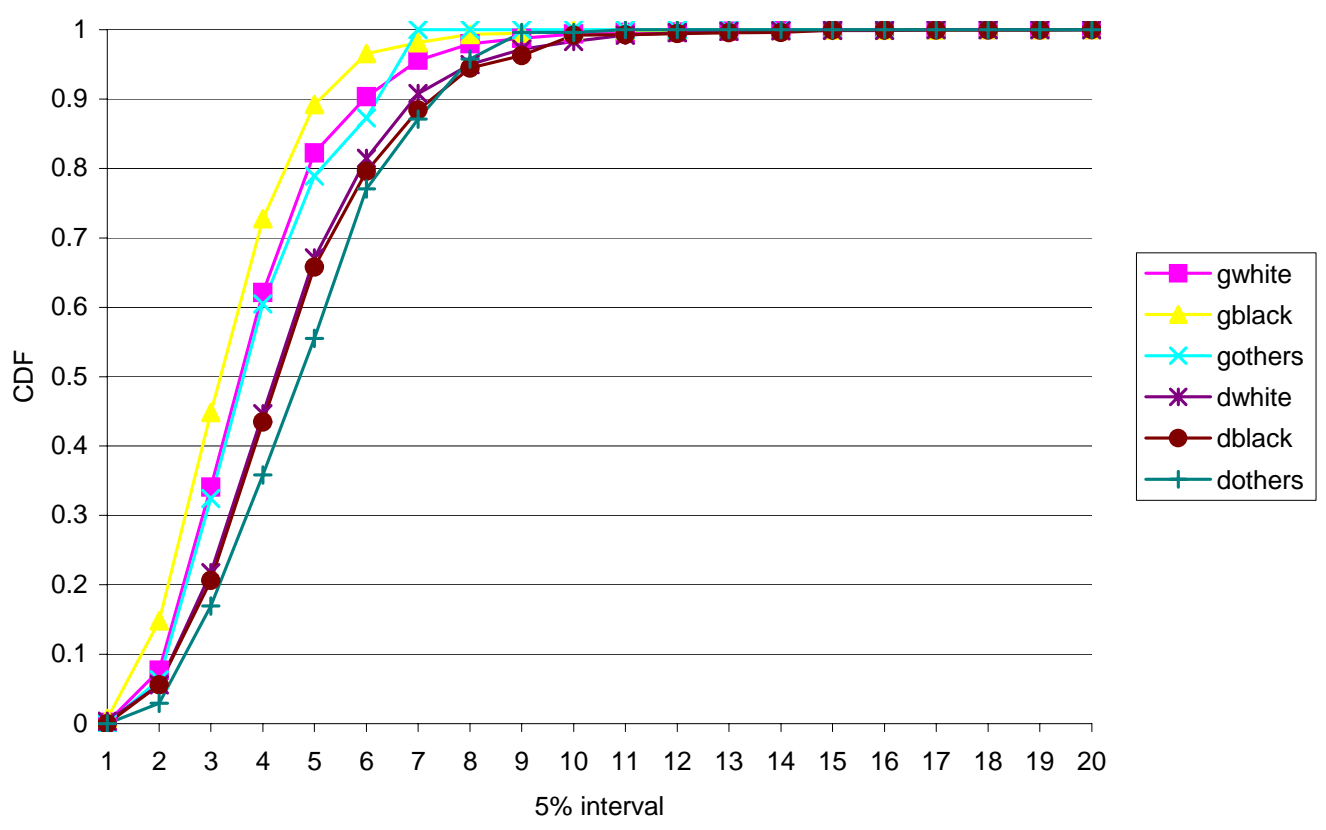


Figure 5.C Un-weighted comulative CDF of gross (g) and disposable (d) incomes by racial status.

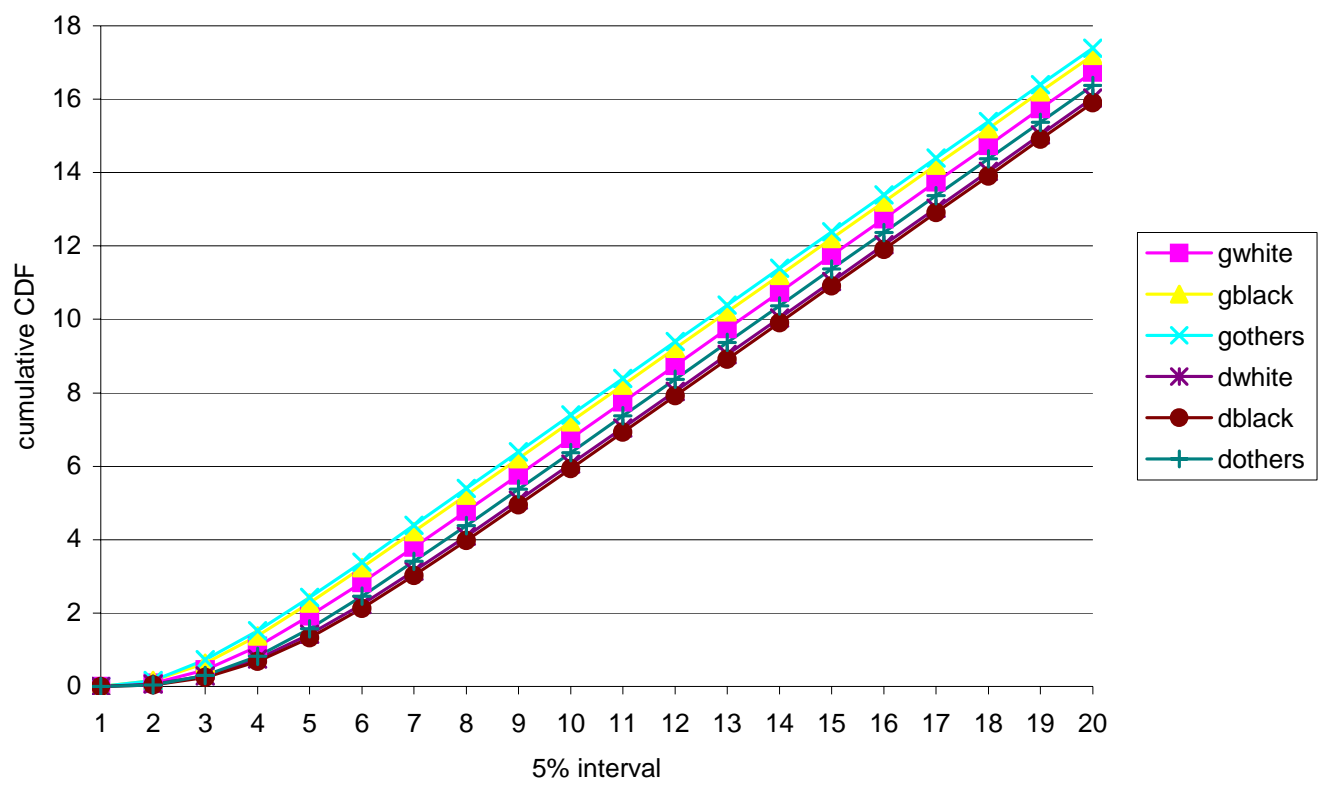

Figure 5.D Weighted comulative CDF of gross ( $g$ ) and disposable (d) incomes by racial status.

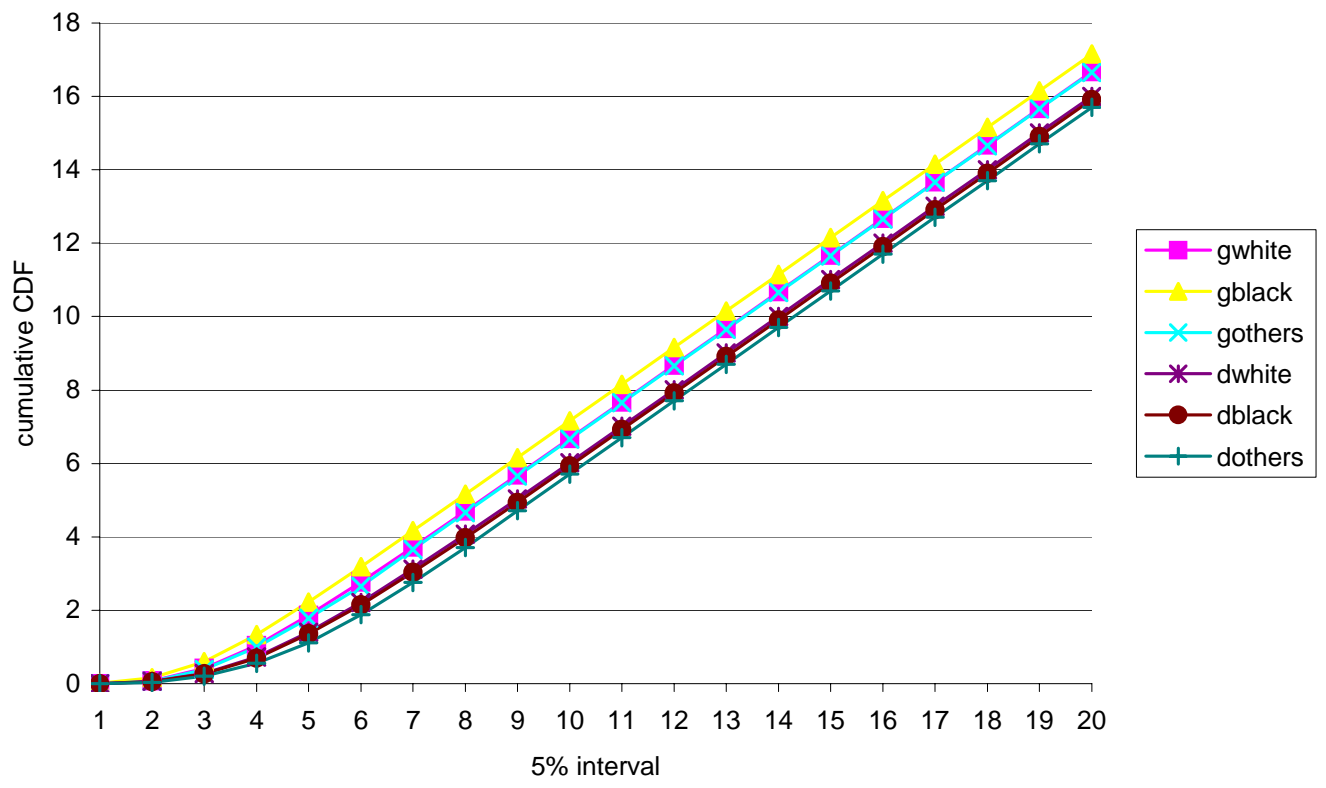


Figure 6.A Unweighted CDF of gross ( $\mathrm{g}$ ) and disposable (d) incomes by gender.

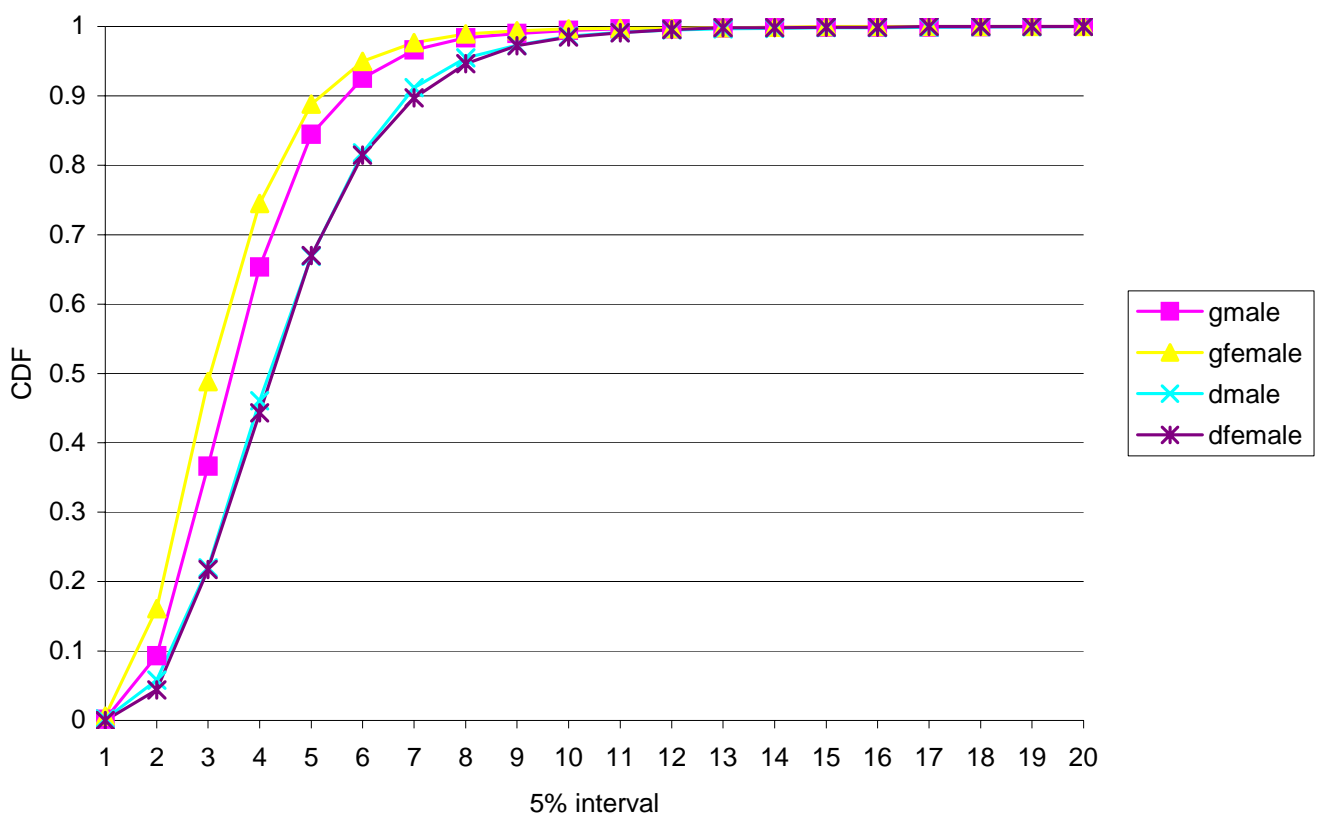

Figure 6.B Weighted CDF of gross (g) and disposable (d) incomes by gender.

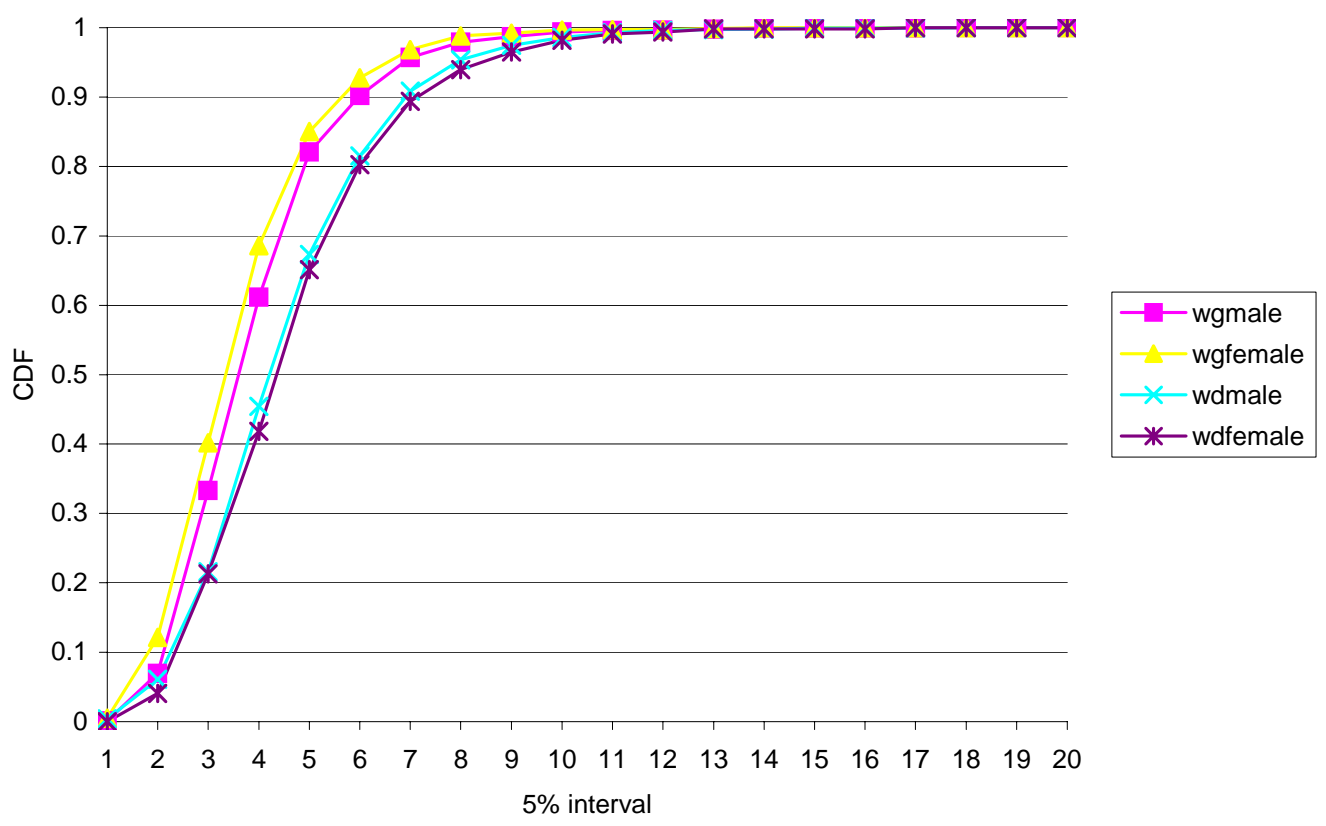


Figure 6.C Un-weighted cumulative CDF of gross ( $\mathrm{g}$ ) and dsisposable (d) incomes by gender.

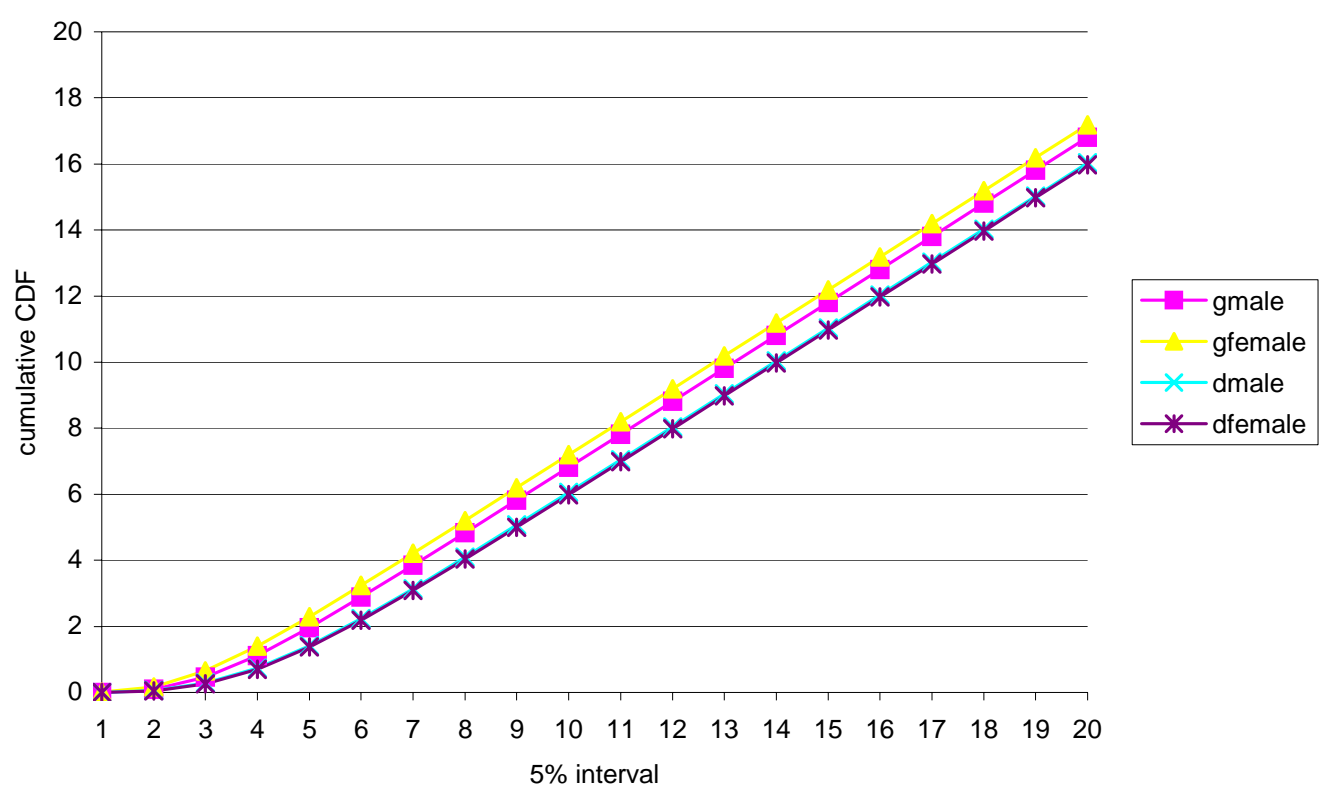

Figure 6.D Weighted cumulative CDF of gross (g) and disposable (d) incomes by gender.

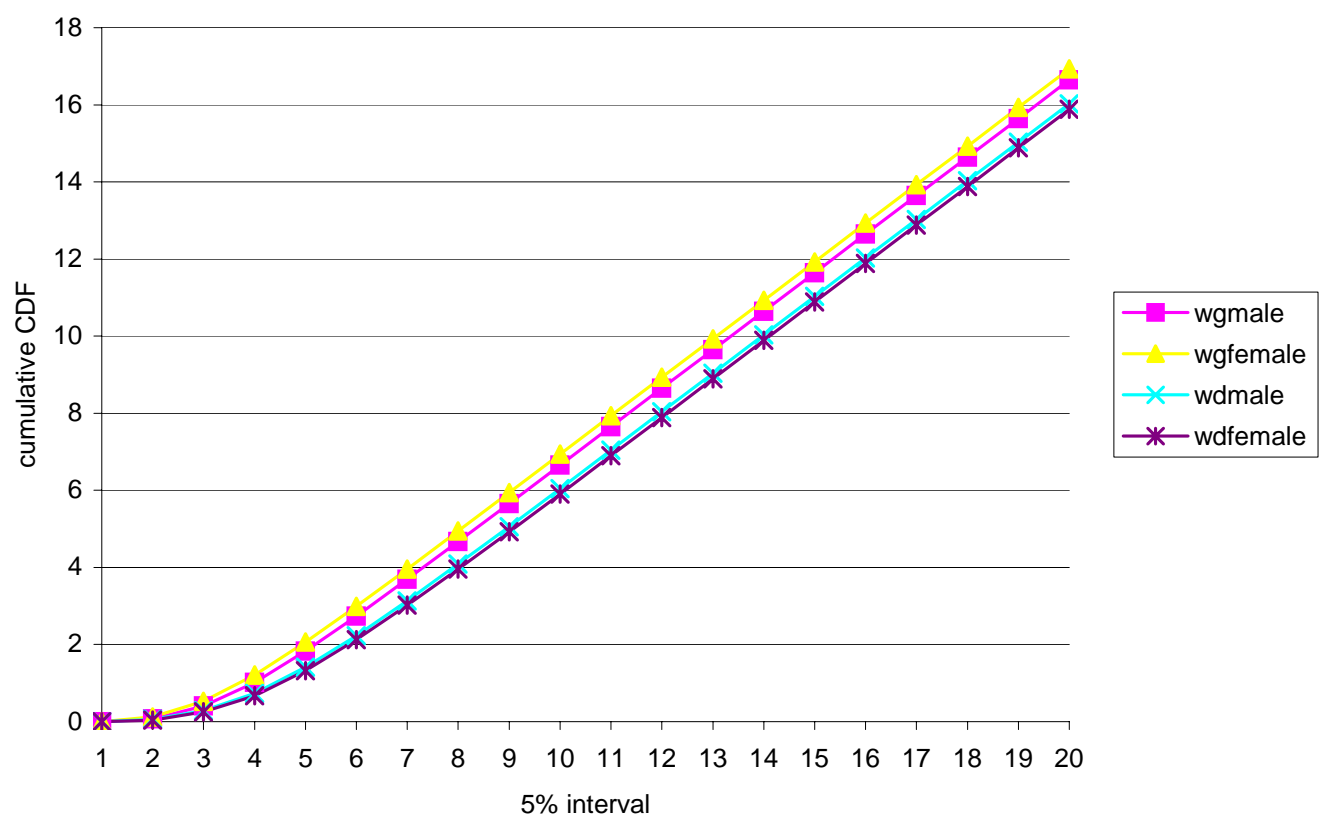


Figure 7.A Un-weighted CDF of gross (g) and disposable (d) incomes by occupation.

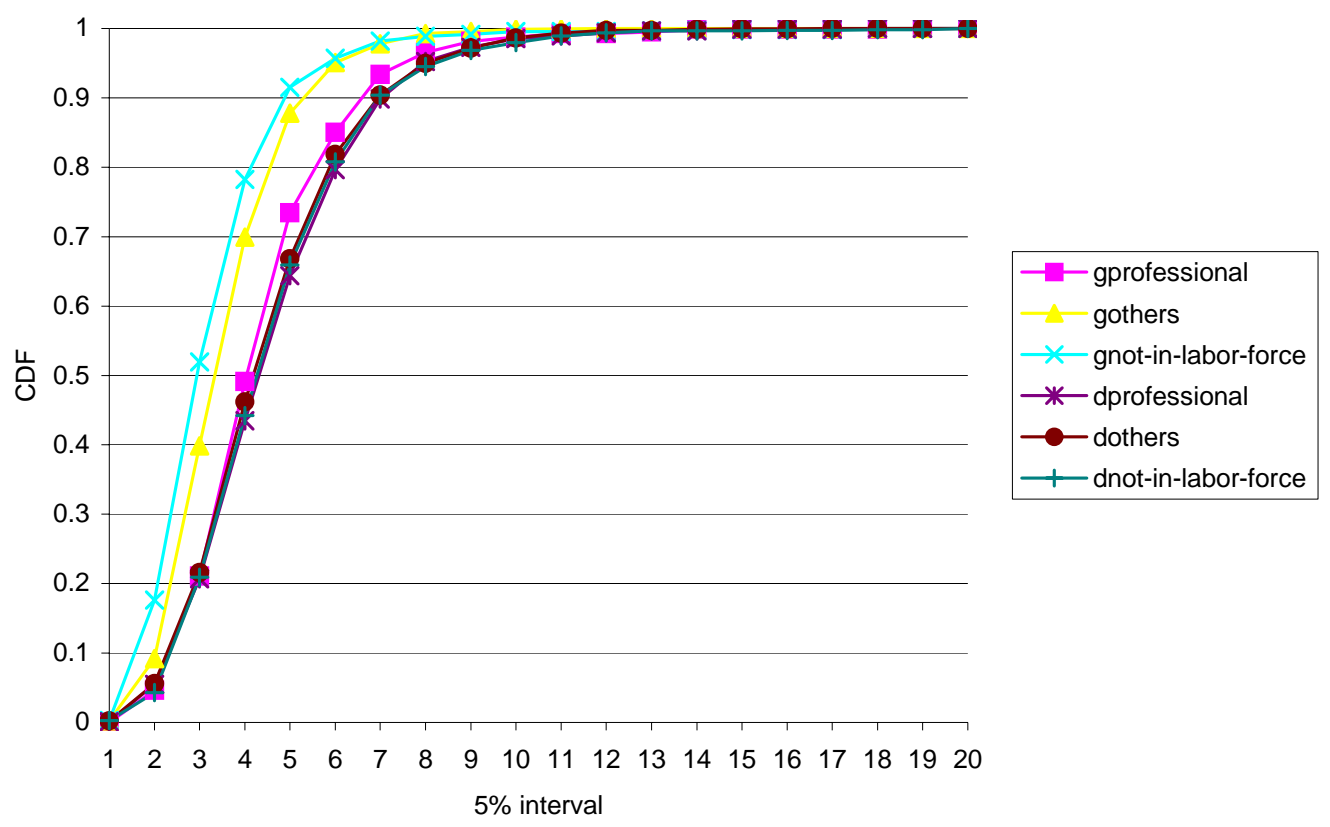

Figure 7.B Weighted CDF of gross (g) and disposable (d) incomes by occupation.

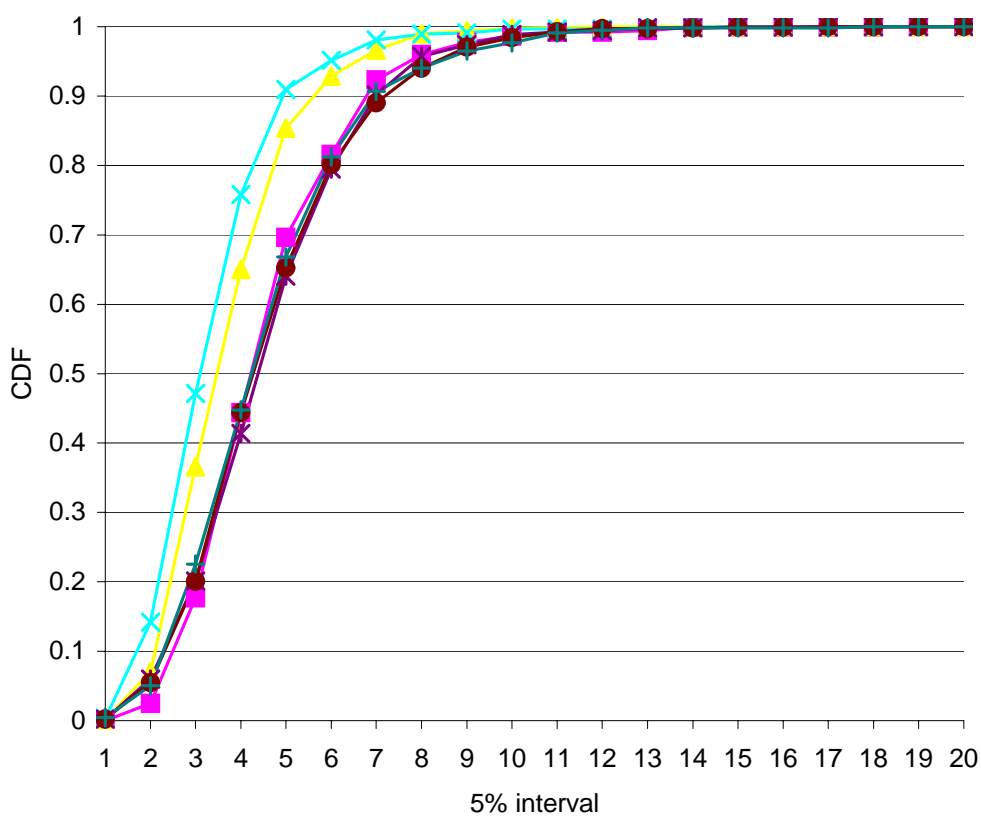

- - gprofessional
- gothers
$-\quad$ gnot-in-labor-force
$\rightarrow$ dprofessional
- dothers
- - dnot-in-labor-force


Figure 7.C Un-weighted cumulative CDF of gross (g) and disposable (d) incomes by occupation.

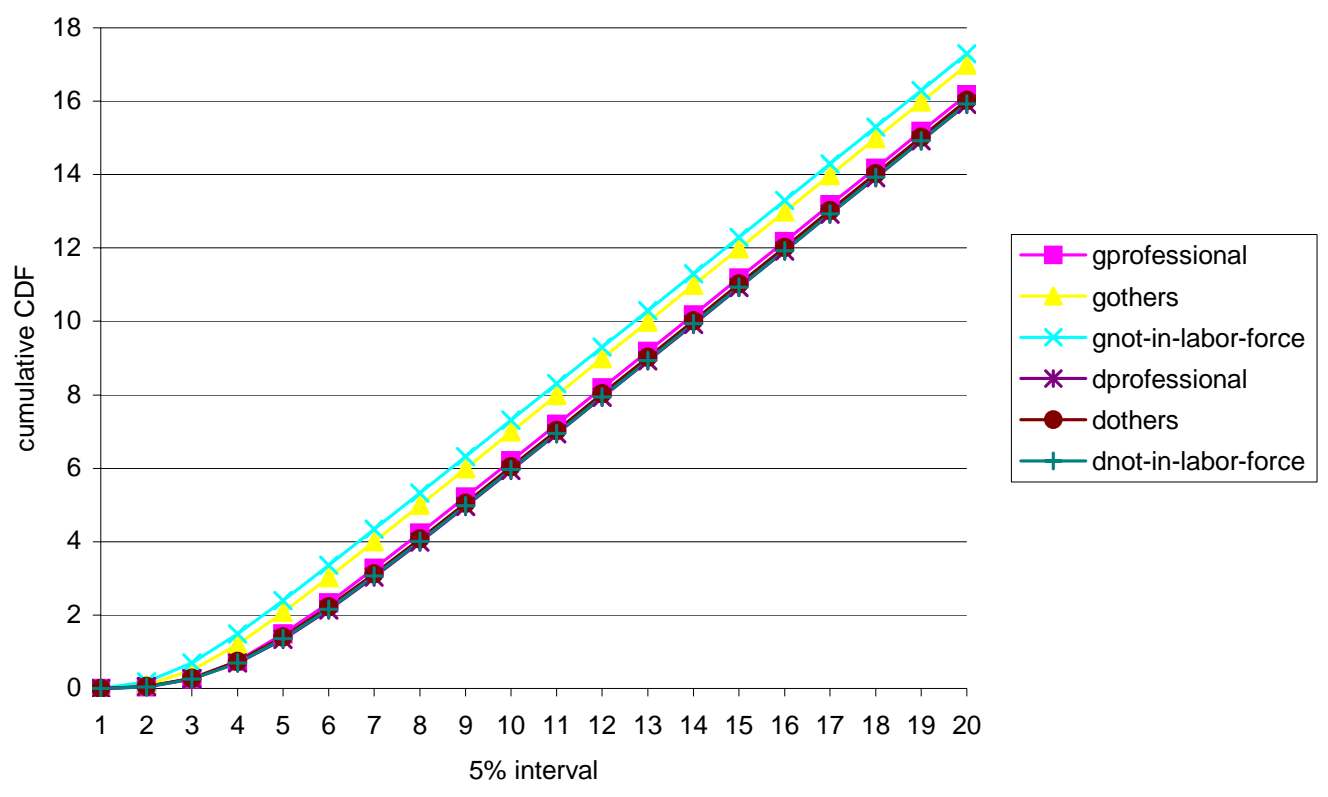

Figure 7.D Weighted cumulative CDF of gross (g) and disposable (d) incomes by occupation.

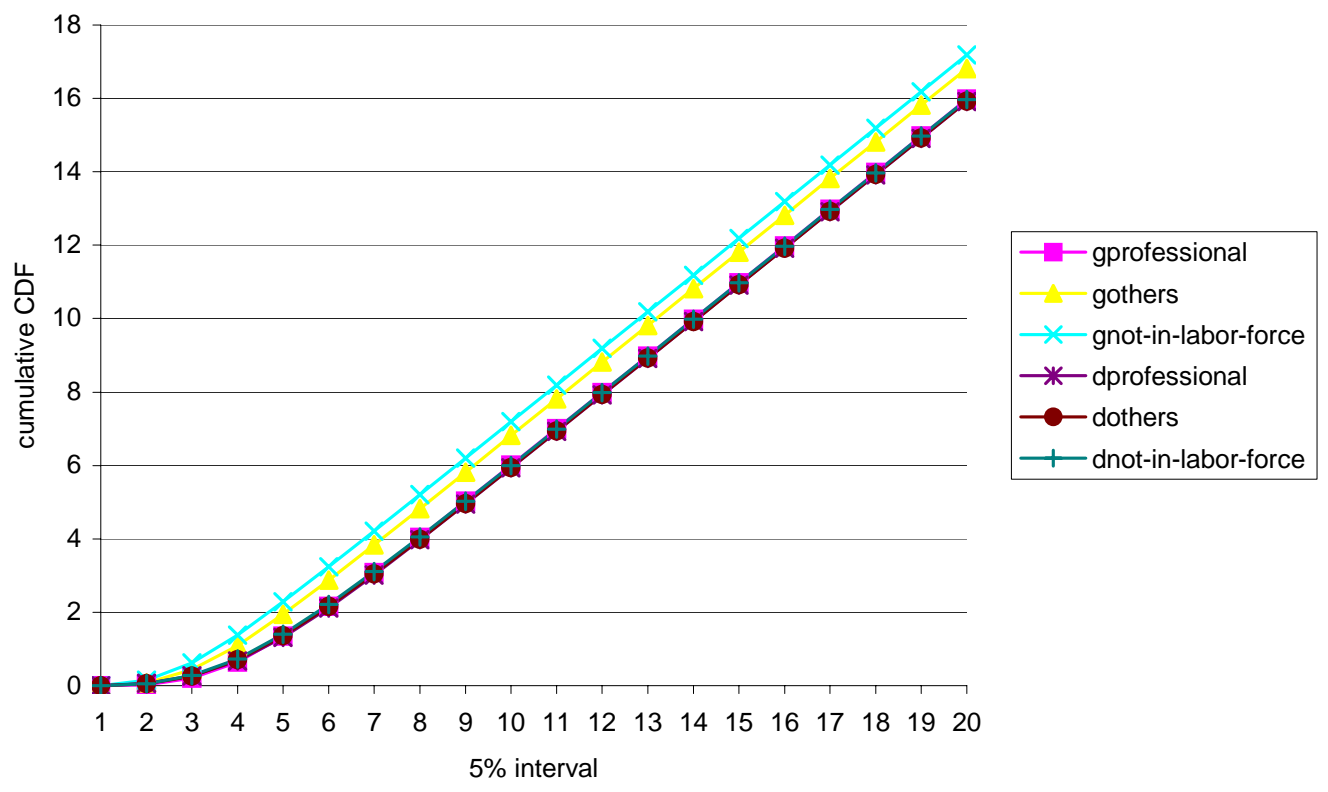


Figure 8.A Unweighted CDF of gross ( $g$ ) and disposable (d) incomes by number of children.

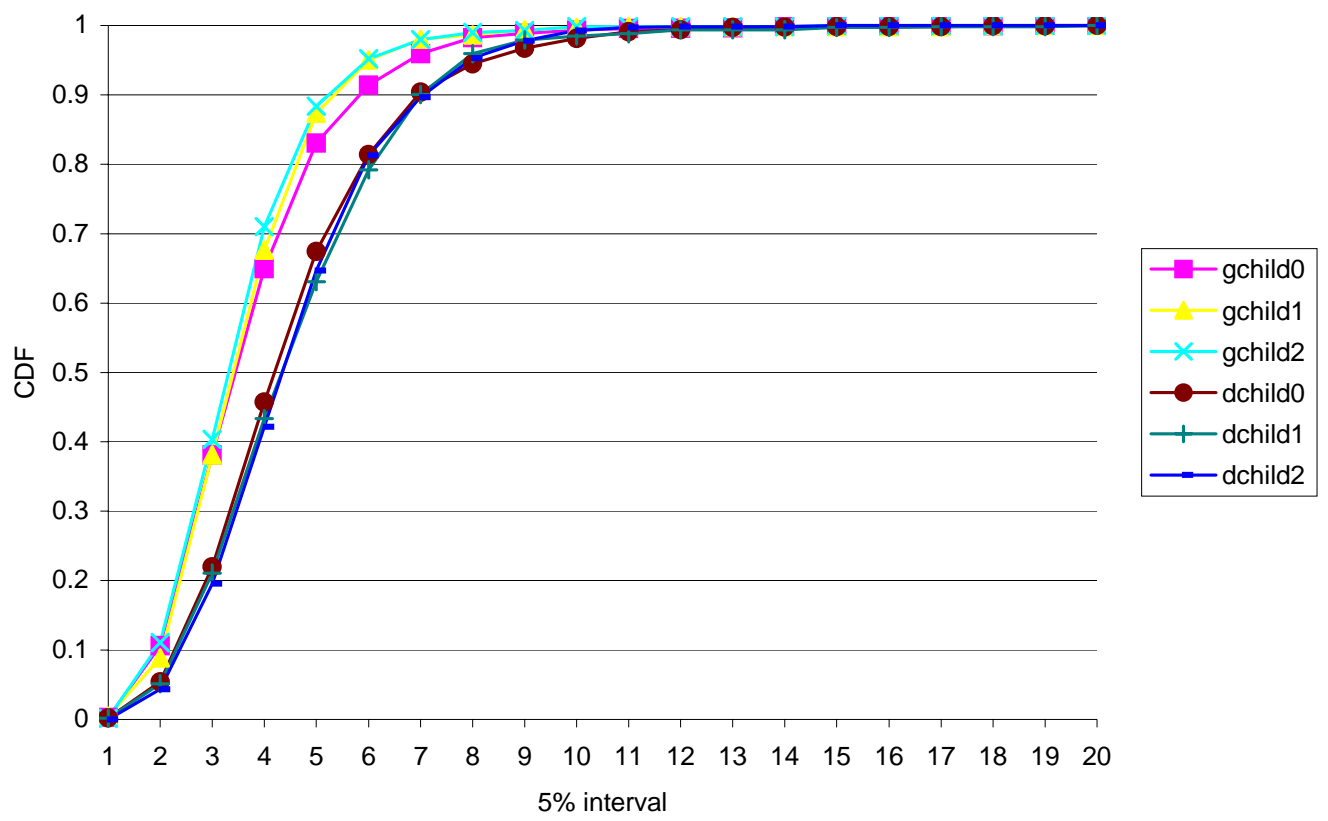

Figure 8.B Weighted CDF of gross ( $\mathrm{g}$ ) and disposable (d) incomes by number of children.

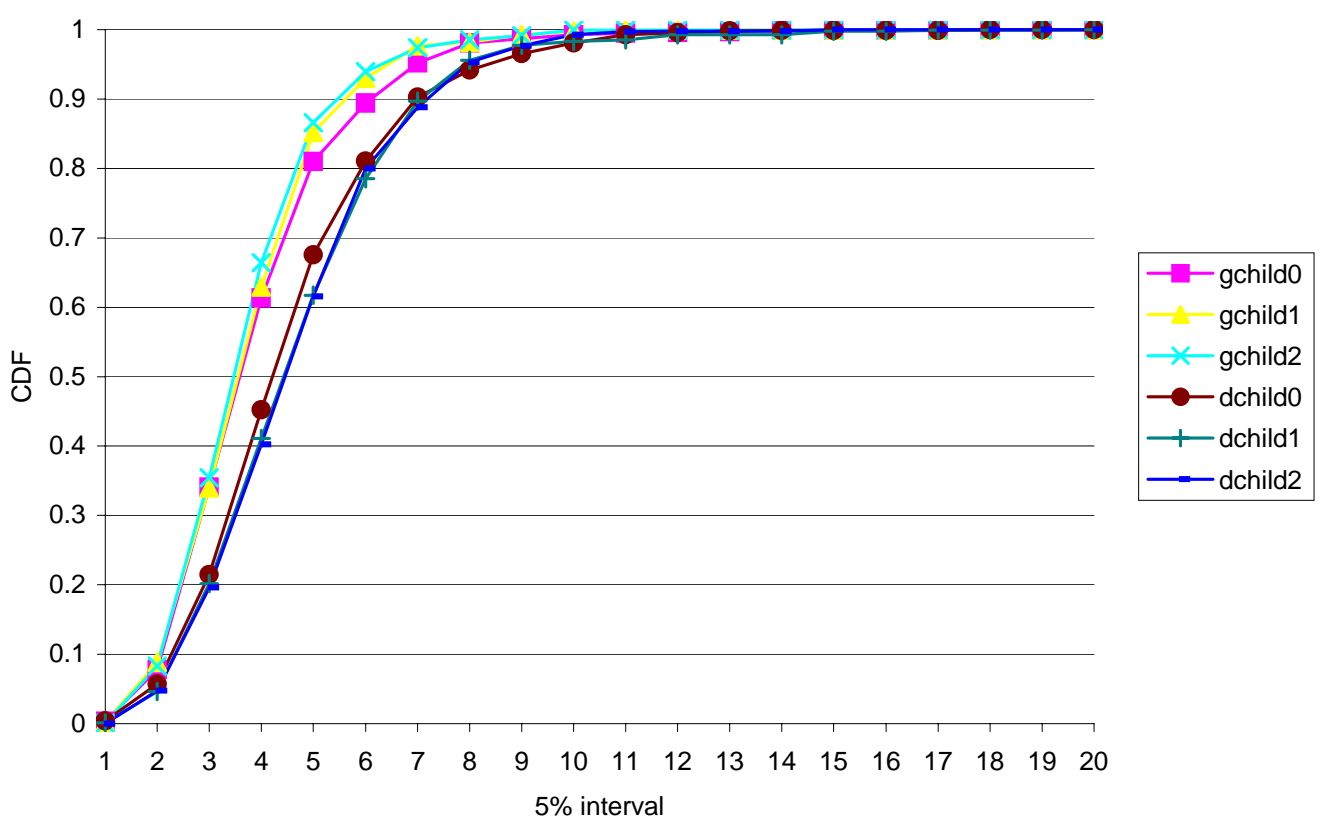


Figure 8.C Un-weighted cumulative CDF of gross ( $\mathrm{g}$ ) and disposable (d) incomes by number of children.

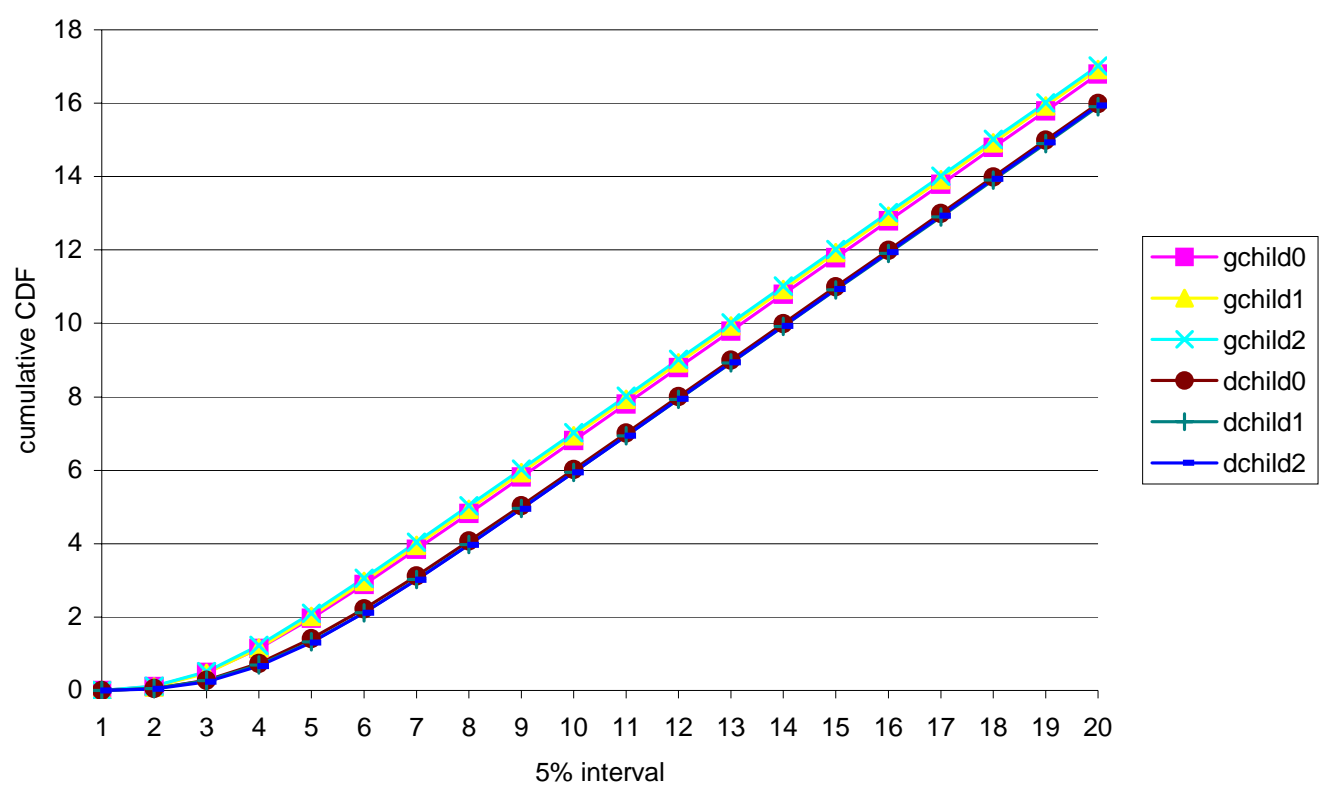

Figure 8.D Weighted cumulative CDF of gross (g) and disposable (d) incomes by number of children.

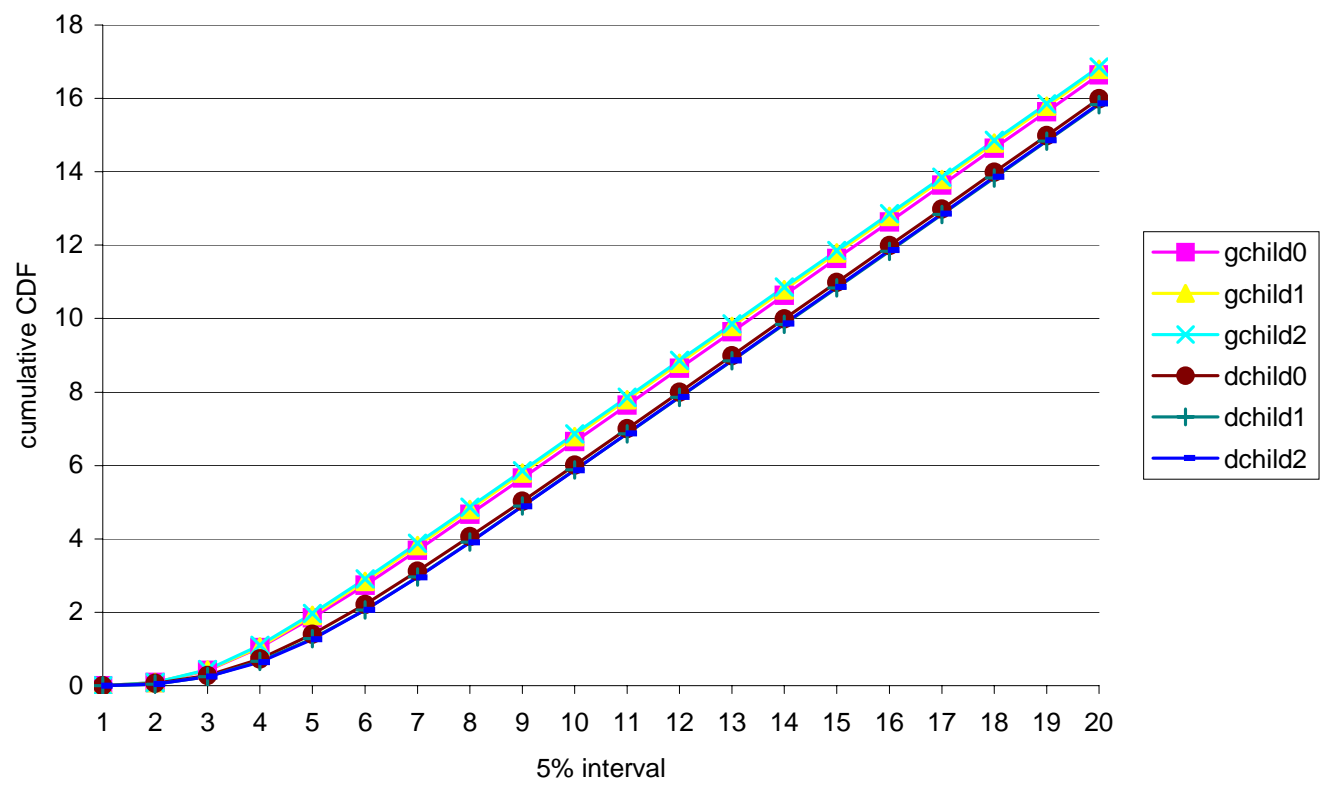


Figure 9.A Un-weighted CDF of gross (g) and disposable (d) incomes by levels of education.

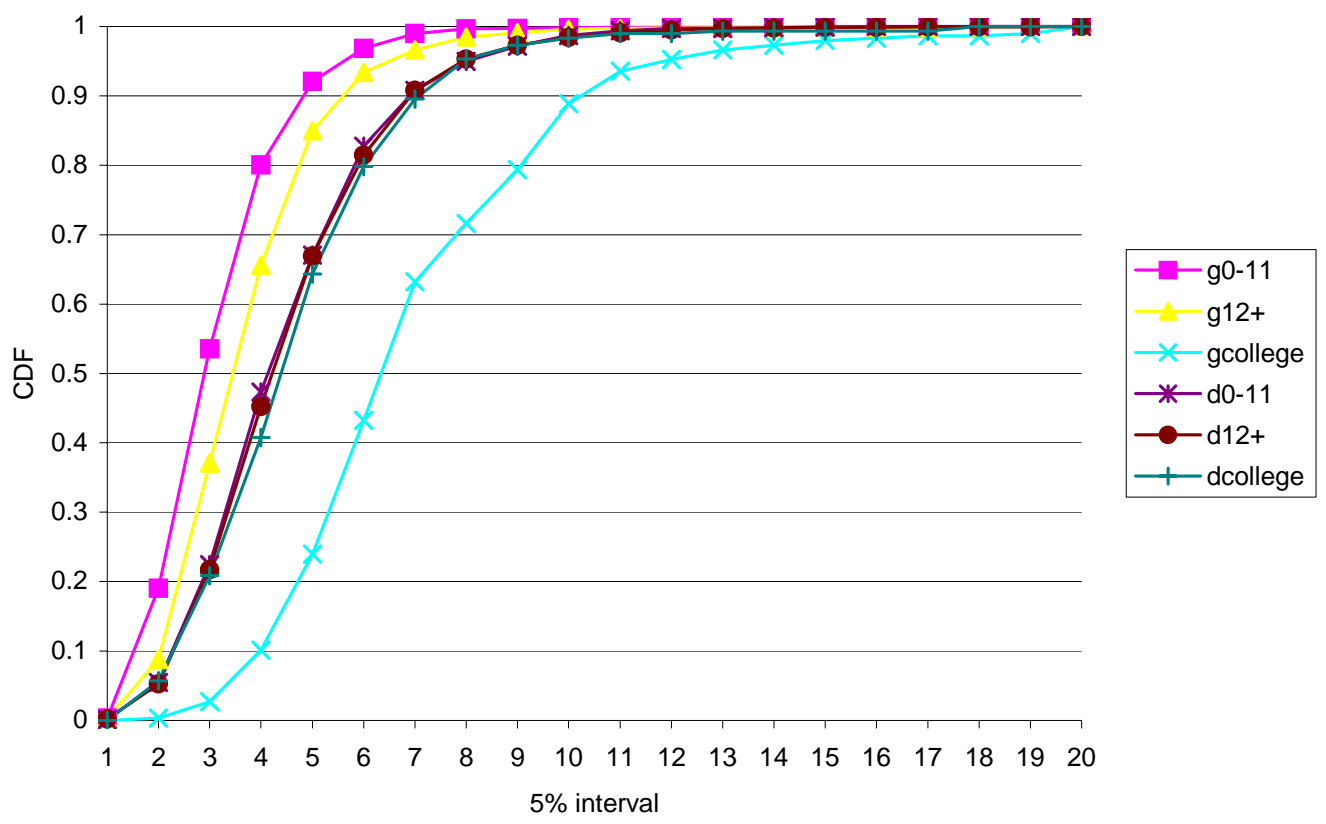

Figure 9.B Weighted CDF of gross (g) and disposable (d) incomes by levels of education.

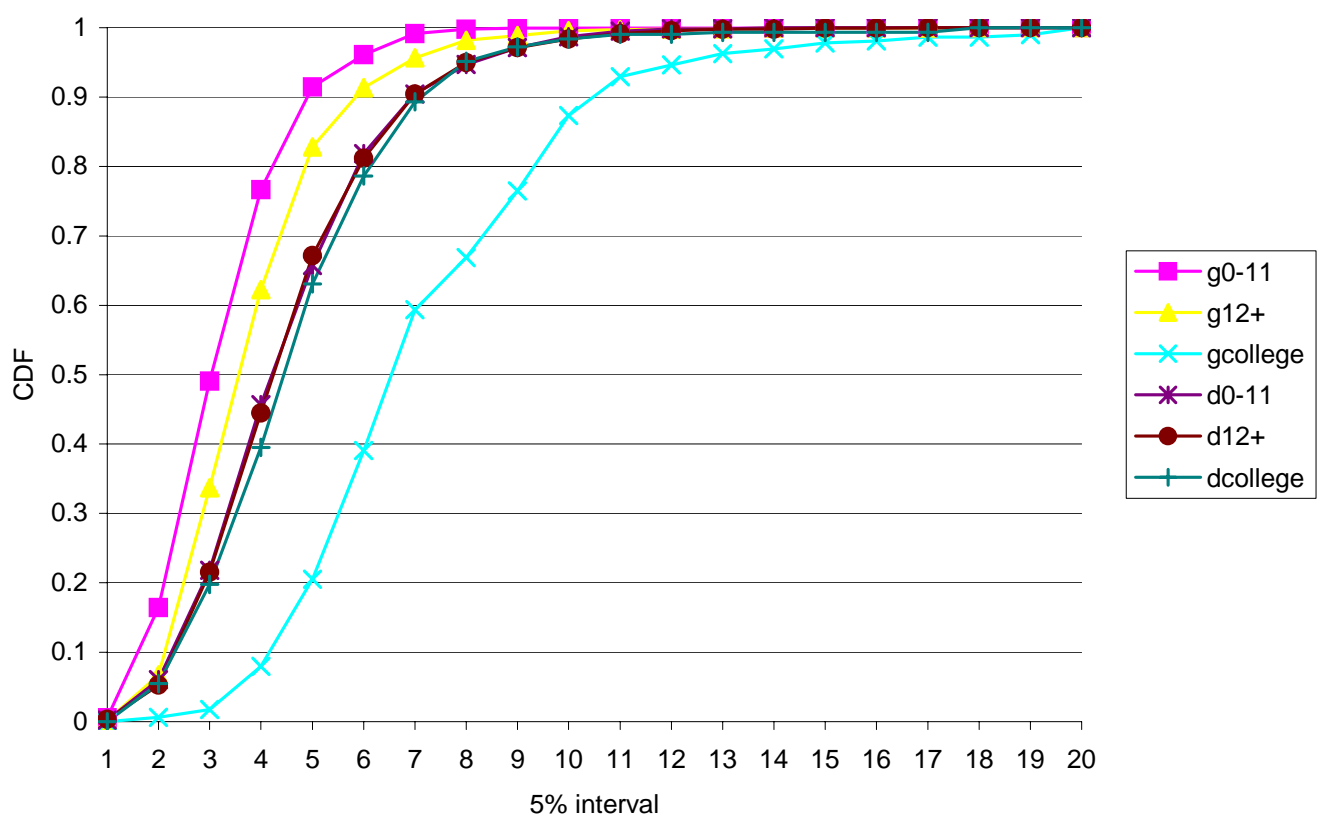


Figure 9.C Un-weighted cumulative CDF of gross ( $g$ ) and disposable (d) incomes by levels of education.

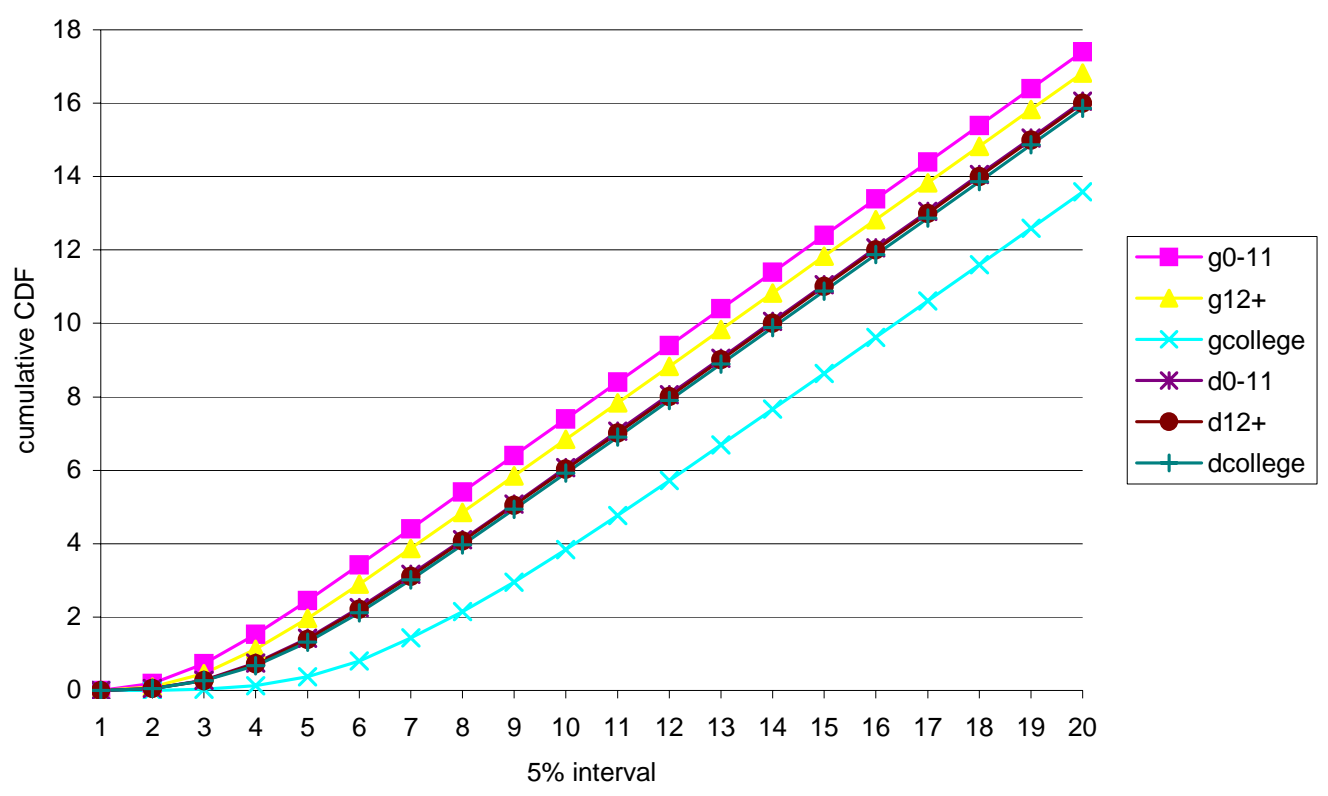

Figure 9.D Weighted cumulative CDF of gross (g) and disposable (d) incomes by levels of education.

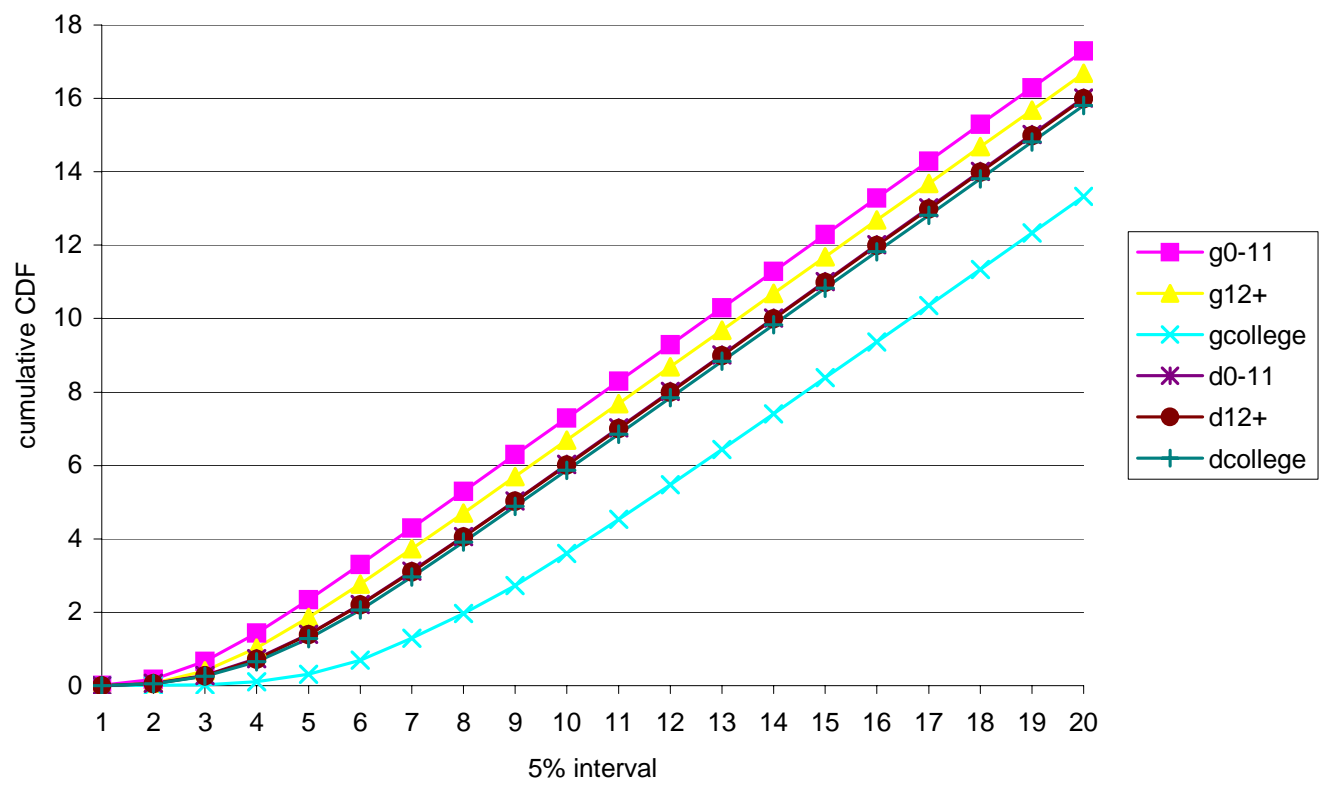


Figure 10.A Un-weighted CDF of gross ( $\mathrm{g}$ ) and disposable (d) incomes by length of unemployment.
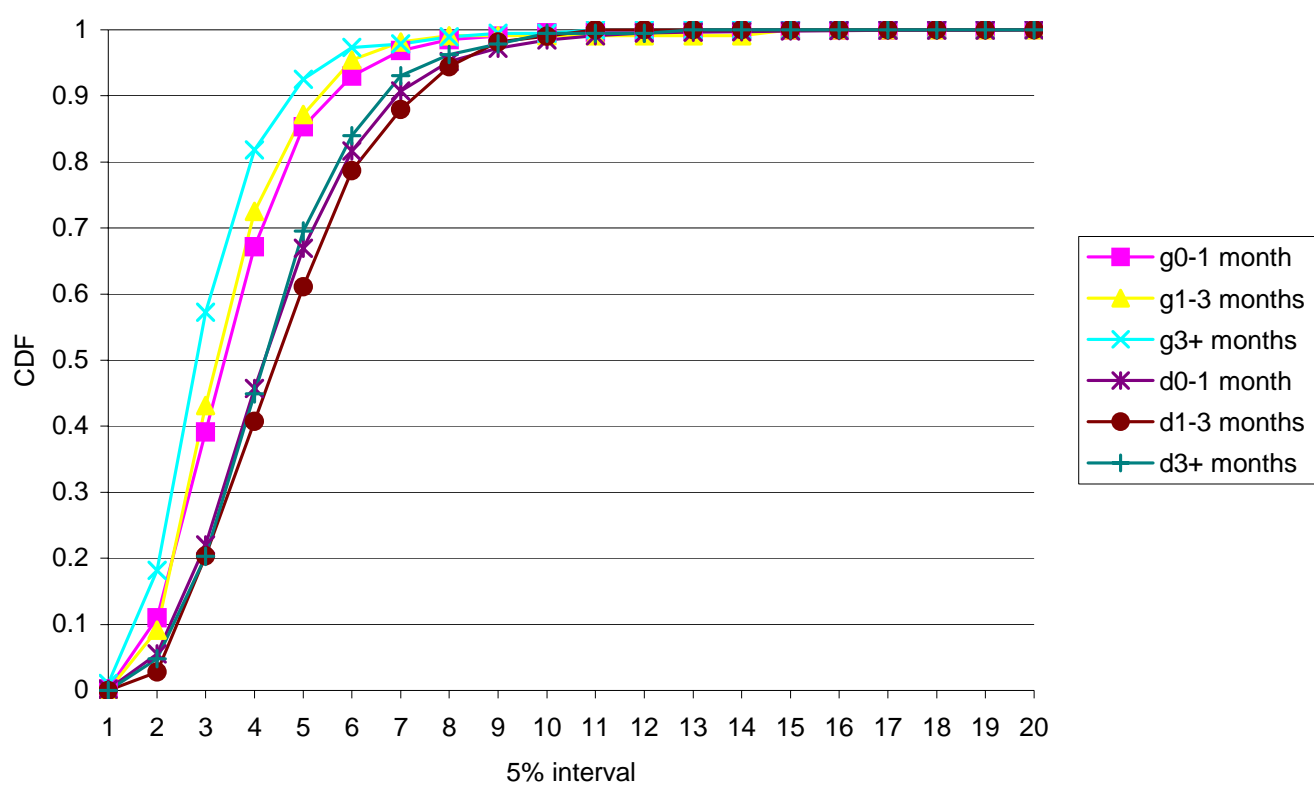

Figure 10.B Weighted CDf of gross (g) and disposable (d) incomes by length of unemployment.
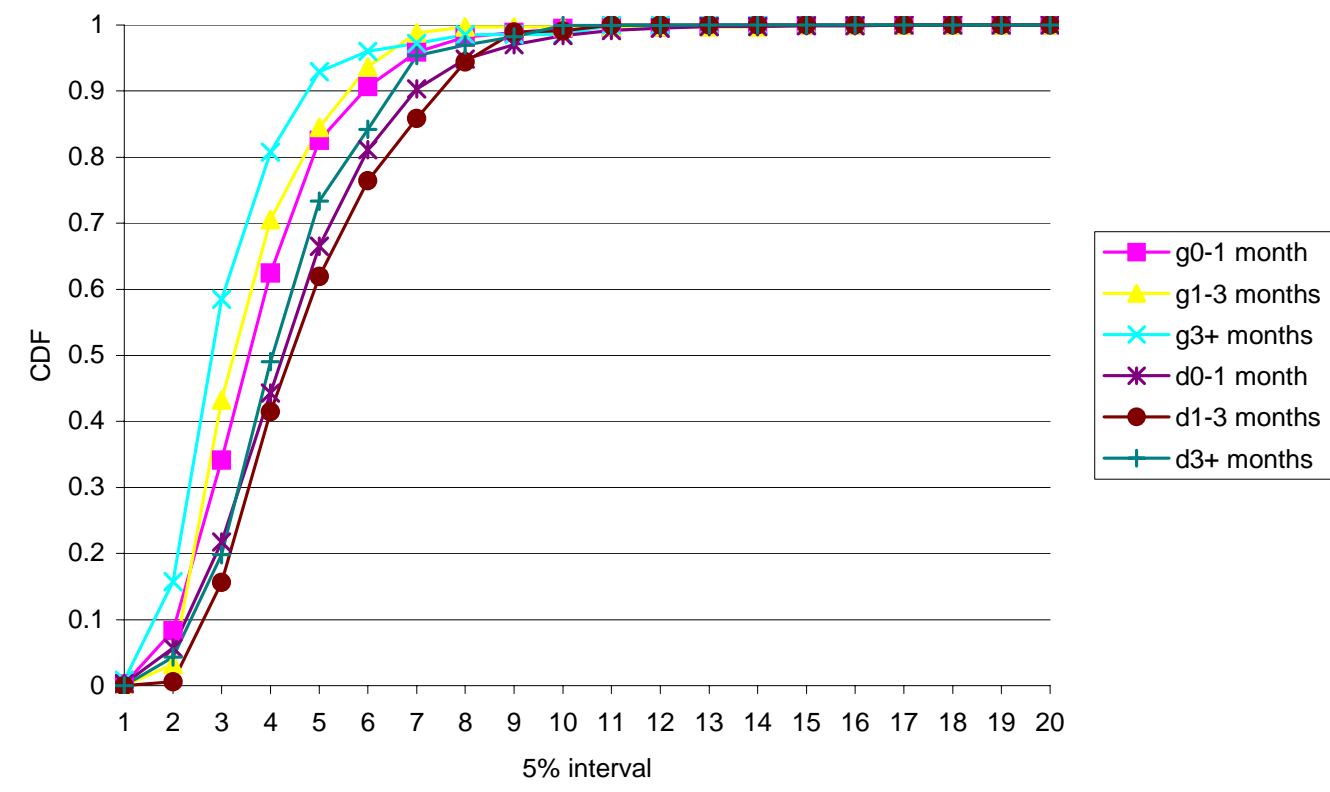
Figure 10.C Un-weighted cumulative CDF of gross (g) and disposable (d) incomes by length of unemployment.

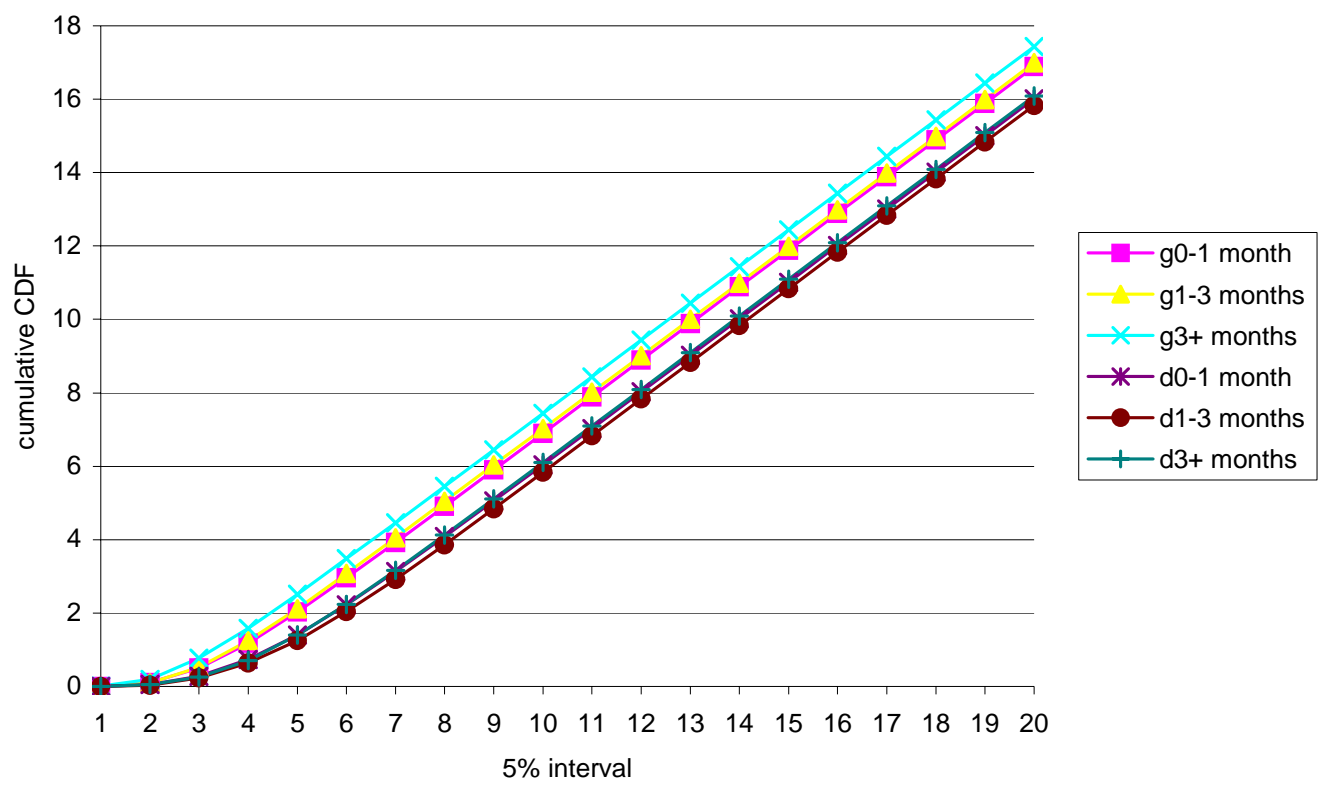

Figure 10.D Weighted cumulative CDF of gross (g) and disposable (d) incomes by length of unemployment.
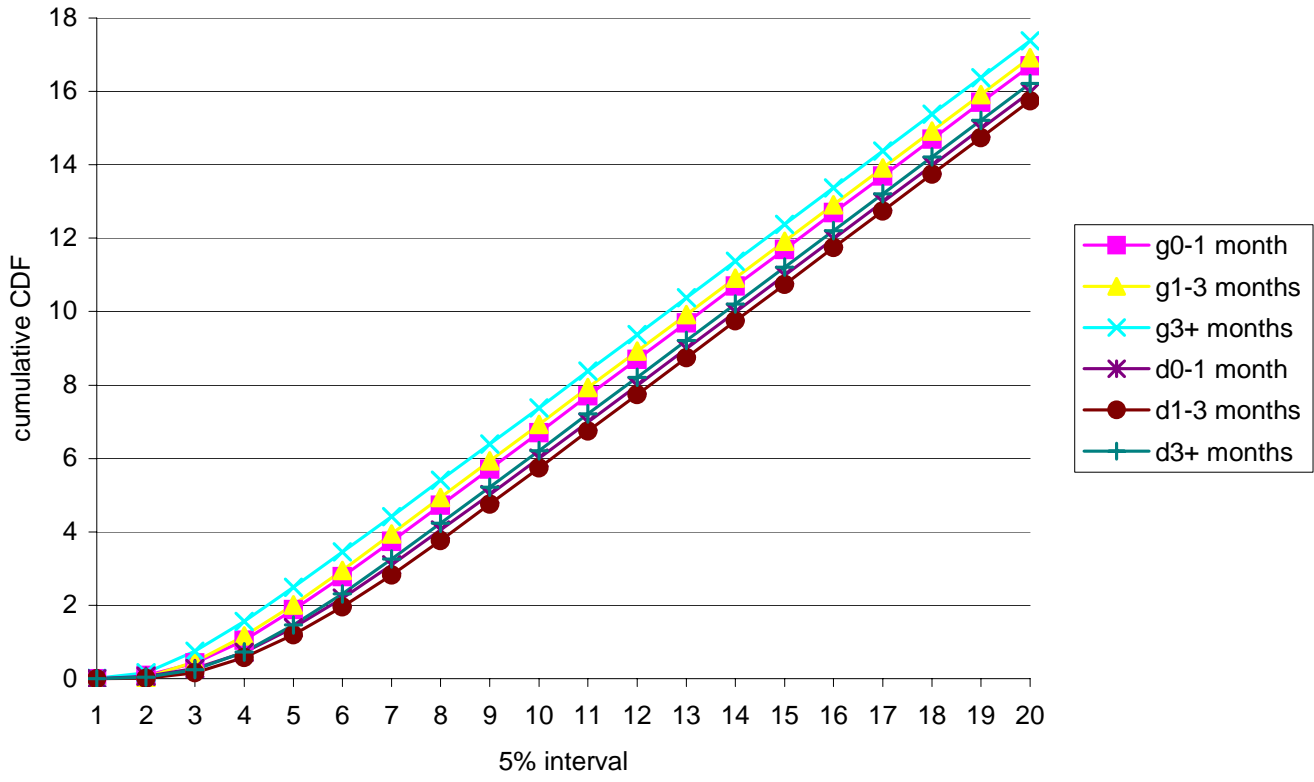
Figure 11.A Un-weighted CDF of gross ( $\mathrm{g}$ ) and disposable (d) oncomes by geographical mobility.

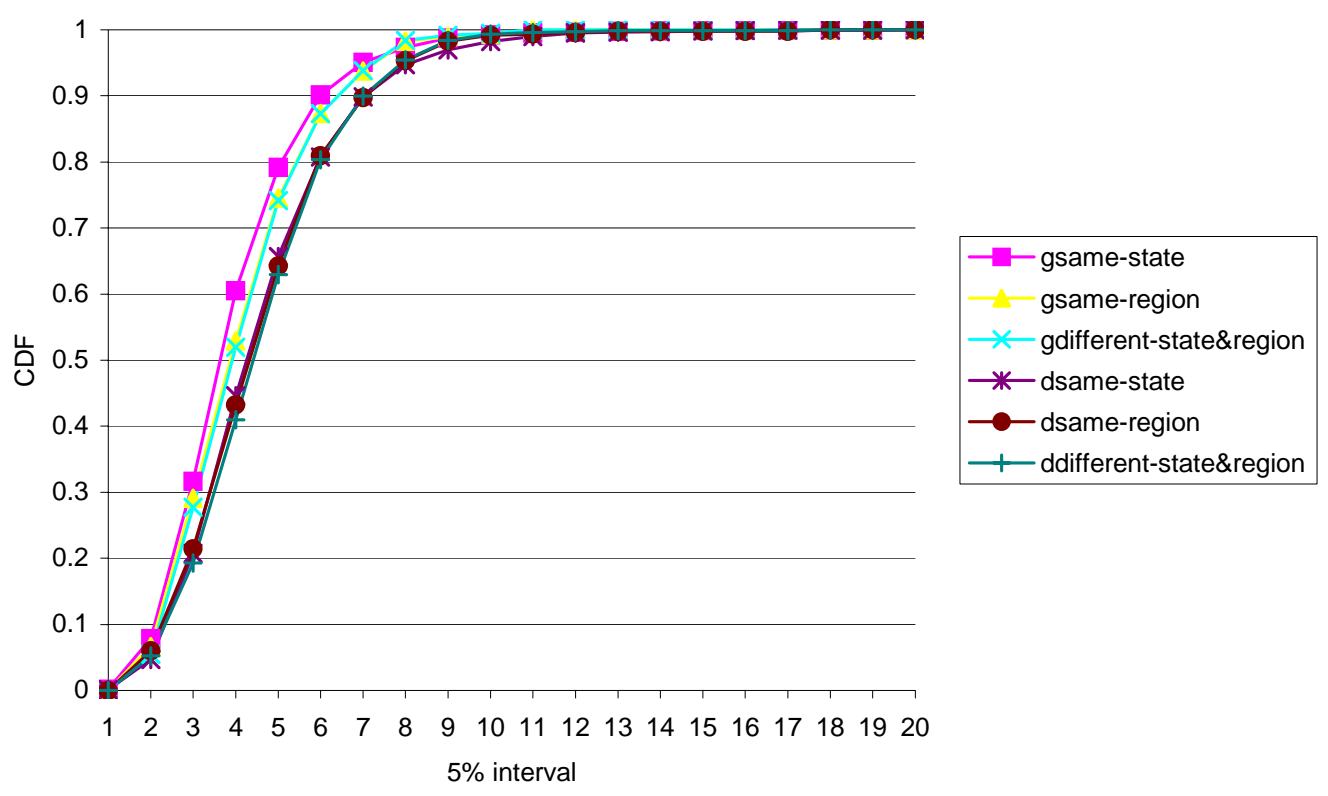

Figure 11.B Weighted CDF of gross (g) and disposable(d) incomes by geographical mobility.

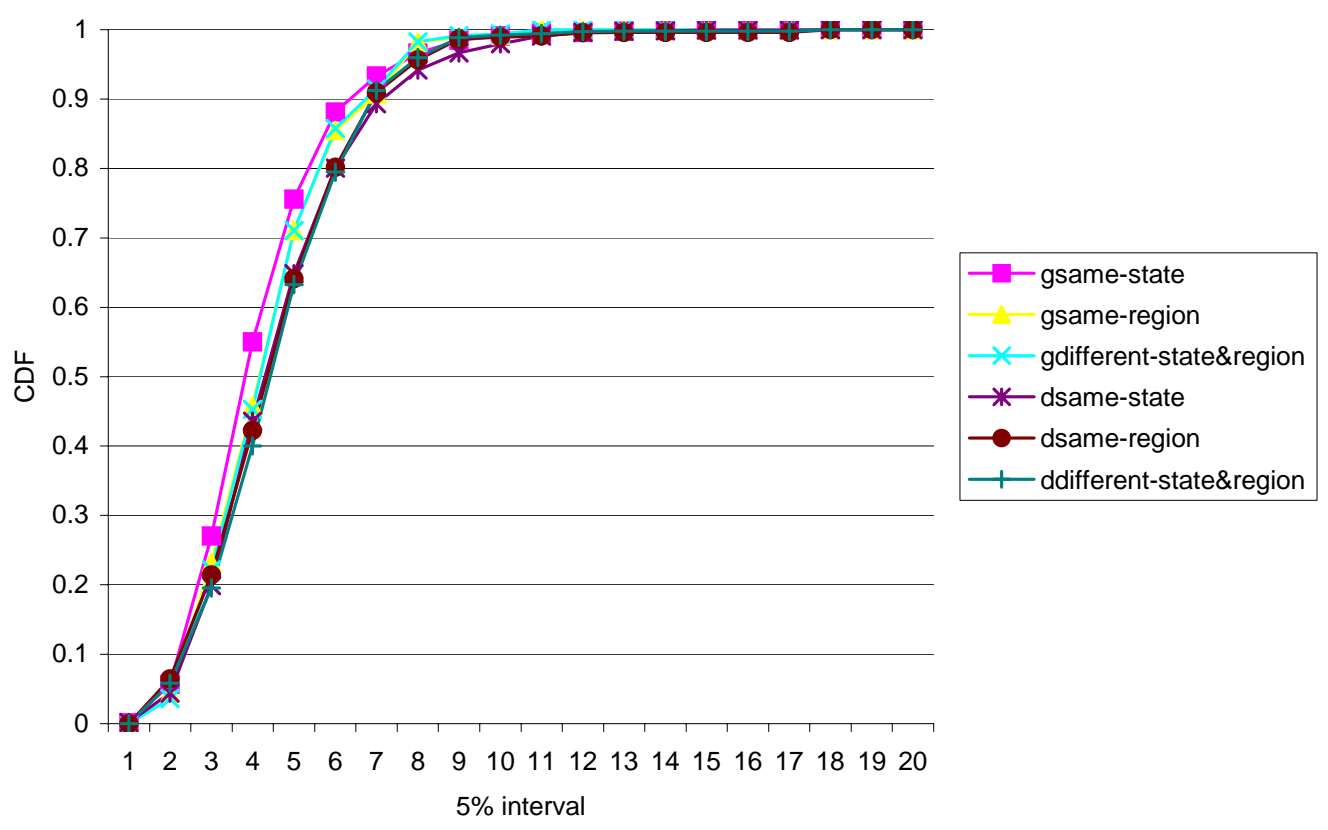


Figure 11.C Un-weighted cumulative CDF of gross ( $\mathrm{g}$ ) and disposable (d) incomes by geographical mobility.

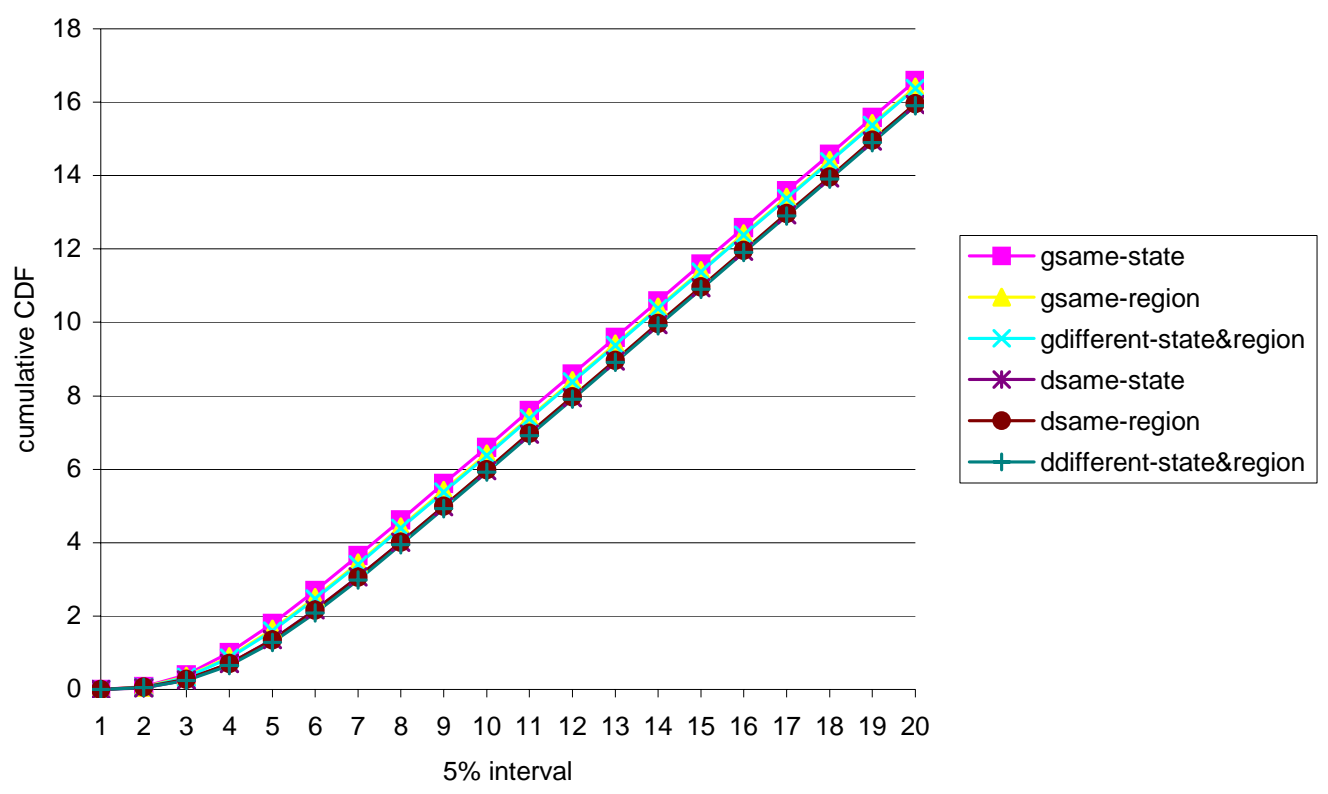

Figure 11.D Weighted cumulative CDF of gross $(g)$ and disposable (d) incomes by geographical mobility.
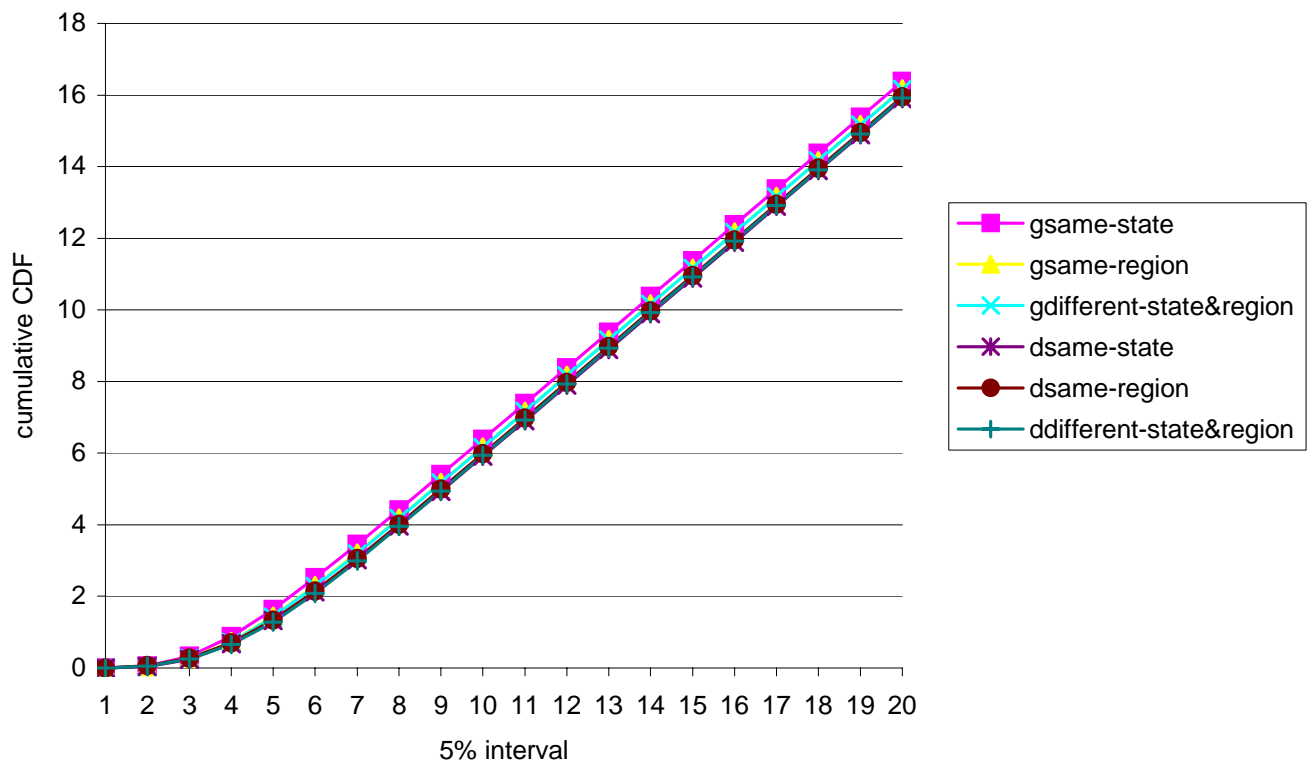
Table 1. Comparisons of gross and disposable incomes by YEAR of observation.

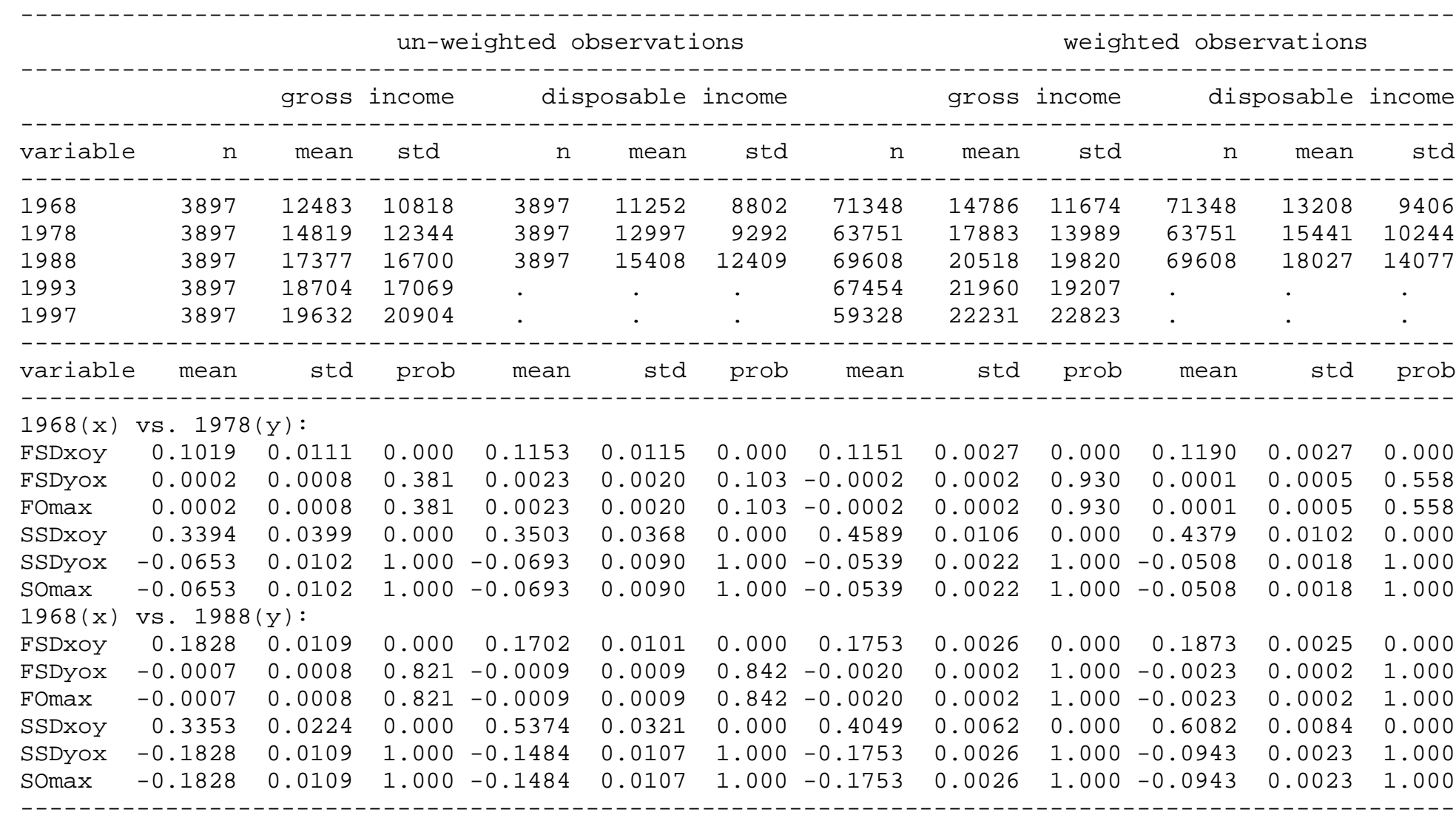

FSDxoy First order Stochastic Dominance of $x$ over $y$

Fomax First order maximal

SSDxoy Second Order Stochastic Dominance of $x$ over $y$

somax second order maximal 
Table 1. Continuous.

\begin{tabular}{|c|c|c|c|c|c|c|c|c|c|c|c|c|}
\hline variable & mean & std & prob & mean & std & prob & mean & std & prob & mean & std & prob \\
\hline \multicolumn{13}{|c|}{ 1968(x) vs. 1993(y): } \\
\hline FSDxoy & 0.1989 & 0.0107 & $\odot .000$ & . & . & . & 0.2001 & 0.0024 & $\odot .000$ & . & . & . \\
\hline FSDyox & -0.0010 & 0.0005 & 0.987 & . & . & . & -0.0019 & 0.0002 & 1.000 & . & . & . \\
\hline Fomax & -0.0010 & 0.0005 & 0.987 & . & . & . & -0.0019 & 0.0002 & 1.000 & . & . & . \\
\hline SSDxoy & 0.6717 & 0.0345 & 0.000 & . & . & . & 0.7536 & 0.0089 & 0.000 & . & . & . \\
\hline SSDyox & -0.1987 & 0.0109 & 1.000 & . & . & . & -0.1415 & $\odot .0 \odot 25$ & 1.000 & . & . & . \\
\hline somax & -0.1987 & 0.0109 & 1.000 & . & . & . & -0.1415 & 0.0025 & 1.000 & . & . & . \\
\hline \multicolumn{13}{|c|}{$1968(x)$ vs. $1997(y):$} \\
\hline FSDxoy & 0.2165 & 0.0110 & $\odot .0 \odot \odot$ & . & . & . & 0.1895 & 0.0027 & 0.000 & . & . & . \\
\hline FSDyox & -0.0005 & 0.0004 & 0.961 & . & . & . & -0.0006 & 0.0001 & 1.000 & . & . & . \\
\hline Fomax & -0.0005 & 0.0004 & 0.961 & . & . & . & -0.0006 & 0.0001 & 1.000 & . & . & . \\
\hline SSDxoy & 0.4945 & 0.0270 & $\odot .0 \odot \odot$ & . & . & . & 0.5295 & 0.0072 & 0.000 & . & . & . \\
\hline SSDyox & -0.2165 & 0.0110 & 1.000 & . & . & . & -0.1895 & 0.0027 & 1.000 & . & . & . \\
\hline somax & -0.2165 & 0.0110 & 1.000 & . & . & . & -0.1895 & 0.0027 & 1.000 & . & . & . \\
\hline \multicolumn{13}{|c|}{ 1978(x) vs. 1988(y): } \\
\hline FSDxoy & 0.0782 & 0.0111 & 0.000 & 0.0862 & 0.0101 & 0.000 & 0.0675 & 0.0020 & 0.000 & $\odot .0855$ & 0.0021 & 0.000 \\
\hline FSDyox & 0.0001 & 0.0012 & 0.491 & -0.0008 & 0.0009 & 0.814 & 0.0005 & 0.0004 & 0.097 & -0.0017 & 0.0003 & 1.00 \\
\hline Fomax & $\odot .0001$ & 0.0012 & 0.491 & -0.0008 & $\odot .0009$ & 0.814 & $\odot .0 \odot \odot 5$ & 0.0004 & 0.097 & -0.0017 & 0.0003 & 1.000 \\
\hline SSDxoy & 0.1835 & 0.0232 & $\odot .000$ & 0.3135 & 0.0325 & 0.000 & ๑. 1926 & 0.0067 & $\odot .0 \odot \odot$ & 0.3283 & 0.0088 & $\odot .0 \odot \odot$ \\
\hline SSDyox & -0.0781 & 0.0113 & 1.000 & -0.0471 & 0.0104 & 1.000 & -0.0541 & 0.0028 & 1.000 & -0.0102 & 0.0022 & 1.000 \\
\hline somax & -0.0781 & 0.0113 & 1.000 & -0.0471 & 0.0104 & $1.00 \odot$ & -0.0541 & 0.0028 & 1.000 & -0.0102 & $\odot .0 \odot 22$ & 1.000 \\
\hline $1978(x)$ & VS. 1993 & (y): & & & & & & & & & & \\
\hline FSDxoy & 0.1070 & 0.0096 & $\odot .0 \odot \odot$ & . & . & . & ๑. 0971 & ๑. .0०22 & 0.000 & ". & . & . \\
\hline FSDyox & -0.0009 & 0.0006 & 0.934 & . & . & . & -0.0019 & 0.0002 & 1.000 & . & . & . \\
\hline Fomax & -0.0009 & 0.0006 & 0.934 & . & . & . & -0.0019 & 0.0002 & 1.000 & . & . & . \\
\hline SSDxoy & 0.4276 & 0.0354 & 0.000 & . & . & . & 0.4328 & 0.0100 & 0.000 & . & . & . \\
\hline SSDyox & -0.0965 & 0.0108 & 1.000 & . & . & . & -0.0537 & $\odot .0024$ & 1.000 & . & . & . \\
\hline somax & -0.0965 & 0.0108 & 1.000 & . & . & . & -0.0537 & $\odot .0 \odot 24$ & $1.0 \odot \odot$ & . & . & . \\
\hline
\end{tabular}


Table 1. Continuous.

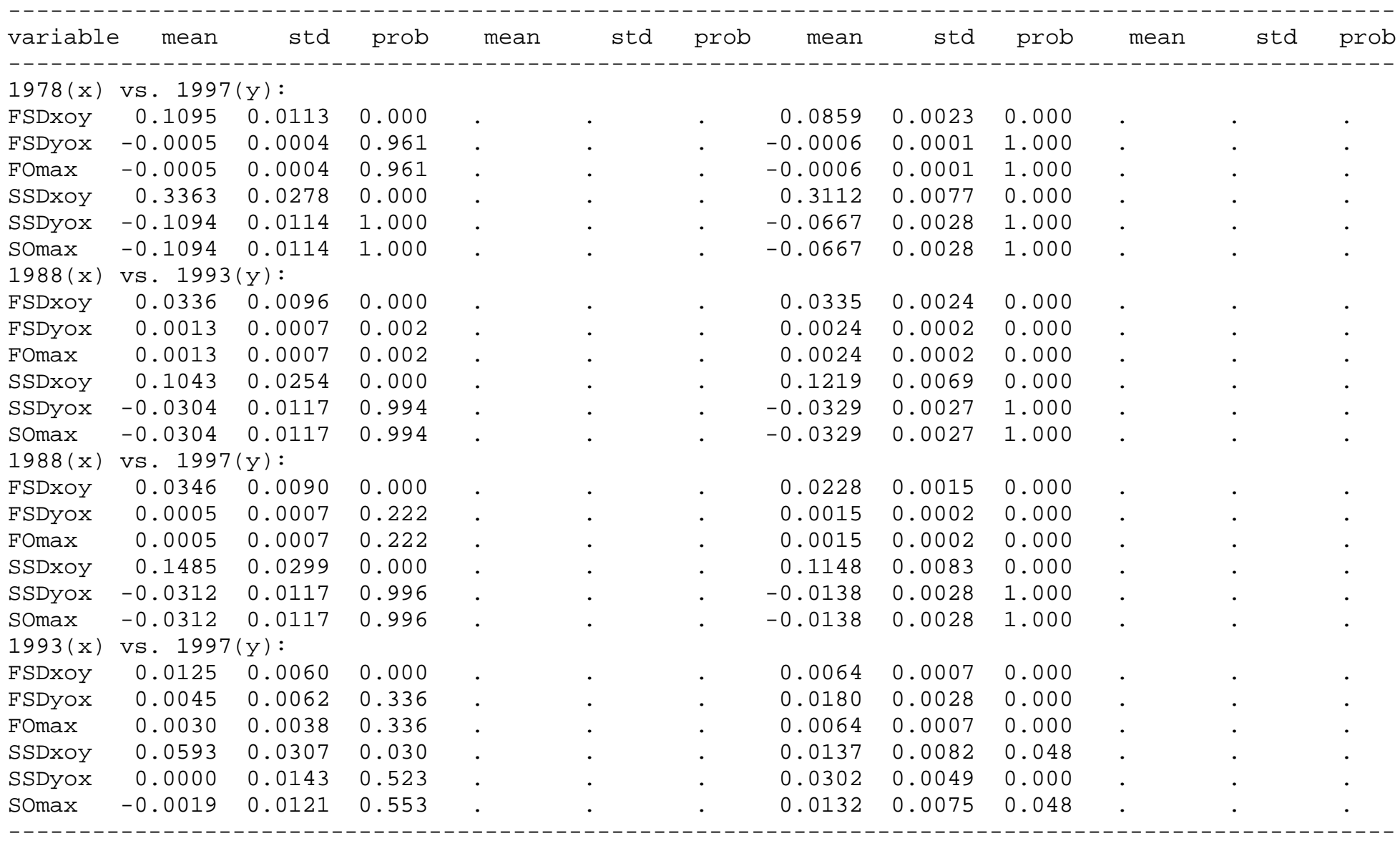


Table 2. Comparisons of mean period (gross 1968-1993 and disposable 1968-88) incomes by AGE of households head in 1993.

\begin{tabular}{|c|c|c|c|c|c|c|c|c|c|c|c|c|}
\hline & & & $u n-w$ & ghted & servat & & & & wei & ed ob & vactu & \\
\hline & & 0 & ncome & & 年 & mo & & g. & & & & \\
\hline ariab & $\mathrm{n}$ & mean & std & $\mathrm{n}$ & mean & std & $\mathrm{n}$ & mean & std & $\mathrm{n}$ & mean & \\
\hline & --- & & & 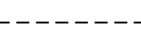 & 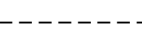 & -- & 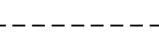 & & 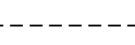 & & & \\
\hline $8-35$ & 1100 & 1547 & 666 & 1199 & 203 & 5937 & & & 6972 & 17463 & & 505 \\
\hline 6 & 0 & & 6759 & 1393 & & & & & 7064 & 22282 & & \\
\hline $1-6$ & 47 & 16850 & 847 & 647 & 271 & 60 & & & 8657 & 13889 & 13191 & 5 \\
\hline $5-$ & 658 & 14380 & 6758 & 658 & 13248 & 6238 & 13820 & 14738 & 6261 & 13820 & 13132 & 592 \\
\hline al & mean & stu & & medn & sta & & & & & & & \\
\hline $8-35(x$ & vs. 36 & $\ldots$ & & & & & & & & & & \\
\hline =SDxoy & $\odot .0740$ & .0163 & 0 & 282 & & & & & $\odot .00 \odot$ & 254 & .0046 & $.0 \odot$ \\
\hline SD & $\cap \cap \cap \triangle 6$ & & $\odot$. & 214 & & & & & 0.001 & 327 & .0032 & \\
\hline Or & & & $\odot$. & 156 & & & & & ข1 & 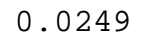 & 40 & \\
\hline $\mathrm{SI}$ & & & $\odot$. & $\$ 47$ & & & & & $\odot \odot$ & 95 & 26 & 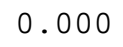 \\
\hline$S[$ & $-\odot$ & 0.0 & $\odot$. & 299 & 49 & & $-c$ & & 1. & 75 & 89 & 33 \\
\hline somax & -0.0042 & ๑. .0019 & 0.996 & 0.0088 & 0.0144 & 0.453 & -0 & ๑.0००5 & 1.000 & 0.0303 & 0.0122 & $\odot .03$ \\
\hline $18-35$ & vs. 51 & $65(y):$ & & & & & & & & & & \\
\hline $\mathrm{SD}$ & 0.076 & $\triangle \Omega$ & & .0238 & & & & & & & & \\
\hline & & & & & & & & & & & 34 & \\
\hline$=0 m$ & & & 0. & ๑. .0152 & & & & & & & 25 & $\rho$ \\
\hline SDxoy & ๑. 2865 & ๑. 0822 & 0.000 & 0.0464 & 0.0449 & 0.021 & 47 & $\odot . \odot$ & $\odot .00 \odot$ & ๑. 0172 & 0.0027 & .00 \\
\hline SDyox & $-\odot .0 \odot 21$ & $\odot .0 \odot 81$ & $\odot .786$ & $\odot .0522$ & $\odot .0603$ & $\odot .229$ & $-\odot .0 \odot 59$ & $\odot .0 \odot \odot 6$ & $1 . \odot \odot \odot$ & $\odot .1467$ & $\odot .0222$ & $\odot . \odot \odot$ \\
\hline Omax & $-\odot .0022$ & 0.0080 & 0.786 & 0.0110 & 0.0122 & 0.250 & $-\odot .0059$ & 0.0006 & 1.000 & 0.0172 & 0.0027 & 0.00 \\
\hline
\end{tabular}


Table 2. Continuous.

\begin{tabular}{|c|c|c|c|c|c|c|c|c|c|c|c|c|}
\hline variable & mean & std & prob & mean & std & prob & mean & std & prob & mean & std & pr \\
\hline \multicolumn{13}{|c|}{$18-35(x)$ vs. $66-(y):$} \\
\hline FSDxoy & 0.0064 & $0.0 \odot 45$ & $\odot .0 \odot \odot$ & 0.0209 & 0.0121 & 0.001 & $\odot .0041$ & 0.0005 & $\odot . \odot \odot \odot$ & $\odot .0098$ & $0.0 \odot 25$ & 0.0 \\
\hline FSDyox & ๑. .0923 & 0.0215 & 0.000 & 0.0339 & 0.0179 & 0.002 & 0.1279 & 0.0056 & 0.000 & 0.0481 & 0.0047 & \\
\hline FOmax & ๑. . 0064 & 0.0045 & $\odot .0 \odot \odot$ & ๑. .0158 & ๑. .0085 & 0.003 & 0.0041 & ๑. 0005 & 0.000 & ๑. . 0098 & 0.0025 & 0.0 \\
\hline SDxoy & 0.0047 & 0.0033 & 0.000 & 0.0390 & 0.0561 & 0.263 & 0.0040 & 0.0005 & 0.000 & -0.0024 & 0.0020 & 0.8 \\
\hline SSDyox & ๑. 2820 & 0.0786 & $\odot .0 \odot \odot$ & 0.0704 & 0.0610 & 0.041 & 0.4155 & ๑. 0191 & $\odot .0 \odot \odot$ & 0.1395 & 0.0194 & \\
\hline somax & 0.0047 & 0.0033 & 0.000 & 0.0100 & 0.0154 & 0.304 & 0.0040 & 0.0005 & 0.000 & -0.0024 & . 0020 & \\
\hline $36-50(x)$ & \multicolumn{12}{|c|}{ vs. $51-65(y)$ : } \\
\hline FSDxoy & 0.0417 & 0.0177 & $\odot .0 \odot \odot$ & 0.0202 & 0.0137 & ๑. . 015 & 0.0430 & 0.0044 & $0.0 \odot \odot$ & ๑. .0083 & 0.0038 & 0. \\
\hline FSDyox & 0.0293 & 0.0140 & 0.002 & 0.0311 & 0.0177 & $\odot .000$ & 0.0174 & ๑. 0026 & $\odot .0 \odot \odot$ & 0.0476 & 0.0051 & \\
\hline Fomax & 0.0243 & 0.0115 & 0.002 & 0.0137 & ๑. .0०84 & 0.015 & 0.0174 & $\odot .0026$ & 0.000 & ๑. .0०83 & 0.0038 & ○. \\
\hline SDxoy & ๑. . 0917 & 0.0714 & $\odot .0 \odot \odot$ & ๑. .0266 & 0.0435 & 0.272 & ๑. 0981 & 0.0183 & 0.000 & 0.0071 & 0.0053 & 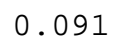 \\
\hline SSDyox & 0.0444 & 0.0307 & $\odot .027$ & 0.0736 & 0.0627 & $\odot .000$ & 0.0173 & 0.0026 & $\odot .0 \odot \odot$ & 0.1037 & 0.0201 & \\
\hline somax & 0.0259 & 0.0201 & 0.027 & 0.0063 & 0.0108 & 0.272 & 0.0173 & 0.0026 & 0.000 & 0.0071 & 0.0053 & \\
\hline $36-50(x)$ & \multicolumn{12}{|c|}{ vs. $66-(y)$ : } \\
\hline FSDxoy & $\odot .0032$ & 0.0034 & 0.000 & 0.0309 & 0.0126 & 0.000 & $\odot .0003$ & $\odot .0 \odot \odot 4$ & $\odot .0 \odot \odot$ & $\odot .0178$ & $\odot .0031$ & 0.0 \\
\hline FSDyox & 0.1568 & 0.0219 & 0.000 & 0.0420 & 0.0189 & 0.000 & 0.1928 & 0.0055 & 0.000 & 0.0520 & 0.0054 & \\
\hline Fomax & 0.0032 & 0.0034 & $\odot .00 \odot$ & 0.0251 & 0.0101 & 0.000 & 0.0003 & 0.0004 & $0.00 \odot$ & 0.0178 & 0.0031 & \\
\hline SSDxoy & $\odot .000 \odot$ & $\odot .0000$ & 0.000 & 0.0471 & 0.0662 & 0.359 & 0.0000 & 0.0000 & 0.000 & -0.0041 & 0.0008 & \\
\hline SSDyox & 0.5306 & 0.0782 & 0.000 & 0.0992 & 0.0583 & 0.000 & 0.6629 & 0.0192 & 0.000 & 0.1235 & 0.0159 & $\odot$. \\
\hline Somax & $\odot .0 \odot \odot \odot$ & $\odot .0 \odot \odot \odot$ & $\odot .0 \odot \odot$ & 0.0196 & 0.0266 & 0.359 & $\odot .0 \odot \odot \odot$ & $0.000 \odot$ & $\odot .0 \odot \odot$ & $-\odot .0 \odot 41$ & $\odot . \odot \odot \odot 8$ & $\odot$. \\
\hline $51-65(x)$ & \multicolumn{12}{|c|}{ vs. $66-(y)$ : } \\
\hline FSDxoy & 0.0015 & 0.0021 & 0.094 & 0.0256 & 0.0140 & 0.000 & 0.0000 & 0.0000 & 0.293 & 0.0204 & 0.0031 & $\odot$. \\
\hline FSDyox & 0.1633 & 0.0256 & $\odot .00 \odot$ & 0.0325 & 0.0184 & 0.002 & 0.1836 & 0.0051 & $0.00 \odot$ & 0.0402 & 0.0048 & \\
\hline Fomax & 0.0015 & 0.0021 & 0.094 & 0.0175 & 0.0094 & 0.002 & 0.0000 & 0.0000 & ๑. 293 & 0.0204 & 0.0031 & \\
\hline SSDxoy & -0.0015 & 0.0015 & 0.641 & 0.0547 & 0.0697 & 0.269 & -0.0029 & 0.0004 & 1.000 & 0.0398 & 0.0222 & 0.0 \\
\hline SSDyox & 0.5496 & ๑. .0925 & $\odot .0 \odot \odot$ & 0.0769 & 0.0641 & 0.023 & $\odot .6937$ & 0.0190 & $\odot . \odot \odot \odot$ & 0.0574 & $\odot .0 \odot 81$ & $\odot .0 €$ \\
\hline Omax & -0.0015 & 0.0015 & 0.641 & ๑. 0151 & 0.0207 & 0.292 & -0.0029 & 0.0004 & 1.000 & 0.0353 & 0.0165 & 0.0 \\
\hline
\end{tabular}


Table 3. Comparisons of mean period incomes by MARITAL STATUS of households head in 1993.

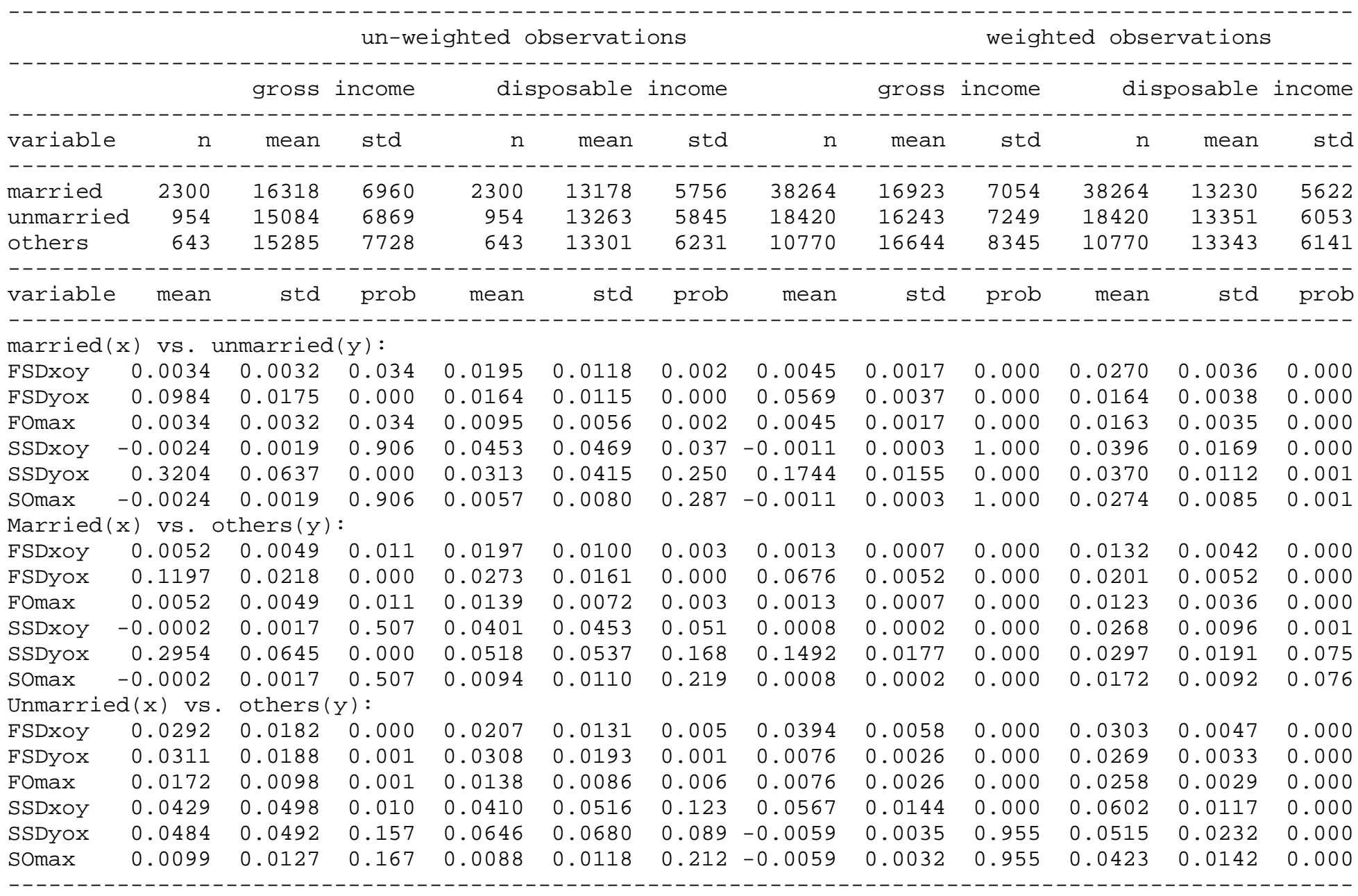


Table 4. Comparisons of mean period incomes by WORKING STATUS of households head in 1993.

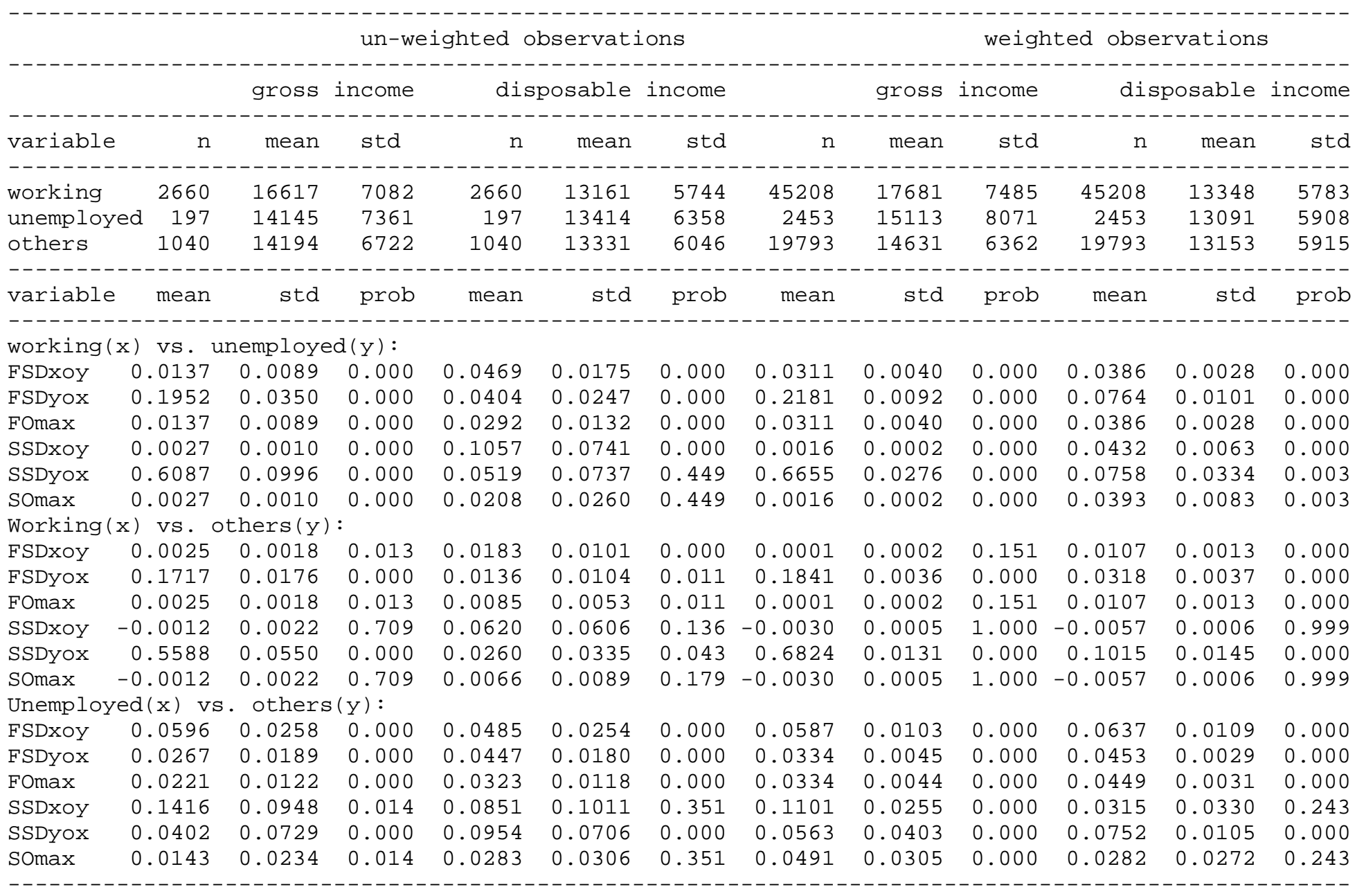


Table 5. Comparisons of mean period incomes by RACE of households head in 1993.

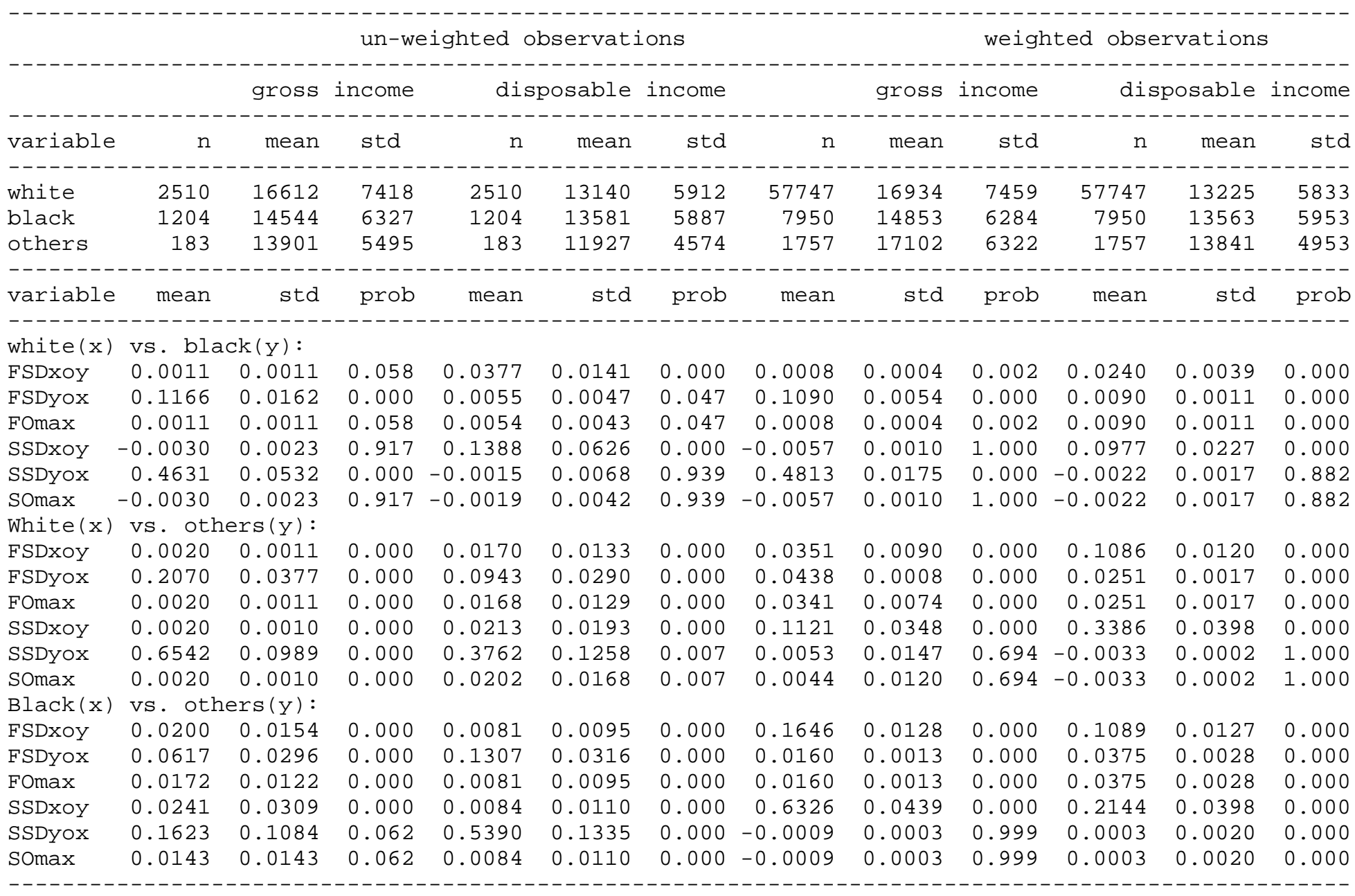


Table 6. Comparisons of mean period incomes by SEX of households head in 1993.

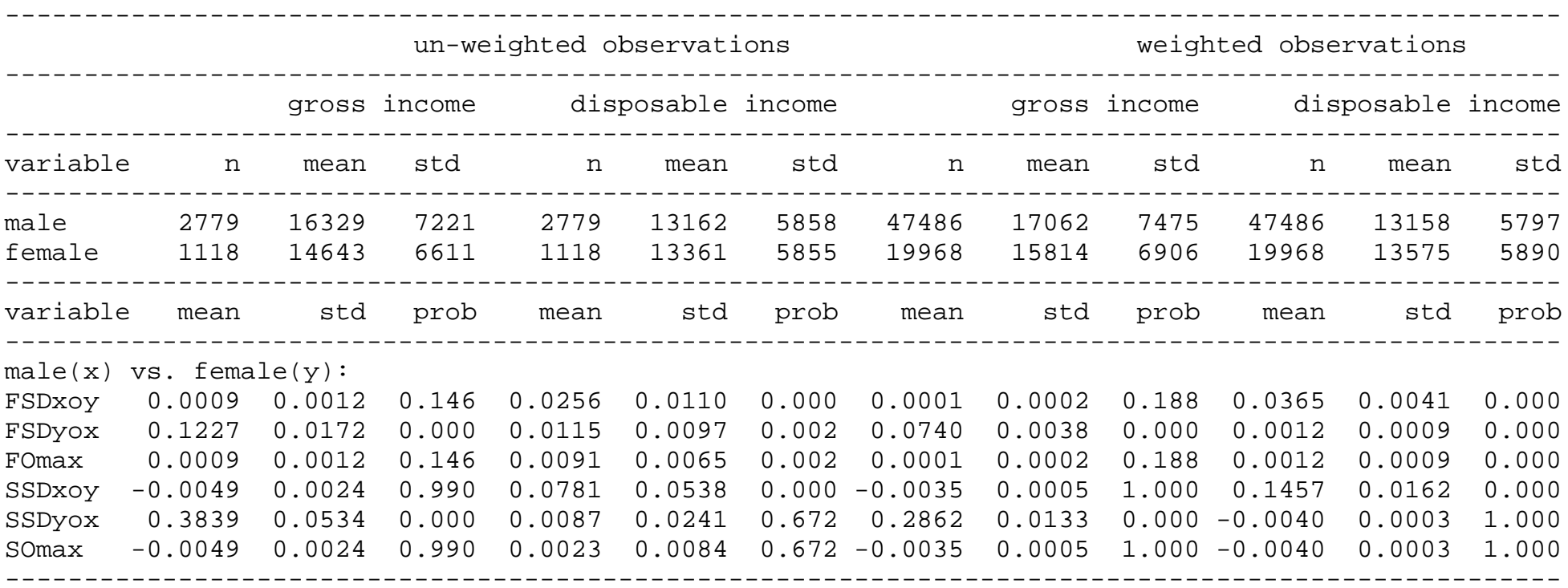


Table 7. Comparisons of mean period incomes by OCCUPATION of households head in 1993.

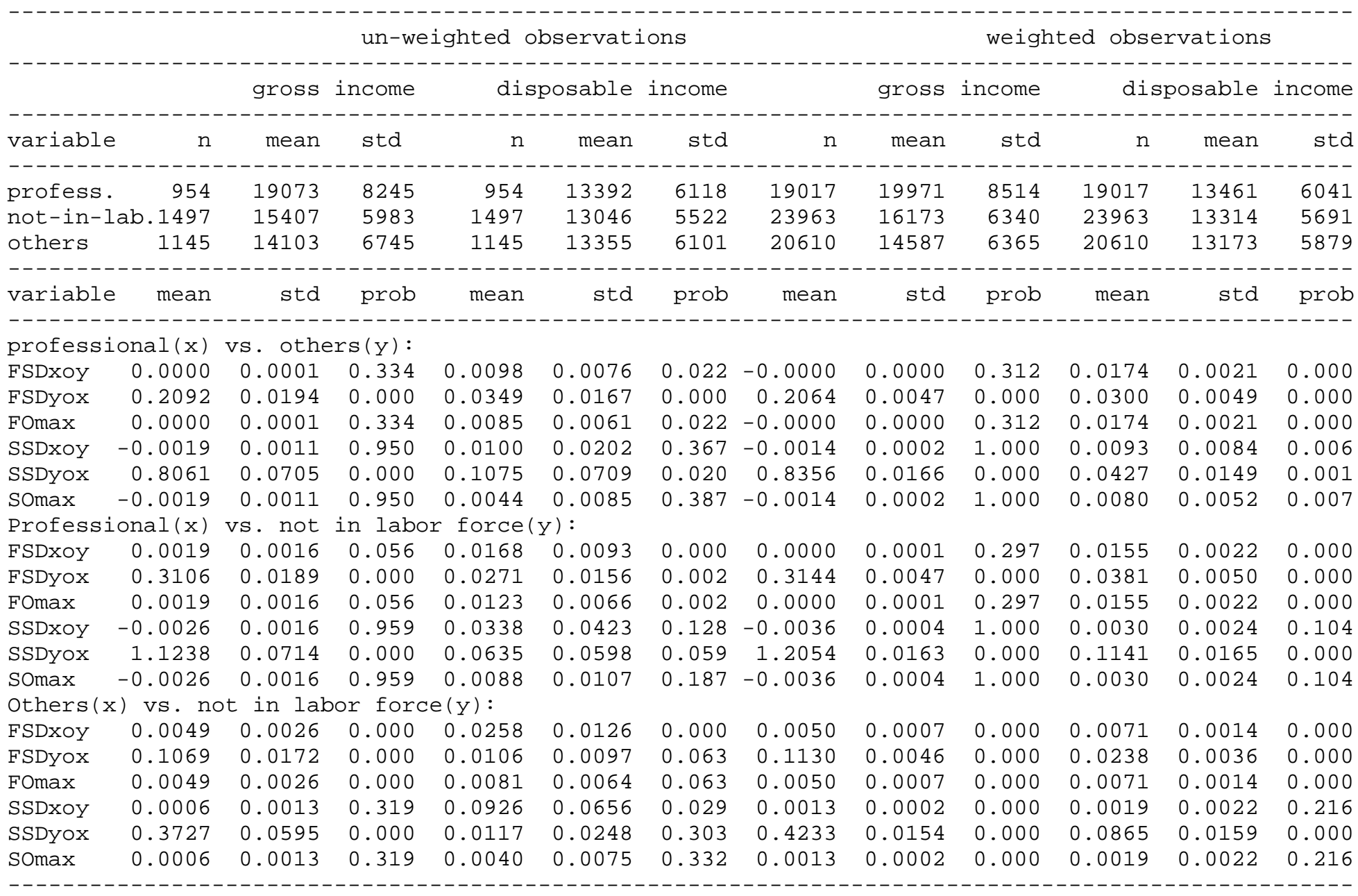


Table 8. Comparisons of mean period incomes by number of CHILDREN in 1993.

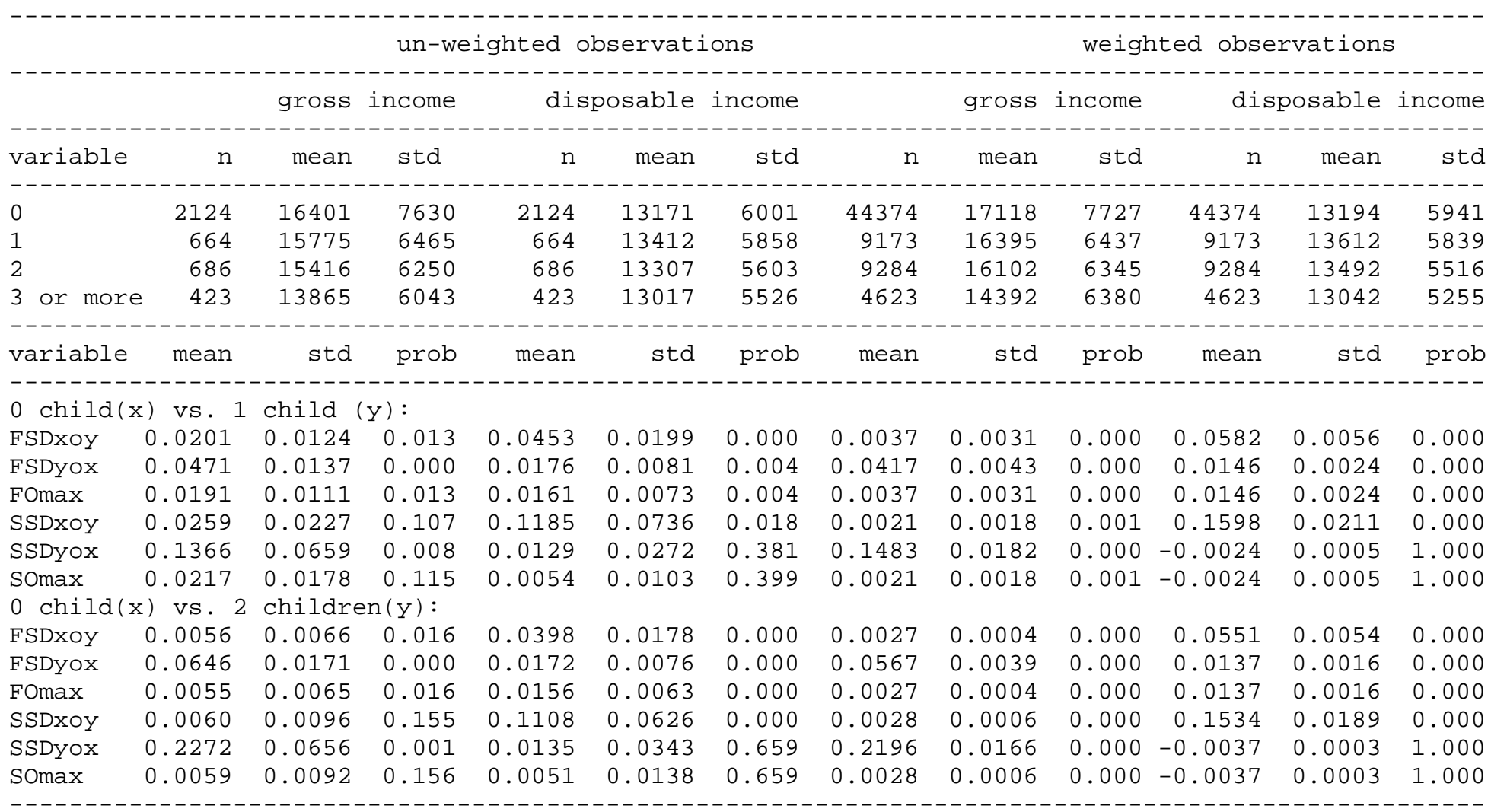


Table 8. Continuous.

\begin{tabular}{|c|c|c|c|c|c|c|c|c|c|c|c|c|}
\hline ariable & mean & std & prob & mean & std & prob & mean & std & prob & mean & std & nro \\
\hline \multicolumn{13}{|c|}{$\odot \operatorname{child}(x)$ vs. 3 and more children (y): } \\
\hline FSDxoy & 0.0019 & $\odot .0 \odot 20$ & $\odot .071$ & 0.0226 & 0.0156 & $\odot .000$ & 0.0030 & 0.0003 & $\odot .000$ & 0.0205 & 0.0039 & ن \\
\hline FSDyox & 0.1552 & 0.0232 & $\odot .0 \odot \odot$ & 0.0223 & 0.0146 & $\odot .001$ & 0.1613 & 0.0066 & $\odot .0 \odot \odot$ & 0.0204 & 0.0022 & \\
\hline Fomax & 0.0019 & 0.0020 & 0.071 & 0.0119 & 0.0072 & 0.001 & 0.0030 & 0.0003 & 0.000 & 0.0186 & .0022 & \\
\hline SDxoy & 0.0006 & 0.0026 & 0.404 & 0.0522 & 0.0562 & 0.000 & 0.0030 & 0.0003 & 0.000 & 0.0464 & 0.0178 & 0. \\
\hline SDyox & 0.5674 & 0.0743 & $\odot .00 \odot$ & 0.0501 & 0.0637 & 0.280 & 0.5814 & ๑. . 0228 & $\odot .0 \odot \odot$ & 0.0205 & 0.0221 & 0.2 \\
\hline somax & 0.0006 & 0.0026 & 0.404 & 0.0076 & 0.0113 & 0.280 & 0.0030 & 0.0003 & 0.000 & 0.0142 & 0.0134 & 0.26 \\
\hline \multicolumn{13}{|c|}{1 child(x) vs. 2 children(y): } \\
\hline FSDxoy & 0.0139 & 0.0103 & $\odot .0 \odot 4$ & $\odot .0297$ & 0.0172 & $\odot . \odot \odot \odot$ & $0.0 \odot 42$ & $\odot .0023$ & $\odot . \odot \odot \odot$ & 0.0135 & $0.0 \odot 46$ & . \\
\hline SDyox & 0.0391 & 0.0190 & 0.000 & 0.0310 & 0.0188 & $\odot . \odot \odot \odot$ & 0.0249 & 0.0057 & $\odot . \odot \odot \odot$ & 0.0140 & $\odot .0036$ & \\
\hline Omax & 0.0118 & 0.0073 & 0.004 & 0.0177 & $\odot .0099$ & 0.000 & $\odot 42$ & 0.0023 & 0.000 & 0.0110 & 0.0025 & \\
\hline SDxoy & 0.0132 & $\odot .0289$ & 0.136 & $\odot .0598$ & $\odot .0556$ & $\odot .0 \odot \odot$ & 011 & $\odot .0 \odot \odot 7$ & 007 & $\odot .0261$ & 0.0202 & $\odot$. \\
\hline SSDyox & 0.1072 & 0.0717 & 0.019 & 0.0610 & 0.0731 & 0.222 & 0.0819 & 0.0258 & 0.000 & 0.0301 & 0.0249 & $\odot$ \\
\hline somax & 0.0054 & 0.0101 & 0.155 & 0.0121 & 0.0168 & 0.222 & 0.0011 & 0.0007 & 0.007 & 0.0101 & 0.0083 & \\
\hline \multicolumn{13}{|c|}{$1 \operatorname{child}(x)$ vs. 3 and more children $(y)$ : } \\
\hline FSDxoy & 0.0065 & 0.0044 & $\odot .00 \odot$ & 0.0209 & 0.0139 & 0.000 & $\odot 46$ & 0.0010 & 0.000 & 0.0066 & 0.0027 & 0.0 \\
\hline FSDyox & 0.1562 & 0.0274 & 0.000 & 0.0530 & 0.0251 & 0.000 & 0.1638 & 0.0086 & 0.000 & 0.0548 & 0.0076 & $\odot . \odot$ \\
\hline Fomax & 0.0065 & $0.0 \odot 44$ & $\odot .000$ & 0.0177 & ๑ . 0110 & $\odot .0 \odot \odot$ & 0.0046 & ๑ . 0010 & 0.000 & $\odot .0066$ & 0.0027 & 0.0 \\
\hline SSDxoy & 0.0031 & 0.0022 & $\odot .00 \odot$ & 0.0273 & 0.0401 & $\odot .0 \odot \odot$ & ๑. . 0015 & 0.0004 & $\odot .0 \odot \odot$ & 0.0057 & 0.0034 & 0.6 \\
\hline SSDyox & 0.5255 & 0.0961 & $\odot .000$ & 0.1424 & 0.1022 & 0.063 & 0. & 0.0293 & 0.000 & 0.2120 & 0.0354 & ○. \\
\hline somax & 0.0031 & 0.0022 & 0.000 & 0.0126 & 0.0158 & 0.063 & 0.0015 & 0.0004 & 0.000 & 0.0057 & 0.0034 & $\odot . \odot$ \\
\hline \multicolumn{13}{|c|}{2 children $(x)$ vs. 3 and more children $(y)$ : } \\
\hline FSDxoy & 0.0061 & 0.0048 & $\odot . \odot \odot \odot$ & $\odot .0198$ & $\odot .0136$ & $\odot .0 \odot \odot$ & $\odot .0068$ & $\odot .0 \odot 18$ & $\odot . \odot \odot \odot$ & $\odot .0141$ & $\odot .0031$ & $\odot . \odot$ \\
\hline FSDyox & 0.1434 & 0.0287 & $\odot .0 \odot \odot$ & 0.0440 & 0.0238 & 0.000 & 0.1535 & 0.0084 & $\odot .00 \odot$ & 0.0460 & 0.0081 & $\odot . \odot$ \\
\hline FOmax & 0.0061 & 0.0048 & $\odot .000$ & 0.0151 & 0.0087 & 0.000 & 0.0068 & 0.0018 & 0.000 & 0.0141 & 0.0031 & $\odot . \odot$ \\
\hline SSDxoy & 0.0010 & $\odot .0027$ & $\odot . \odot \odot \odot$ & 0.0282 & 0.0510 & 0.000 & 0.0023 & 0.0018 & 0.000 & 0.0138 & 0.0033 & 0.0 \\
\hline SSDyox & 0.5253 & 0.1195 & $\odot .0 \odot \odot$ & 0.1104 & 0.0835 & $\odot . \odot \odot \odot$ & 0.5872 & 0.0353 & $\odot .0 \odot \odot$ & 0.1218 & 0.0302 & $\odot . \odot$ \\
\hline somax & 0.0010 & 0.0027 & 0.000 & 0.0077 & 0.0133 & 0.000 & 0.0023 & 0.0018 & 0.000 & 0.0138 & 0.0033 & $\odot .0$ \\
\hline
\end{tabular}


Table 9. Comparisons of mean period incomes by EDUCATION of households head in 1993.

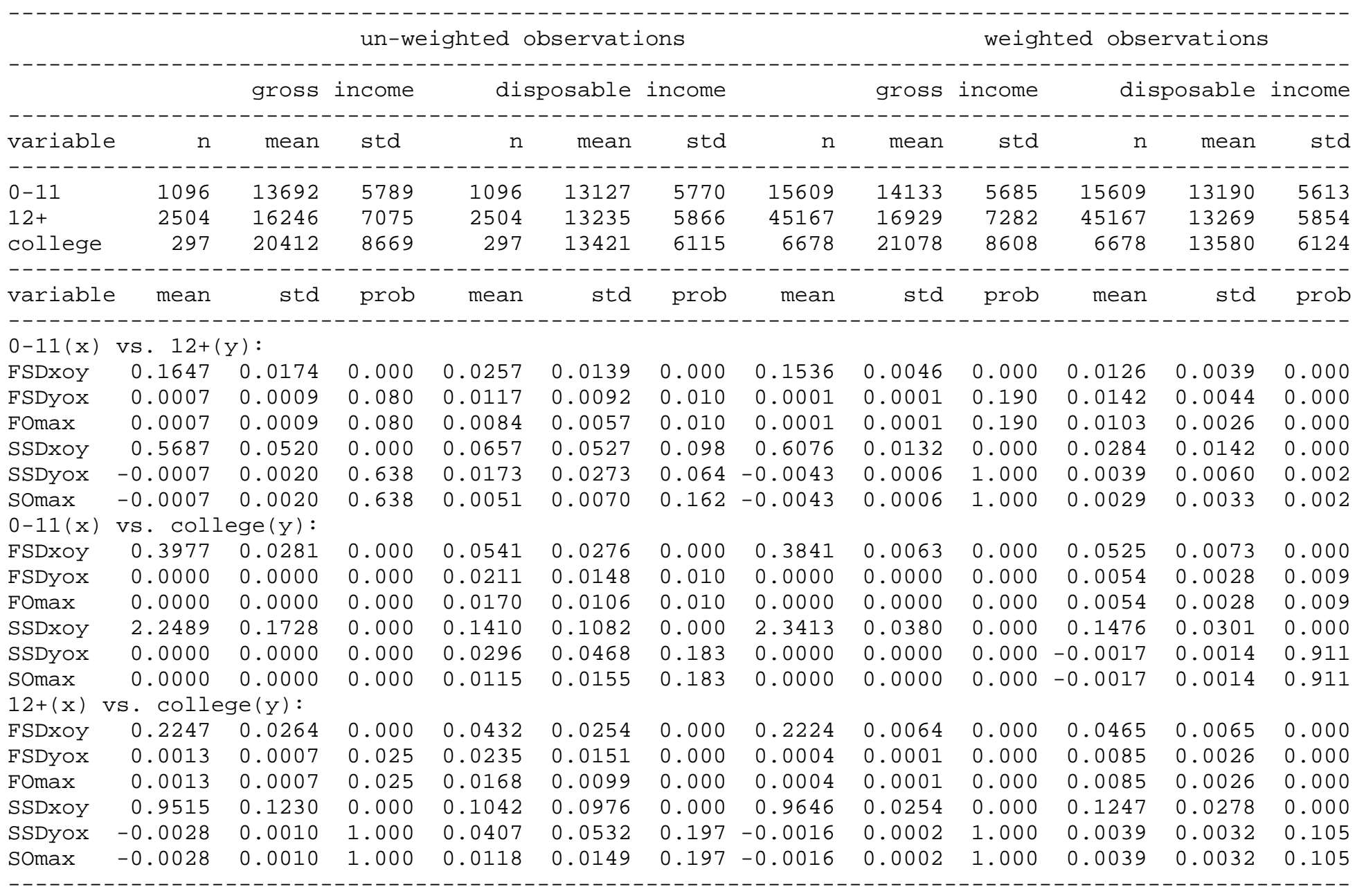


Table 10. Comparisons of mean period incomes by UNEMPLOYMENT HOURS of households head in 1993.

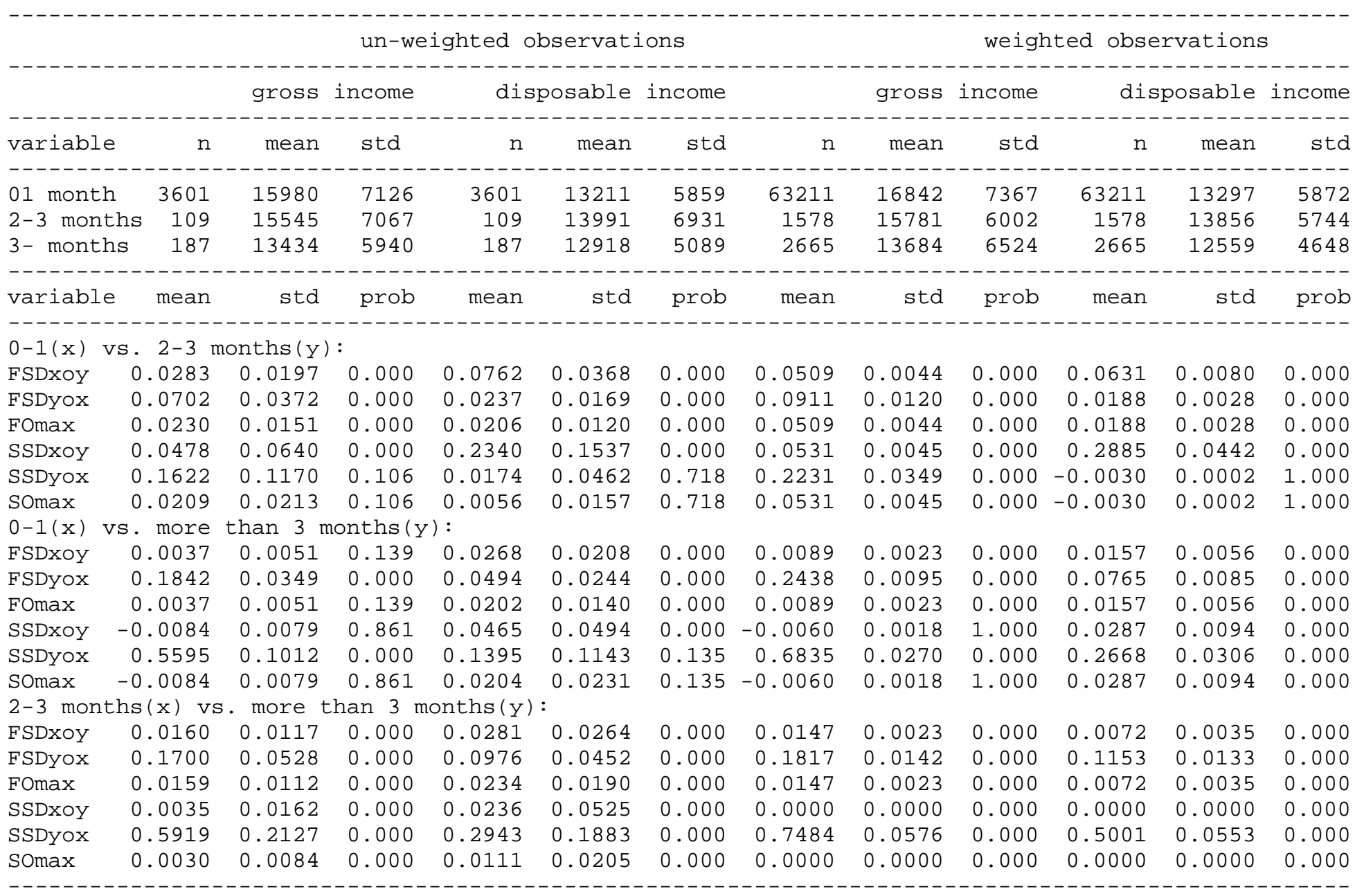


Table 11. Comparisons of mean period incomes by GEOGRAPHICAL MOBILITY of households head in 1993.

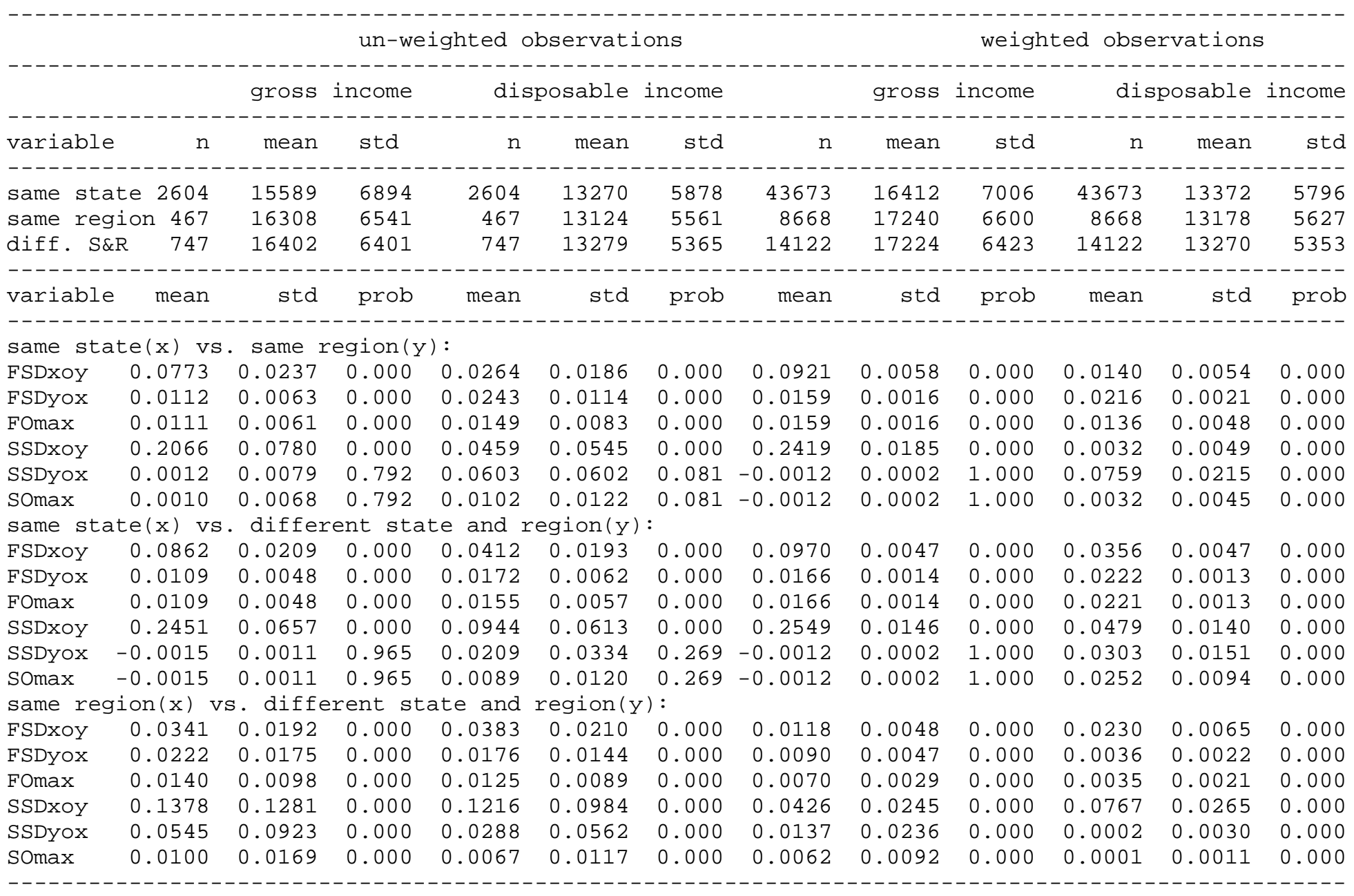


Table 12. Summary of the number of observations by income definition and various sub-groups of household.

\begin{tabular}{|c|c|c|c|c|c|c|c|c|c|c|}
\hline & & \multicolumn{2}{|c|}{1968} & \multicolumn{2}{|c|}{1978} & \multicolumn{2}{|c|}{1988} & \multirow{2}{*}{$\begin{array}{c}1993 \\
\text { Gross }\end{array}$} & \multirow{2}{*}{$\begin{array}{r}1997 \\
\text { Gross }\end{array}$} & \multirow{2}{*}{$\begin{array}{c}\text { 1968-1993 } \\
\text { Gross\&Disposable } \\
\end{array}$} \\
\hline Attributes & Sub-groups & Gross & Disposable & Gross & Disposable & Gross & Disposable & & & \\
\hline \multirow{4}{*}{ CHILDREN } & 0 & 1989 & 1989 & 2955 & 2955 & 3742 & 3742 & 5145 & 3349 & 2124 \\
\hline & 1 & 668 & 668 & 1223 & 1223 & 1299 & 1299 & 1788 & 1297 & 664 \\
\hline & 2 & 720 & 720 & 1064 & 1064 & 1246 & 1246 & 1821 & 1286 & 686 \\
\hline & 3 or more & 1425 & 1425 & 912 & 912 & 827 & 827 & 1182 & 816 & 423 \\
\hline \multirow[t]{2}{*}{ SEX } & Male & 3455 & 3455 & 4399 & 4399 & 5010 & 5010 & 6863 & 4749 & 2779 \\
\hline & Female & 1347 & 1347 & 1755 & 1755 & 2104 & 2104 & 3073 & 1999 & 1118 \\
\hline \multirow[t]{4}{*}{ AGE } & -35 & 1570 & 1570 & 2896 & 2896 & 3105 & 3105 & 3507 & 2205 & 1193 \\
\hline & $36-50$ & 1643 & 1643 & 1386 & 1386 & 1913 & 1913 & 3364 & 2682 & 1393 \\
\hline & $51-65$ & 1094 & 1094 & 1167 & 1167 & 1174 & 1174 & 1585 & 953 & 647 \\
\hline & 66- & 495 & 495 & 705 & 705 & 922 & 922 & 1480 & 908 & 658 \\
\hline \multirow[t]{3}{*}{ RACE } & White & 3077 & 3077 & 3704 & 3704 & 4356 & 4356 & 6096 & 4130 & 2510 \\
\hline & Black & 1571 & 1571 & 2240 & 2240 & 2626 & 2626 & 2875 & 2036 & 1204 \\
\hline & Others & 154 & 154 & 210 & 210 & 132 & 132 & 965 & 582 & 183 \\
\hline \multirow[t]{3}{*}{ WSTATUS } & Working & 3492 & 3492 & 4398 & 4398 & 5068 & 5068 & 6652 & - & 2660 \\
\hline & Unemployed & 174 & 173 & 288 & 288 & 391 & 391 & 683 & - & 197 \\
\hline & Others & 1136 & 1136 & 1468 & 1468 & 1655 & 1655 & 2601 & - & 1040 \\
\hline \multirow[t]{3}{*}{ MARITAL } & Married & 3107 & 3107 & 3663 & 3663 & 4058 & 4058 & 5459 & 3641 & 2300 \\
\hline & Single, Widow & 956 & 956 & 1474 & 1474 & 1834 & 1834 & 2626 & 1846 & 954 \\
\hline & Others & 739 & 739 & 1017 & 1017 & 1222 & 1222 & 1851 & 1261 & 643 \\
\hline \multirow[t]{3}{*}{ EDUCATION } & Low $0-11$ & 2645 & 2645 & 2479 & 2479 & 2203 & 2203 & 3432 & - & 1096 \\
\hline & Medium, 12+ & 1711 & 1711 & 2918 & 2918 & 3746 & 3746 & 5890 & - & 2504 \\
\hline & High, College & 446 & 446 & 757 & 757 & 1165 & 1165 & 614 & - & 297 \\
\hline WEIGHT & Average & 16.25 & 16.25 & 16.16 & 16.16 & 17.12 & 17.12 & 13.38 & 14.68 & \\
\hline Observations & & 4802 & 4802 & 6154 & 6154 & 7114 & 7114 & 9936 & 6748 & 3897 \\
\hline
\end{tabular}

